\title{
SYSTEMATIC REVIEW AND META-ANALYSIS OF PRIMARY CARE-BASED PHYSICAL ACTIVITY INTERVENTIONS AMONG OLDER ADULTS
}

\author{
A Dissertation \\ presented to \\ the Faculty of the Graduate School \\ at the University of Missouri-Columbia \\ In Partial Fulfillment \\ of the Requirements for the Degree \\ Doctor of Philosophy \\ By \\ JENNIFER OTMANOWSKI \\ Dr. Jo-Ana Chase, Dissertation Supervisor \\ December 2020
}


The undersigned, appointed by the dean of the Graduate School, have examined the dissertation entitled

SYSTEMATIC REVIEW AND META-ANALYSIS OF PRIMARY CARE-BASED PHYSICAL ACTIVITY INTERVENTIONS AMONG OLDER ADULTS

presented by Jennifer Otmanowski,

a candidate for the degree of doctor of philosophy,

and hereby certify that, in their opinion, it is worthy of acceptance.

Professor Jo-Ana Chase

Professor Vicki Conn

Professor Jane Armer

Professor Stephen Sayers 


\section{DEDICATION}

This dissertation is dedicated to my family. My husband Ken has done everything he possible could to help me succeed, from helping me with Excel to doing more than his share of chores. He is the most generous person I know. My daughters, Caitlin, Emily, Rachel, and Becca have all helped in big and small ways from proof reading papers to keeping me hydrated. Mostly, they all believed in me so much that even when I wanted to, quitting was never an option. 


\section{ACKNOWLEDGEMENTS}

I would like to thank my dissertation supervisor and adviser, Dr. Jo-Ana Chase for her encouragement, support, and guidance. She has been so patient about reading my work and provided valuable feedback. I would also like to thank my committee members, Dr. Vicki Conn, Dr. Jane Armer and Dr. Stephen Sayers for generously sharing their time and talents. I would like to also thank Dr. Pam Cooper who provided coding assistance with careful attention to keeping within my budget. As a recipient of the Toni and Jim Sullivan research I would like to thank the Sullivan family for their generous support of this research. Finally, thank you to my coworkers who tried to lighten my teaching load whenever they could. 


\section{TABLE OF CONTENTS}

ACKNOWEDGEMENTS

.ii

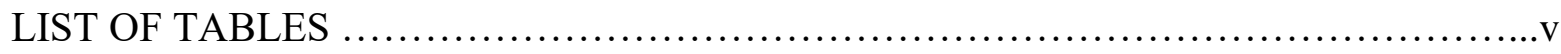

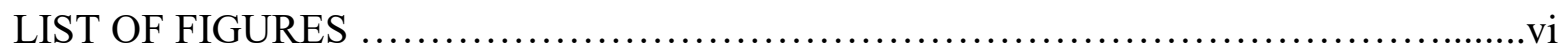

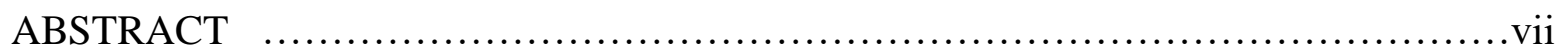

\section{CHAPTERS}

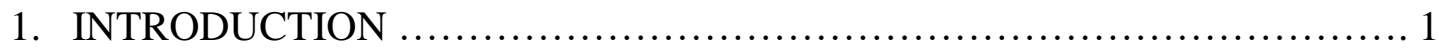

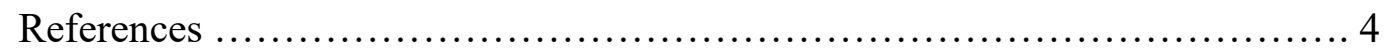

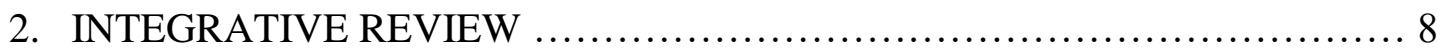

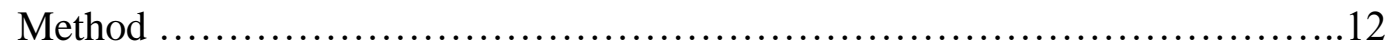

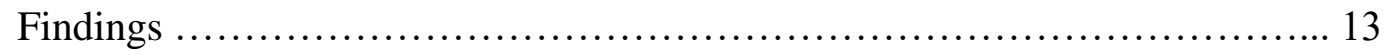

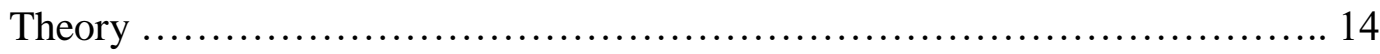

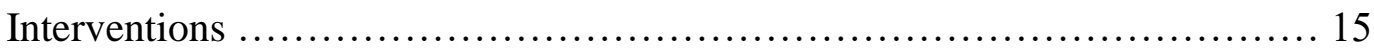

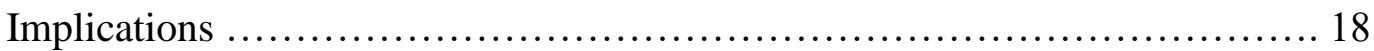

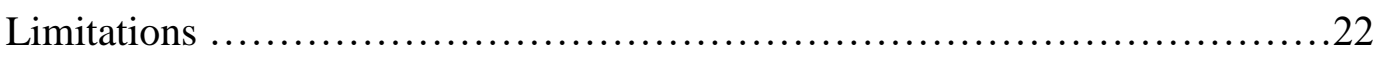

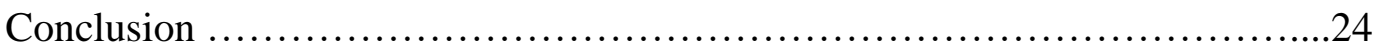

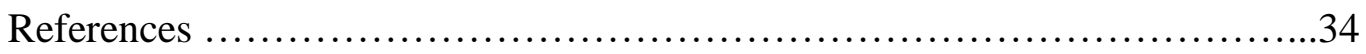

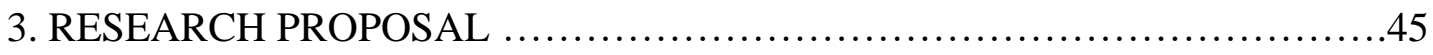

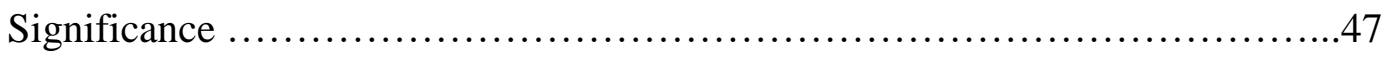

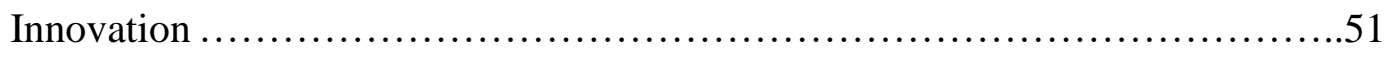

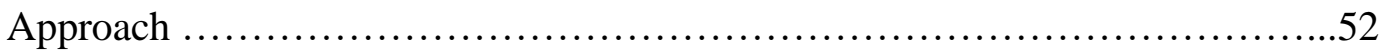


Literature Search

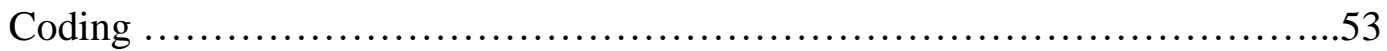

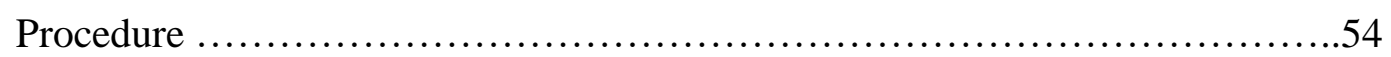

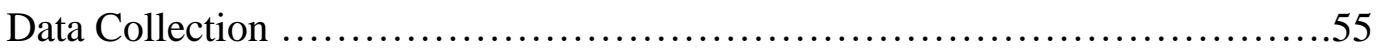

Data Analysis .......................................................55

Women and Minorities ..............................................59

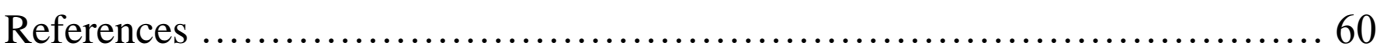

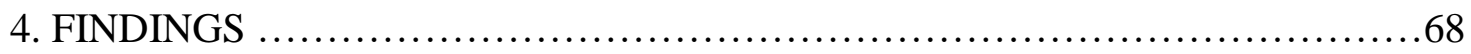

Methods ............................................................ 70

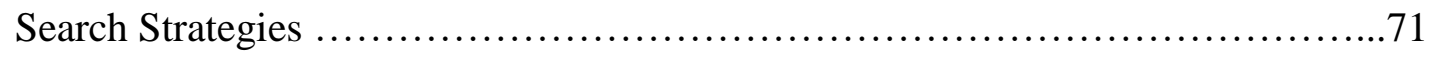

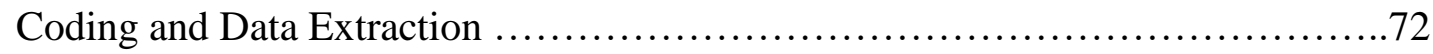

Analysis .......................................................... 73

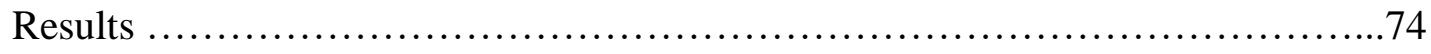

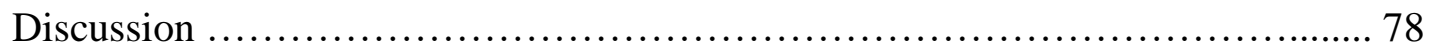

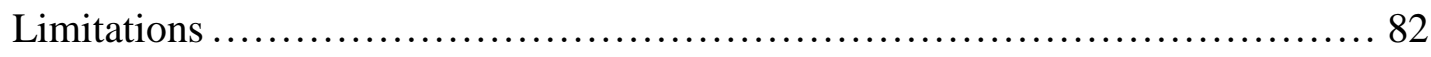

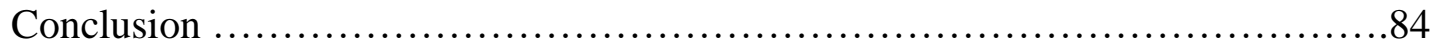

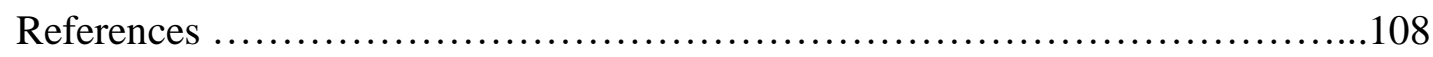

5. SUMMARY ........................................................... 119

References ......................................................... 122

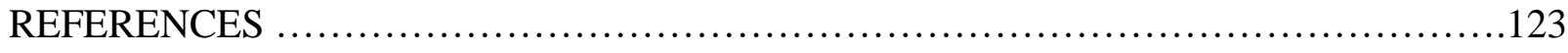

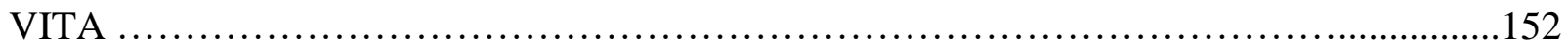




\section{LIST OF TABLES}

TABLE $\quad$ PAGE

Table 2.1: Included Studies .................................................. 24

Table 2.2: Assessment of Bias Using the PEDro Scale ............................... 30

Table 2.3: Resources for Recommending Physical Activity $\ldots \ldots \ldots \ldots \ldots \ldots \ldots \ldots \ldots \ldots . \ldots \ldots \ldots$

Table 3.1: Categories of Data Collection .......................................... 85

Table 4.1: Included Two Group Studies .................................... 86

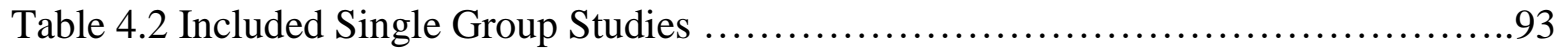

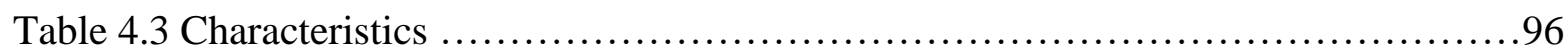

Table 4.4: Effect Sizes ......................................................... 97

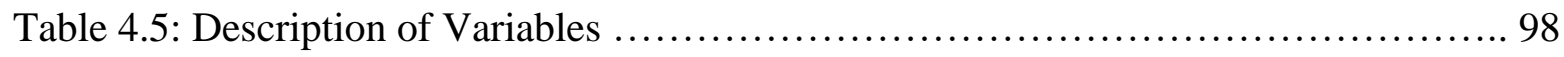

Table 4.6: Moderator Analysis of Dichotomous Variables ............................ 100

Table 4.7: Moderator Analysis of Continuous Variables ..............................101

Table 4.8: PEDRO Scale Included Studies ..................................... 102 


\section{LIST OF FIGURES}

FIGURE PAGE

Figure 2.1: Prisma Diagram .............................................. 33

Figure 4.1: Prisma Diagram................................................... 104

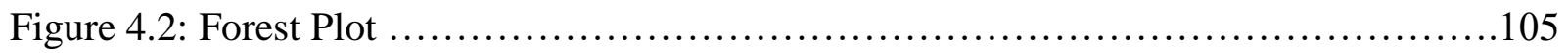

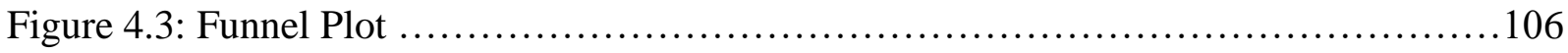




\title{
SYSTEMATIC REVIEW AND META-ANALYSIS OF PRIMARY CARE-BASED PHYSICAL ACTIVITY INTERVENTIONS AMONG OLDER ADULTS

\author{
Jennifer Otmanowski
} \\ Dr. Jo-Ana Chase, Dissertation Supervisor
}

\begin{abstract}
Background. Most healthcare providers agree that increasing physical activity (PA) in older adults is beneficial but providing effective interventions can be difficult. The purpose of this research is to determine the effectiveness of primary care interventions to increase PA levels in older adults and to analyze which interventions are most effective.
\end{abstract}

Methods. A comprehensive search was conducted to find studies that tested interventions delivered in primary care to improve levels of physical activity in adults $\geq 65$ or with a mean age of $\geq 70$. Standardized mean difference effect size was calculated related to changes in physical activity levels. Moderator analysis was performed to explore the relationship between participant characteristics, interventions, and interventionists, and effect size.

Results. Overall mean effect size 0.27 (95\% CI 0.15-0.39, $p=0.000$ ) was calculated for 25 twogroup comparisons involving 4,685 total participants. Mean age of participants was 75.08. Most involved counseling by the primary provider or different healthcare providers. Counseling was provided in person or via the phone. The use of physical or occupational therapists, number of counseling sessions and an exercise referral were significant moderators. There was little evidence to support counseling over exercise referrals. The use of theory and use of a pedometer did not modify the effect size. 
Conclusion. PA interventions delivered in primary care are effective. PA interventions can be effectively delivered by other healthcare providers working with the primary provider. Many different behavior change strategies may be used to promote PA. More research is needed to explore interventions to promote long term changes in PA levels as well as interventions for adults $>80$ years old and older adults that are members of minority groups. 


\section{CHAPTER 1}

\section{INTRODUCTION}

We have within our tool kits, an effective and economical prevention and treatment modality that can prevent cancers and chronic diseases, modify the trajectory of chronic diseases, and preserve cognition and mobility in older adults. Physical activity (PA) offers these benefits and more for the older adult patient. Unfortunately, few older adults consider PA a vital part of their healthcare regimen and others have the mistaken belief that they are already engaging in sufficient activity (Justin et al., 2013; Biedenweg, et al., 2017). Only 16.3\% of adults 65-75 meet the recommended guidelines for PA and an even smaller number, only $9.9 \%$ of adults 75 and older meet the guidelines (CDC, 2018). The American College of Sports Medicine (ACSM) along with the American Medical Association launched the Exercise is Medicine® (EIM) campaign in 2007 to promote the inclusion of physical activity promotion and assessment in health care (ACSM, 2018). This dissertation is a systematic review and meta-analysis to examine the effects of interventions to increase physical activity in older adults delivered in primary care. Moderator analysis examined the specific types of interventions, their delivery method, and their relationship to levels of physical activity to guide providers in the delivery of physical activity recommendations.

Physical activity is defined as any skeletal movement that produces increased energy expenditure and can include planned exercise as well as movement throughout the day (World Health Organization, 2018). Activity should be at a moderate or greater intensity level and utilize all major muscle groups. Guidelines per the Center for Disease Control are 150 minutes of moderate intensity activity or 75 minutes of vigorous intensity activity per week (U.S. Department of Health and Human Services, 2018). Physical activity that is performed for the 
purpose of physical fitness (exercise) is considered in physical activity levels as well as physical activity that is attained through daily activities (Dasso, 2018).

PA research has demonstrated that even small amounts of PA can have positive effects on the health of older adults (Marques et al., 2019). Low to moderate intensity PA is associated with reduced risk of chronic disease including cancer, Parkinson's disease, hip or femoral fracture and Alzheimer's disease in men and hypertension, diabetes, chronic lung disease, stomach or duodenal ulcer, Parkinson's disease and hip or femoral fracture in women (Marques et al., 2019). These positive disease prevention benefits were seen even in those who participated in only one session of PA per week (Marques et al., 2019). Other benefits of PA include a lower risk of falls (Batcir and Melzer, 2018; Harvey et al., 2018), lower mortality and fewer hospitalizations (Ramos et al., 2019). A meta-analysis involving 46,602 participants found decreased cancer mortality in breast cancer regardless of whether the PA was pre or post diagnosis (Zhong et al., 2014). Older adults who participate in PA regardless of the intensity are better able to preserve their cognitive function (Reis et al., 2019).

While healthcare providers are generally aware of the recommendations, they may find themselves at a loss as to how to motivate patient to increase activity. Healthcare providers face many barriers to providing PA interventions including time constraints, feelings that they do not have enough knowledge to recommend PA and the belief that attempts at intervening are futile (Malan et al., 2015; Mathew et al., 2017). Yet, older adults do respond positively to their provider's advice to increase their PA (Balde et al., 2003; Blair et al., 2012; Navarro et al., 2007). Additionally, the primary care provider has the advantage of seeing their patients an average of 5.5 times per year providing opportunities to reinforce their recommendations (CDC, 2018). 
This dissertation explores the role of the primary care provider in providing PA interventions to older adults. Chapter 2 is a published manuscript entitled Practical Implications for Providing Physical Activity Counseling for the Older Adult: An Integrative Review exploring the topic of PA counseling in primary care. Chapter 3 describes the methodology of the systematic review and meta-analysis conducted for this dissertation research. Chapter 4 is the manuscript-style report of study findings. Chapter 5 summarizes the implications for physical activity interventions in primary care based on the systematic review and meta-analysis findings. 


\section{References}

American College of Sports Medicine (ACSM) (2018). American college of sports medicine and exercise is medicine initiative support UN commitment to reducing non-communicable disease. https://www.acsm.org/read-research/newsroom/news-releases/newsdetail/2018/09/27/ACSM-EIM-support-United-Nations-commitment-reducingnoncommunicable-disease

Balde, A., Figueras, J., Hawking, D.A., \& Miller, J.R. (2003). Physician advice to the elderly about physical activity. Journal of Aging and Physical Activity, 11(1), 90-977. https://journals.humankinetics.com/view/journals/japa/11/1/article.p90.xml.

Batcir, S. \& Melzer, I. (2018). Daily bicycling in older adults may be effective to reduce fall risks-A case-control study, Journal of Aging and Physical Activity, 26(4), 579-576. https://doi.org/10.1123/japa.2017-0263

Biedenweg, K., Meischke, H., Bohl, A., Hamerback, K., Williams, B., Poe, P., Phelan, E. (2013). Understanding older adults' motivators and barriers to participating in organized programs supporting exercise behaviors. Journal of Primary Prevention, 35(1), 1-11.

Center for Disease Control and Prevention. (2020). Behavioral Risk Factor Surveillance System. https://www.cdc.gov/brfss/index.html

Center for Disease Control (2018). Summary health statistics: National health interview survey. Retrieved from https://ftp. cdc. gov/pub/Health_Statistics/NCHS/NHIS/SHS/2018_SHS_Table_C-8.pdf 
Dasso, M. (2018). How is Exercise Different from Physical Activity? A Concept Analysis. Nursing Forum, 54, 45-52. doi: 10.1111/nuf.12296García-Hermoso, A. Ramirez-Vélez, R., Sález de Asteasu, M.L. Martínez-Velilla,N., Zambom-Ferraresi, Valenzuela, P.L., Lucia, A., \& Izquierdo, M. (2020). Safety and effectiveness of long term exercise interventions in older adults: A systematic review and meta-analysis of randomized controlled trials. Sports Medicine, 50, 1095-1106. https://doi.org/10.1007/s40279-020$01259-\mathrm{y}$

Harvey, S., Rissel, C., Pijnappels, M. (2018). Associations between bicycling and reduced fallrelted physical performance in older adults, Journal of Aging and Physical Activity, 26, 514-519. https://doi.org/10.1123/japa.2017-0243

Justin, M., Azizan, A., Hassan, V., Salleh, Z., Manaf, H. (2013). Barriers to participation in physical activity and exercise among middle-aged and elderly individuals. Singapore Medicine Journal, 54(10): 581-586 doi:10.11622/smedj.2013203

Malan, Z., Mash, B., Everett-Murphy, K. (2015). A situational analysis of training for behavior change counselling for primary care providers. South Africa. African Journal of Primary Health Care and Family Medicine, 7(1). Doi: 10.4102/phcfm.v7i1.731

Marques, A., Miguel, P., Martins, J., Gouveia, E., Valeiro, M. (2019). Cross-sectional and prospective relationship between low-to-moderate-intensity physical activity and chronic diseases in older adults from 13 European Countries, Journal of Aging and Physical Activity, 27(1), 93-101. https://journals.humankinetics.com/view/journals/japa/27/1/article-p93.xml 
Mathew, A., Natasha, J., Alastair, T., van den Berg, P., Foster, C. (2017). An education programme influencing health professionals to recommend exercise to their type 2 diabetes patients - Understanding the processes. BMC Health Services Research, 17(130). doi: 10.1186/s12913-017-2040-7

Navarro, J. E.J.Sanz, J.L.G., Del Castillo, J.M., Izquierdo, A.C., Rodreiquez, M. M. (2007). Motivational factors and physician advice for physical activity in older urban adults. Journal of Aging \& Physical Activity, 15(3), 241-256.

Ramos, M., Lamotte, M., Gerlier, L., Sangre,, P., Miquel-Cases, A., Haughney, J. (2019). Costeffectiveness of physical activity in the management of COPD patients in the UK. International Journal of Chronic Obstructive Pulmonary Disease, 14, 227-239. Doi: 10.2147/COPD.s181194.

Reis, E., Laughlin, G., Bergstrom, J., Kritz-Silverstein, D., Richard, E., Barrett-Connor, E., McEvoy, L. (2019). Lifetime physical activity and late-life cognitive function: the Rancho Bernardo study, Age and Ageing, 48(2), 241246, https://doi.org/10.1093/ageing/afy188

World Health Organization. (2018). Physical Activity. https://www.who.int/en/news-room/factsheets/detail/physical-activity

U.S. Department of Health and Human Services. (2018). Physical activity guidelines for Americans (2nd ed). https://health.gov/paguidelines/secondedition/pdf/Physical_Activity_Guidelines_2nd_edition.pdf 
Zhong, S., Jiang, T., M, T., Zhang, X., Chen, W., Lv, M., \& Zhao, J. (2014). Association between physical activity and mortality in breast cancer: A Meta-analysis of cohort studies. European Journal of Epidemiology, 29(6). Doi: 10.1007/s10654-014-9916-1. 


\section{CHAPTER 2}

\section{PRACTICAL IMPLICATION FOR PROVIDING PHYSICAL ACTIVITY COUNSELING}

FOR THE OLDER ADULT Otmanowski, Jennifer A. RN, MSN, CNE (Doctoral

Candidate) ${ }^{1}$; Chase, Jo-Ana D. PhD, APRN-BC (Assistant Professor). ${ }^{1}$ Practical

implications for providing physical activity counseling for the older adult, Journal of the

American Association of Nurse Practitioners: July 2020 - Volume 32 - Issue 7 - p 511-

519 doi: 10.1097/JXX.0000000000000483

Research by the American College of Sports Medicine demonstrated that $60 \%$ of patients stated that they would be more likely to begin exercising if advised to exercise by their healthcare provider (Blair, Sallus, Huber \& Archer, 2012). While most clinicians recognize the importance of recommending physical activity (PA) to their older adult patients, they struggle with barriers such as time constraints, lack of training and lack of confidence in the effectiveness of their interventions (Hébert, Caughy, \& Shuvall, 2012; Walsh, Swangard, Davis, McPhee, 1999). Nurse Practitioners (NPs) have the potential to become key providers of PA counseling. NPs see a high volume of patients, an estimated 1.02 billion patients a year and so can have a wide impact (Knowles, 2017). Nurses are members of a trusted profession and so their interventions may be more likely to be accepted by patients (Brenen, 2018). The purpose of this review is to examine PA counseling intervention research among adults age 65 and older and to identify best practices for clinical practice.

The population of adults age 65 and older is rapidly growing in the United States and is the least active of any age group (Watson et al., 2016). The next decade will see the generation termed the Baby Boomers reach their late 70s and 80s. PA declines as people age, with the annual decline accelerating with increasing age (Bachman et al., 2014; Thompson et al., 2014). 
Globally, 5.3 million deaths per year are associated with physical inactivity (Li et al., 2012). Physical inactivity in the older adult leads to loss of muscle mass, declines in strength and endurance and problems with maintaining balance which can contribute to functional decline, loss of independence, and subsequent nursing home placement (Rist, Nguyen, Whitmer \& Glymour, 2016).

PA is associated with a reduced risk of stroke, cardiovascular disease, breast and colon cancers, hypertension, type 2 diabetes, Parkinson's disease and dementia and has positive effects on lipid levels and glycemic control (Guure, Ibrahim, Adam \& Said, 2017; Mosen et al., 2017; Ou, Chen, Shih, \& Tarng;. Kyu et al., 2016). Additionally, PA can reduce the rate of falls and improve cognition in the older adult (Aoyama, Suzuki, Kuzuya, 2015; Langlois, 2012). Some of the complaints for which patients visit their providers can be moderated by PA. For example, increased PA is associated with almost immediate positive changes in sleep quality (Kredlow et al., 2015). Additionally, PA is associated with lower rates of depression, improved cognition, and higher quality of life (Paulo et al., 2016; Langlois et al., 2012). Consequently, PA is gaining ground as a global priority for the development of public health policies (World Health Organization, 2013).

To reap the benefits of PA, individuals can participate in any movement generated by skeletal muscles that utilizes energy (World Health Organization, 2018). The 2018 PA recommendations for older adults from the United States Department of Health and Human Services (USDHHS, 2018) are 150 minutes to 300 minutes of moderate aerobic activity a week or 75 to 100 minutes of vigorous aerobic activity with at least two days that include a musclestrengthening activity. Aerobic activities consist of activities where participants move their large muscles in rhythmic method for an extended amount of time (World Health Organization, 2010). 
Examples of aerobic activities include walking, running, biking, swimming, dancing, or aerobic exercise classes. Additional recommendations for the older adults include balance training as well as aerobic and muscle training activities. The level of effort should be determined by the older adult's fitness level and participants can improve physical fitness by gradually increasing PA intensity and duration (Dasso, 2018). Older adults who cannot attain the 150 minutes per week guidelines due to chronic conditions should strive to be as active as possible (USDHHS, 2018). Unfortunately, despite the health benefits of PA, the proportion of adults over age 75 sufficiently active per the guidelines is only $35-44 \%$ (USDHHS, 2017).

Many studies have attempted to increase PA in older adults with PA counseling interventions. PA counseling is defined as offering advice or guidance in a verbal or written form to encourage someone to increase PA. PA counseling can be in-person or by phone, which may help overcome the issue of time constraints, the primary barrier for physicians in initiating a PA prescription program (Patel, Schofield, Kolt \& Keog, 2011). PA counseling can be based on a variety of theories such as Bandura's social cognitive theory (Bandura, 1997) and the transtheoretical model (Prochaska, Redding, \& Viswanath, 2015).

Exercise prescriptions are sometimes incorporated in PA counseling interventions. These prescriptions are dispensed after evaluating the patient's goals along with their physical condition and comorbidities. A prescription represents a familiar method of communication between a provider and a patient and has been successful in improving PA levels over verbal advice alone (Swinburn, Walter, Arroll, Tilyard \& Russel, 1998). The American Medical Association and the American College of Sports Medicine (ACSM) are leading advocates of the exercise prescription. Their Exercise is Medicine ${ }^{\circledR}($ EIM) program promotes exercise referrals 
to increase PA levels and promote health. ACSM has published the Health Care Providers' Action Guide (2019) which includes an exercise prescription sample.

Behavior change theories often provide a framework for counseling interventions and have been demonstrated to improve the success of interventions (Chase, 2015). Social cognitive theory (SCT) is one that is used widely to guide PA interventions. One of the major constructs of SCT is self-efficacy. Self-efficacy with regards to PA refers to a person's belief in their ability to perform exercises or walk outdoors. Self-efficacy can be increased through vicarious reinforcement or modeling, verbal persuasion, managing physiological arousal and enactive mastery (experiencing success; Bandura, 1997). Another behavior change theory is selfregulation theory which involves the process of regulating behavior by moving toward, or occasionally away from goals. Individuals use feedback and self-evaluation to self-correct as they move toward their goal (Kanfer \& Kanfer, 1991). Like SCT, the transtheoretical model of change has also been used extensively in PA research. In this model, the healthcare provider identifies the patient's stage of change before initiating appropriate interventions (Prochaska, Redding \& Viswanath, 2015).

Recent reviews and meta-analyses have found that interventions to increase PA in older adult are effective. These studies did not focus on PA counseling interventions specific to the oldest old population (Chase, 2015; Olanrewaju, Kelly, Cowan, Brayne, \& Lafortune, 2016). A recent systematic review on health coaching captured studies with participants $\geq 60$ years old resulting in a mean age of 60-79 (Oliveira et al., 2017). Additionally, the last 10 years have seen an explosion in research related to PA interventions with the number of articles written about PA in primary care doubling between 2012 and 2004, necessitating this synthesis of the PA counseling research generated in the past ten years (Lion et al., 2018). This present review aims 
to summarize the recent body of PA counseling and exercise prescription literature among adults $\geq 65$ years old (Center for Medicare and Medicaid Services, 2020). This review proposes to answer the following questions: 1) which types and combinations of PA counseling interventions are efficacious in increasing time spent in PA in the older adult? 2) which behavioral theories support counseling interventions that result in increased time spent in PA?

\section{Method}

This review utilized the Preferred Reporting Items for Systematic and Meta-Analysis (PRISMA) guidelines and the search procedure as outlined in the PRISMA diagram (Moher, Liberati, Tetzlaff, \& Altman, 2009) in Figure 1. Databases utilized for this search include CINAHL, PsycINFO, PubMed, Scopus and SPORTDiscus along with a review of bibliographies of retrieved articles. The search was completed in January of 2020. The following is an example of the search utilized in PubMed: exercise OR physical activity AND counselling OR counseling OR counsel AND older adult. To capture an older population, the search was restricted to adults $\geq 65$ years old (Center for Medicare and Medicaid Services, 2020). Counseling was defined as a process where a patient learns how to increase their PA and is assisted in addressing barriers to PA by a professional competent in relevant psychological skills. This process may also include goal setting and assessments of readiness to change. Counseling interventions can be delivered in many different modalities and by different interventionists. Eligible studies described PA counseling interventions, which may include exercise prescriptions, in-person counseling, counseling by trained peer leaders, and counseling conducted by phone calls in the generally healthy population. to focus on the average older adult, articles that included participants diagnosed with a specific disease process were excluded. Only peer-reviewed, full-text articles were included, and dates were restricted to the past 10 years to 
capture the recent growth in PA literature. Articles that were written in languages other than English were excluded as this author does not read any other languages.

A total of 465 articles were screened for eligibility by reviewing the title and abstract (Figure 1). Twelve articles were included with an outcome measure of PA participation. Two articles meeting the inclusion criteria were obtained from CINAHL, three articles from PsycINFO, one article from Scopus, three articles from PubMed, and none from SportDiscus. An ancestry search resulted in three additional studies. Information extracted from eligible studies included study design, sample size, age of participants, outcome measures, type of interventions, frequency of interventions, provider of intervention, length of follow up, outcome measures, and theoretical frameworks. Study details can be found in Table 1.

Study quality was assessed using the Physiotherapy Evidence Database (PEDro) scale (Refer to Table 2; Verhagen et al., 1998). The PEDro scale evaluates methodological quality of trials. Criteria related to external and internal validity and the presence of sufficient statistical reporting for inferences are used to assess the methodological quality. The PEDro scale has been found to be a valid instrument for determining the quality of clinical trials (de Morton, 2009, Maher, Sherrington, Herbert, Moseley \& Elkins, 2003).

\section{Findings}

\section{Study Characteristics}

In keeping with the global nature of the problem of physical inactivity, the 12 studies reviewed for this paper were representative of several different countries. The Netherlands, France, New Zealand, Sweden, Romania, Scotland, United Kingdom and Finland each contributed one study and four studies were from the United States. All the studies reviewed for 
this paper are randomized controlled trials with two of the studies using cluster or stratified randomization (Kerr et al., 2018; Bickmore et al., 2013). All studies reported an outcome measure of time spent in PA although in some of the studies, PA was not the primary outcome. In two of the studies the primary outcome was reducing frailty (Barreto, 2018; de Vries, 2013), in one study the primary outcome was fall prevention (Arkkukangas, Söderlund, Eriksson, \& Johansson, 2019) and one of the studies had multiple health outcomes (Robare, 2011). The participants represented in our synthesis are significantly older than previous syntheses, with mean ages range from 71.6 to 85.3.

The PEDro scores ranged from six to eight (Refer to Table 2.2). Intention to treat was carried out in eight out of the 12 studies. Random allocation was included in each of the twelve studies. In all but two of the studies, the treatment and control group had similar characteristics at baseline such as PA levels, age, and education. For all groups of participants represented, at least one between-group statistic was reported. Six of the studies utilized objective measures of PA outcomes, such as accelerometer and pedometer (Barreto et al., 2018, Kerr et al., 2018, Kolt et al., 2012, McMurdo et al., 2010, Mutrie et al., 2012 \& Thompson et al., 2014).

\section{Theories}

Four different behavioral theories were utilized including transtheoretical model of change, social cognitive theory, social learning theory, and self-regulation theory. Social cognitive theory (SCT) with a specific focus on self-efficacy was used most and has historically been a prevalent framework for PA research. Four studies in this review used SCT to inform their counseling interventions (Kerr et al., 2018; Mutrie et al., 2012; Rasinaho et al., 2011). The studies differ in their adherence to theory constructs. In their use of peer counselors, Kerr et al. (2018) were able to provide vicarious experience or self-modeling, important constructs in SCT. 
Additionally, they utilized verbal persuasion and performance outcomes or feedback. Rasinaho et al. (2011) focused their counseling strategies on reducing and overcoming barriers to increasing time spent in PA, techniques that are not specific to SCT.

In addition to SCT, Rasinaho et al. (2011) used the transtheoretical model of change. Rasinaho et al. (2011) and Arkkukangas et al. (2019) identified their participant's state of change through a brief questionnaire and used the information to guide their counseling approach. Conversely, Herghelegui et al. (2017) assessed for readiness to change, but did not describe how those delivering the counseling incorporated the identified stage of change.

In McMurdo et al. (2010), researchers used self-regulation theory along with pedometers to increase PA in sedentary older women. A walking target was set for the first month that was $20 \%$ above the participant's baseline. Action plans were created along with plans to address barriers to PA. A brief education session focused on motivation for walking along with goal setting, self-monitoring, and feedback. Four other studies in this review did not identify a theoretical framework (Barreto et al., 2018; Bickmore, et al., 2013; Kolt et al., 2012; Thompson et al., 2014).

\section{Interventions}

In all the studies, an intervention was considered successful if time spent in PA increased from baseline or if time spent in PA differed from the control group. In all but one study, the counseling was provided verbally, and the initial counseling was in person. The one study that did not rely on verbal in-person advice used an automated health coach accessed via a tablet (Bickmore et al., 2013). A variety of other interventions were utilized to supplement the counseling, including pedometers, phone calls, and motivational interviewing, a counseling style 
focused on resolving the ambivalence that keeps individuals from achieving their goals.

Pedometers provide feedback to the participant, as well as an objective measure of PA. Phone calls were used after the initial in-person counseling to provide continued support.

Short Term vs Long Term Results. Short term PA increases were observed in several studies (Baretto et al., 2018; Bickmore et al.,2013; de Vries, 2012; Herhelegiu et al., 2017; McMurdo,2010; Mutrie et al., 2012). Successful long-term interventions were more elusive. While some studies showed positive results at the end of the intervention, participants' activity levels reverted to baseline at follow up (Barreto eta al., 2018; Bickmore et al., 2013; McMurdo et al., 2010). Two studies demonstrated continued positive results at post intervention follow up at twelve or more months (Rashinaho et al., 2011; Kerr et al., 2018). Both studies utilized social cognitive theory and multiple contacts with the interventionist during the maintenance phase. The Kerr et al. (2018) study involved interventions on an individual level (goal setting, pedometers, and phone counseling) as well as interventions at a community level (group education and peer leaders). The Rashinaho et al. (2011) study involved follow up phone calls every 4 months for 2 years. The most successful interventions for attaining long term results had a structured maintenance phase and relied on behavioral change strategies and theories.

Step Counting. A step counting device was utilized in four of the studies to provide motivation as a supplement to counseling strategies, as well as to record outcomes (Bickmore et al., 2013; Kolt et al., 2012; McMurdo et al., 2010; Thompson et al., 2014). However, in two of the studies, participants did not sustain or maintain step increases with a pedometer without the accompanying counseling support (McMurdo et al., 2010 and Bickmore et al., 2013). These results imply that pedometer alone cannot enact long term behavior change. 
Phone calls. Phone calls are a popular method for continuing counseling interventions after initial in person counseling (Kerr et al., 2018; Kolt et al., 2012; McMurdo et al., 2010; Rasinaho et al., 2011). Phone calls can provide motivation and encouragement or help participants overcome barriers. Follow up phone calls can enhance compliance with the PA interventions (Lilienthal, Pignol, Holm, \& Vogeltanz-Holm, 2014). A recorded call from the nurse in the office, NP, or the physician can also be a money- and time-saving strategy (Mutrie et al., 2012).

Interventionists. Studies were heterogeneous regarding the interventionist. Only one study examined an exercise prescription provided by a physician (Kolt et al., 2012). Other interventionists included nurses, physiotherapist, geriatricians, peer leaders, physical therapists, PA instructors, health counselors, and an automated exercise coach. Kerr et al. (2018) is unique among the studies as the only one that uses trained peer leaders to provide the primary intervention.

Counseling Strategies. Older participants can be strongly motivated by the desire to help manage chronic conditions and maintain and active lifestyle, yet at the same time chronic conditions can limit participation (Newson \& Kemps, 2007). Since older adults do have many barriers to participating in PA, two studies included strategies for reducing barriers in the counseling sessions (Herghelegiu et al., 2017; Mutie et al., 2012). Herghelegui et al. (2017) used a health risk assessment tool to identify the participant's barriers to PA prior to initiating interventions. The ability of the counselor to alleviate concerns and provide reassurance and encouragement is a vital role when working with the older adult. Bardach and Schoenberg (2018) were able to demonstrate improvements in PA levels by providing information to the participants about improvements in their health status. The researchers emphasized 
improvements in lab values and progress towards weight loss goals to motivate the participants. Goal setting was a strategy used in several studies (de Vries et al., 2016; Kolt et al., 2012; Robare et al., 2011)

\section{Implications}

The research supporting the positive effects of increasing PA in the older adult population is extensive. While the most intense interventions generally have greater success, NPs should not be discouraged from beginning to incorporate PA interventions into their practices (Conn, Valentine, \& Cooper, 2002). Our findings suggest that PA counseling is an important strategy for increasing PA behavior in this vulnerable population. This review expands upon previous work by examining studies aimed at maximizing the effect of PA counseling interventions in the oldest old population.

The Health Provider's Action Guide (2019) from The American College of Sports Medicine provides practical advice for the NP wishing to incorporate PA counseling into office visits. The guide provides educational brochures for the office, a tool for assessing and recording PA levels, and sample exercise prescriptions. The guide also makes recommendations for patients with special needs and chronic conditions, as well as how to refer to exercise professionals (Refer to Table 3). Healthcare providers should prescribe a low intensity level and short duration of PA at the onset for older adults that are highly deconditioned (Lee et al., 2017). Before progressing to aerobic training, older adults with frailty indicators, such as low energy, poor grip strength, slow walking speed, or unintentional weight loss (Xue, 2011), should participate in exercises that build muscle strength and balance. The first step for the NP is to assess the patient's current health and activity level. The American College of Sports Professionals offers a preparticipation screening tool (Refer to Table 3). The National Institute 
on Aging (2018) and the American College of Sports Medicine (2019) recommend the use of exercise prescriptions as a practical and economical intervention to providers to use in combination with counseling to promote PA. While older adults are responsive to verbal encouragement to increase PA, they prefer the addition of written instructions or a prescription (Pfeiffer, Clay \& Conaster, 2001). Writing an exercise prescription in an economic and effective way to incorporate PA interventions into practice. Exercise prescriptions should specify exercise frequency, intensity, duration, modality, and progression (Lee, Jackson \& Richardson, 2017). Helping the patient to set a goal and including it on the prescription can promote success. Sample exercise prescriptions can be found in the article by Lee, Jackson, and Richardson (2017) (Refer to Table 3). Using a behavior change theory or technique is a good strategy for tailoring counseling interventions. For example, counseling based on social cognitive theory has been shown to be an effective strategy, at least in the short term (Herghelegiu et al., 2017; Kerr et al., 2018, Mutrie et al., 2012). To tailor PA interventions, NPs may consider assessing patients' selfefficacy, or perceived confidence to engage in PA behaviors. PA counseling strategies could target various contributors to self-efficacy, such as identifying ways to improve performance mastery and providing verbal encouragement (Bandura, 1997). Additionally, utilizing the transtheoretical theory of change to assess a patient's readiness for change can help the NP deliver the support the patient needs at each stage of behavior transformation (Herhelegiu et al., 2017). A patient in the precontemplation stage may benefit from discussion of the health benefits of exercise, while a patient in the contemplation stage may benefit from a discussion of the pros and cons of exercise (American College of Sports Medicine, 2019). A brochure about PA for older adult can be downloaded from National Institute on Aging (Refer to Table 3). Older adults may have low self-efficacy for exercise, so starting with something familiar such as 
walking may help increase their success. Additionally, verbal encouragement from the provider can help build the patient's self-efficacy. Follow up phone calls can be made by the NP or the office staff to provide support and encouragement. Successful interventions contain multiple opportunities for reinforcement of the older adult's efforts at increasing PA (Herhelegui et al., 2017).

Incorporating other disciplines as PA counselors reduces the burden on physicians, NPs, and physician assistants who may have time constraints during office visits. For example, physical therapists or kinesiologists are specially trained in PA counseling (Shirley, Van der Ploeg, \& Bauman, 2010). Barreto et al. (2018) and Kerr et al. (2018) demonstrated that it is possible to train other personnel or peer leaders to provide PA counseling. A multidisciplinary approach could be utilized where the primary provider leverages their credibility with the patient to make referrals to other providers of PA counseling. If the patient is very deconditioned, functionally limited, or has chronic conditions, they may need more guidance. The American College of Sports Medicine suggests enlisting the help of office staff to generate a list of qualified exercise professionals and offers tips on how to identify qualified individuals (Refer to Table 3). Community senior centers may have supervised exercise classes to which older adults may be referred.

While the risk of injury from participation in PA by the older adult may be a concern for the provider, the benefits of participation in PA outweighs the small risk of injury to the older adult (Stathokostas, Theou, Little, Vandervoort \& Raina, 2013). The older adult can experience fears related to falling, over exerting, or sustaining injury. In addition to emphasizing the health benefits of PA, counseling should also address patient's fears surrounding increasing their activity level (Baert et al., 2011). NPs may allay patient concerns about the risk of injury from 
participation in PA by discussing safety strategies. An older adult who is experiencing falls may need a referral to physical therapy for balance training prior to starting a new exercise regimen (Lee, 2017). NPs may also share CDC brochures on fall prevention strategies and educate the older client that PA may reduce fall risk (CDC, 2019; Cowper et al., 2017).

Several methodological limitations were noted among studies included in this review. For example, racial/ethnic diversity and certain age groups were not well-represented. Individuals from racial/ethnic minority groups are less likely to participate in healthy exercise and dietary behaviors than Caucasians (August \& Sorkin, 2011). Yet increasing PA in these individuals is essential. Obesity rates in African American women, for example, are increasing. Obesity combined with low levels of PA contributes to high rates of heart disease and diabetes (Bland \& Sharma, 2017). Additionally, the old-old (85-94 years) and the oldest old (95+) are not well represented in PA research. Yet, frailty, a condition modifiable by PA, has been shown to be a predictor for nursing home placement (Kojima, 2018). The need for further research regarding how to encourage older adults from diverse backgrounds and of advanced age cannot be underestimated. Additionally, research is needed to demonstrate long term compliance with PA, thus further supporting the benefits of providing PA interventions.

Consistent use of objective measures to determine levels of PA, as well as larger sample sizes,, are needed to better establish counseling effectiveness. The collection of accurate PA outcomes is vital for reporting and analyzing data across studies. Social desirability bias can cause participants to choose responses that they believe are more socially acceptable and can influence results (Sallis \& Saelens, 2000). Poor recall due to memory impairments in some older adult can further impact the use of self-report in PA research (Sallis \& Saelens, 2000). 
Further research regarding the healthcare cost savings related to chronic disease prevention due to greater PA could support incentives for providing PA interventions in primary care. PA counseling interventions have been associated with not only an increase in PA behavior, but also a decrease in falls with a cost that is only a small fraction of an individual's health care costs, about 6\% (Cowper et al., 2017). Participants who received the Coach2Move intervention reached their outcomes for physical therapy and were discharged after significantly fewer visits than the control group, a significant savings in health care dollars (de Vries et al., 2016).

\section{Limitations}

Limitations of this review include a lack of adequate studies utilizing a variety of disciplines, including physicians, nurses, physical therapists and health counselors, as well as studies to determine the minimal amount of counseling encounters needed to improve and maintain PA levels. This current review was limited to only five data bases; CINAHL, PsycINFO, PubMed, SPORTDiscus, and Scopus. Inclusion of more studies involving racially/ethnically diverse participants and the older old adult would be beneficial for identifying interventions for these special populations. The use of objective measures in PA research is important since most adults overestimate their activity levels (Sallis \& Saelens, 2000). The concern that participants may overestimate their activity on questionnaires at baseline may impact the ability to demonstrated significant increases in PA. Subsequent reviews should include a more extensive data search along with meta-analysis to determine the most effective interventions in primary care to promote $\mathrm{PA}$ in adults $\geq 65$. 


\section{Conclusion}

PA counseling can be an effective way to improve PA levels in older adults. NPs can employ diverse PA counseling strategies in varied clinical settings to improve the PA levels of older patients. The theoretical frameworks that proved efficacious in the reviewed studies were the SCT and transtheoretical theory of change. NPs can incorporate these theories by promoting exercise self-efficacy in their patients and by assessing for stages of change. Resources are available for writing exercise prescriptions. While following up with the patient by phone or in person is recommended. During counseling sessions, it is important to address the patient's fears related to increasing PA, emphasize the benefits of PA, and help the patient set PA goals. Using an interdisciplinary approach, as well as employing alternative techniques to in-person counseling, may improve efficiency. Further research is needed to determine the ideal amount and duration of counseling, and any differences in the older adult's response to counseling based on diverse demographic characteristics. 
Table 2.1

Included Articles

\begin{tabular}{|c|c|c|c|c|c|}
\hline $\begin{array}{l}\text { Author, Year, } \\
\text { Location }\end{array}$ & Design & Theory & $\begin{array}{c}\text { Sample } \\
\text { Characteristics }\end{array}$ & Intervention & Results \\
\hline $\begin{array}{l}\text { Arkkukangas } \\
\text { et al., (2019) } \\
\text { Sweden }\end{array}$ & $\begin{array}{l}\text { Randomized } \\
\text { controlled } \\
\text { trial }\end{array}$ & $\begin{array}{l}\text { Transtheoretical } \\
\text { Model }\end{array}$ & $\begin{array}{l}\text { Mean age of all } \\
\text { groups: } 83 \\
\text { Exercise } \\
\text { Program } \\
\mathrm{n}=61 \\
\text { Exercise } \\
\text { Program + } \\
\text { Motivational } \\
\text { Interviewing } \\
(\mathrm{MI}) \\
\mathrm{n}=58 \\
\mathrm{CON} n=56\end{array}$ & $\begin{array}{l}\text { Intervention Duration } \\
\text { (Months): } 3 \\
\text { Interventionist: } \\
\text { Physical Therapists } \\
\text { Intervention: Otago } \\
\text { Exercise Program } \\
\text { (OEP)/OEP with MI }\end{array}$ & $\begin{array}{l}\text { Outcome Measure: } \\
\text { Frändin/Grimby Activity } \\
\text { Scale } \\
\text { No difference between groups } \\
\text { in the Frändin/Grimby Activity } \\
\text { Scale } \\
\text { Within groups, the OEP + MI } \\
\text { group significantly improved } \\
(P=.02) \text { physical } \\
\text { performance, fall self- } \\
\text { efficacy, activity levels, } \\
\text { handgrip strength, adherence } \\
\text { to the exercises and decline in } \\
\text { fall frequency } \\
\text { Differences in the OEP and } \\
\text { control groups in the } \\
\text { Frändin/Grimby Activity Scale } \\
\text { not significant }\end{array}$ \\
\hline $\begin{array}{l}\text { Barreto et al., } \\
(2018) \\
\text { France }\end{array}$ & $\begin{array}{l}\text { Randomized } \\
\text { controlled } \\
\text { trial }\end{array}$ & None Noted & $\begin{array}{l}\text { Multi domain }+ \\
\text { Omega 3: mean } \\
\text { age: } 76, n=417 \\
\text { Omega3: mean } \\
\text { age: } 76.1, \mathrm{n}=422 \\
\text { Multidomain: } \\
\text { Mean age, } 75.5 \\
\mathrm{n}=420 \\
\text { Placebo + usual }\end{array}$ & $\begin{array}{l}\text { Intervention Duration } \\
\text { (Months): } 36 \\
\text { Interventionist: PA } \\
\text { instructor } \\
\text { Intervention: } \\
\text { Cognitive training, } \\
\text { Nutritional and PA } \\
\text { counseling, Omega } 3 \\
\text { supplements }\end{array}$ & $\begin{array}{l}\text { Outcome Measure: MET- } \\
\text { min/week } \\
\text { Nutritional and PA counseling } \\
\text { increased MET-min/week at } 6 \\
\text { months ( } p \leq 0.002) \text { and had } \\
\text { limited decline at } 2 \text { and } 3 \text { year } \\
\text { follow up. Omega-3 } \\
\text { supplementation } \\
\text { did not affect PA levels }\end{array}$ \\
\hline
\end{tabular}




\begin{tabular}{|c|c|}
\hline $\begin{array}{l}\text { Bickmore, } \\
\text { et al., (2013) } \\
\text { United States }\end{array}$ & $\begin{array}{l}\text { Randomized } \\
\text { controlled } \\
\text { trial }\end{array}$ \\
\hline
\end{tabular}

De Vries, et al., Randomized None Noted (2015) controlled trial

N

$\begin{array}{lll}\text { Herhelegiu } & \text { Randomized } & \text { Transtheoretical } \\ \text { et al., (2017) } & \text { controlled } & \text { Model } \\ \text { Romania } & \text { trial } & \end{array}$

Mean age of all Intervention Duration participants: 71.3 (Months): 12

Treatment $n=132$

CON: $n=131$

Interventionist:
Embodied

Conversational Agent

Intervention:

Coaching daily for 2

months then

intermittently for 10

month maintenance

phase

Intervention:

mean age: 78.4 ,

$\mathrm{n}=64$

CON: mean age:

$78.6, n=65$

Mean age:

Intervention:

$74.8, \mathrm{n}=100$

CON: Mean age:

$75, \mathrm{n}=100$

\section{Intervention Duration}

(Months): 6

Interventionist:

Physical Therapists

Intervention:

Coach2Move. Goal oriented treatment plan fitting barriers of the patient and his or her environment.

Intervention Duration

(Months): 6

Interventionist:

Geriatrician

Intervention: Monthly

15-30-minute

counseling sessions
Outcome measure: Steps via pedometer

Statistically significant

increase at 2 months ( $p=.01$ )

No longer significant at 12

months $(p=.09)$

\section{Outcome Measure: LASA}

Physical Activity

Questionnaire (LAPAQ).

Between group mean

differences for PA: $17.9 \mathrm{~min}$

per day at 6 months

Outcome Measures: Mets

collected via the International Physical Activity

Questionnaire (IPAQ)

Intervention: PA increased by a median of 180.0 MET

minutes/week $(95 \%$

confidence interval (CI)

43.4 $\pm 316.6, p=0.01$ )

Control group: PA decreased

by a median of $346.5 \mathrm{MET}$

minutes/week (95\% CI 
178.4 $\pm 514.6, p<0.001)$ due to seasonal effect

\begin{tabular}{|c|c|c|c|c|c|}
\hline $\begin{array}{l}\text { Kerr et al., } \\
(2018) \\
\text { United States }\end{array}$ & $\begin{array}{l}\text { Cluster } \\
\text { randomized } \\
\text { controlled } \\
\text { trial }\end{array}$ & $\begin{array}{l}\text { Social Cognitive } \\
\text { Theory }\end{array}$ & $\begin{array}{l}\text { Intervention: } \\
\text { Mean age: } \\
\text { 85.3.n=151 } \\
\text { CON: Mean age } \\
81.9, \mathrm{n}=156\end{array}$ & $\begin{array}{l}\text { Intervention Duration } \\
\text { (Months): } 12 \\
\text { Interventionist: Health } \\
\text { Educators and Peer } \\
\text { Leaders } \\
\text { Intervention: } \\
\text { Individual-goal setting, } \\
\text { Interpersonal- group } \\
\text { walks, and community } \\
\text { level-pedestrian } \\
\text { advocated } \\
\text { improvements } \\
\text { in walkability }\end{array}$ & $\begin{array}{l}\text { Outcome Measure: } \\
\text { Accelerometer reading } \\
\text { Intervention; Significant } \\
\text { increase in PA (about } 56 \text { min } \\
\text { of moderate-vigorous PA per } \\
\text { week or } 119 \text { min of light PA) } \\
\text { Control group: no change } \\
\text { overall }\end{array}$ \\
\hline $\begin{array}{l}\text { Kolt et al., } \\
(2012) \\
\text { New Zealand }\end{array}$ & $\begin{array}{l}\text { Cluster } \\
\text { randomized } \\
\text { controlled } \\
\text { trial }\end{array}$ & None Noted & $\begin{array}{l}\text { Intervention: } \\
\text { Mean age: } 73.9 \text {, } \\
n=165 \\
\text { CON: Mean age: } \\
74.3, n=165\end{array}$ & $\begin{array}{l}\text { Intervention Duration } \\
\text { (Months): } 3 \\
\text { Interventionist: } \\
\text { Primary Care Physician } \\
\text { Intervention: } \\
\text { Group 1: Green } \\
\text { prescription with } \\
\text { pedometer and } \\
\text { in person prescription } \\
\text { followed by } 3 \text { telephone } \\
\text { counseling sessions } \\
\text { provided by activity } \\
\text { counselor } \\
\text { Group 2: Green with } \\
\text { in person prescription } \\
\text { followed by } 3 \text { telephone }\end{array}$ & $\begin{array}{l}\text { Group } 1 \text { (pedometer-based) } \\
\text { increased leisure } \\
\text { walking by } 63.0 \mathrm{~min} / \mathrm{wk} \text { on } \\
\text { average, more than double the } \\
\text { increase in Group } 2 \text { (no } \\
\text { pedometer) of } 30.9 \mathrm{~min} / \mathrm{wk} \text { at } \\
3-4 \text { months }\end{array}$ \\
\hline
\end{tabular}




$\begin{array}{lll}\text { McMurdo,et al., } & \begin{array}{l}\text { Randomized } \\ \text { controlled }\end{array} & \begin{array}{l}\text { Self-regulation } \\ \text { Theory }\end{array} \\ \text { Scotland } & \text { trial } & \end{array}$

Mutrie et al., (2012)

United

Kingdom counseling sessions provided by activity counselor- No pedometer-focus on setting time goals rather than step counting

Mean age of all groups: 77.3 BCI $n=68$ $\mathrm{BCI}+$ pedometer $\mathrm{n}=68$

$\mathrm{CON} n=68$

Intervention

mean

age of 71.6

Control mean age of 70.0 $\mathrm{n}=20$

$\mathrm{CON} n=21$
Intervention Duration (Months): 6 Interventionist:

Trained study coordinators

\section{Intervention:}

Group1: Behavioral

Change Intervention (BCI)

Group 2: Behavioral

Change Intervention (BCI) plus pedometer Group 3: Usual Care Participants were contacted $1 \mathrm{x} /$ week for the first month, then every 2 weeks for 2 months, and then monthly

Intervention Duration (Months): 3

Interventionist: Nurse Intervention:

Two 30-minute nurse led counseling sessions, use of pedometer
Outcome Measure:

Accelerometer reading

Secondary outcome- lower extremity function Results: PA at 3 months was higher in the BCI group than in the control group ( $p=.002)$ and the pedometer plus group $(p=.04)$.

No significant difference between BCI group and BCI + pedometer
Outcome Measures: Sealed pedometers and an activ $\mathrm{PAL}^{\mathrm{tm}}$ monitor.

\section{Results:}

12 Weeks: Intervention increased step counts by 2119 steps/day $(p=.001)$ 
Rasinaho et al., (2011) Finland

Randomized controlled trial

Social Cognitive Theory

Transtheoretical Model

Robare et al., (2011)

$\infty$ United States

$\begin{array}{ll}\text { Randomized } & \text { Social Learning } \\ \text { controlled } & \text { Theory } \\ \text { trial } & \end{array}$

trial controlled
Mean age of both groups:

77.6

Intervention: $\mathrm{n}=318$

CON: $n=314$

Mean age of both groups:

73.9

Lifestyle Plus $\mathrm{n}=188$

Education and Counseling $\mathrm{n}=201$
Control group: received intervention 12 weeks

later

Intervention Duration

(Months): 24

Interventionist:

Physiotherapist

Intervention: 1 hour of face to face counseling followed by phone counseling sessions 3 times per year

Intervention Duration (Months): 24

Interventionist: Health

Counselors

Intervention:

BECI: Brief education and counseling

interventions

BECI-plus: Received

brief education and counseling intervention plus a physical activity intervention (the Key to Life Exercise

Intervention) and, for those with a history of hypertension, a dietary sodium nutritional intervention
Outcome Measures: Number of physical activities attended Results: Effect was

significant for water aerobics (odds ratio (OR) 2.49, 95\% confidence interval CI 1.165.36), and for walking for fitness (OR 1.58, 95\% CI 1.05-2.40)

Participants followed for 3.5

years

Outcome Measures:

Modified Activity

Questionnaire

Results: Levels of PA

Declined 1.6 hours per week in the BECI-plus group 
Thompson et al., (2014)

United States
Randomized

controlled

trial
Mean age: 79.5

Intervention:

$\mathrm{n}=25$

CON: $n=24$
Intervention Duration

(Months): 12

Interventionist:

Counselor

Intervention: Face to

face counseling every 2

months, phone

counseling weekly and

FitBit. Utilized

READY, get SET, and

GO from the Go4Life

materials Control

group: FitBit only 
Table 2.2

\section{Pedro Scale}

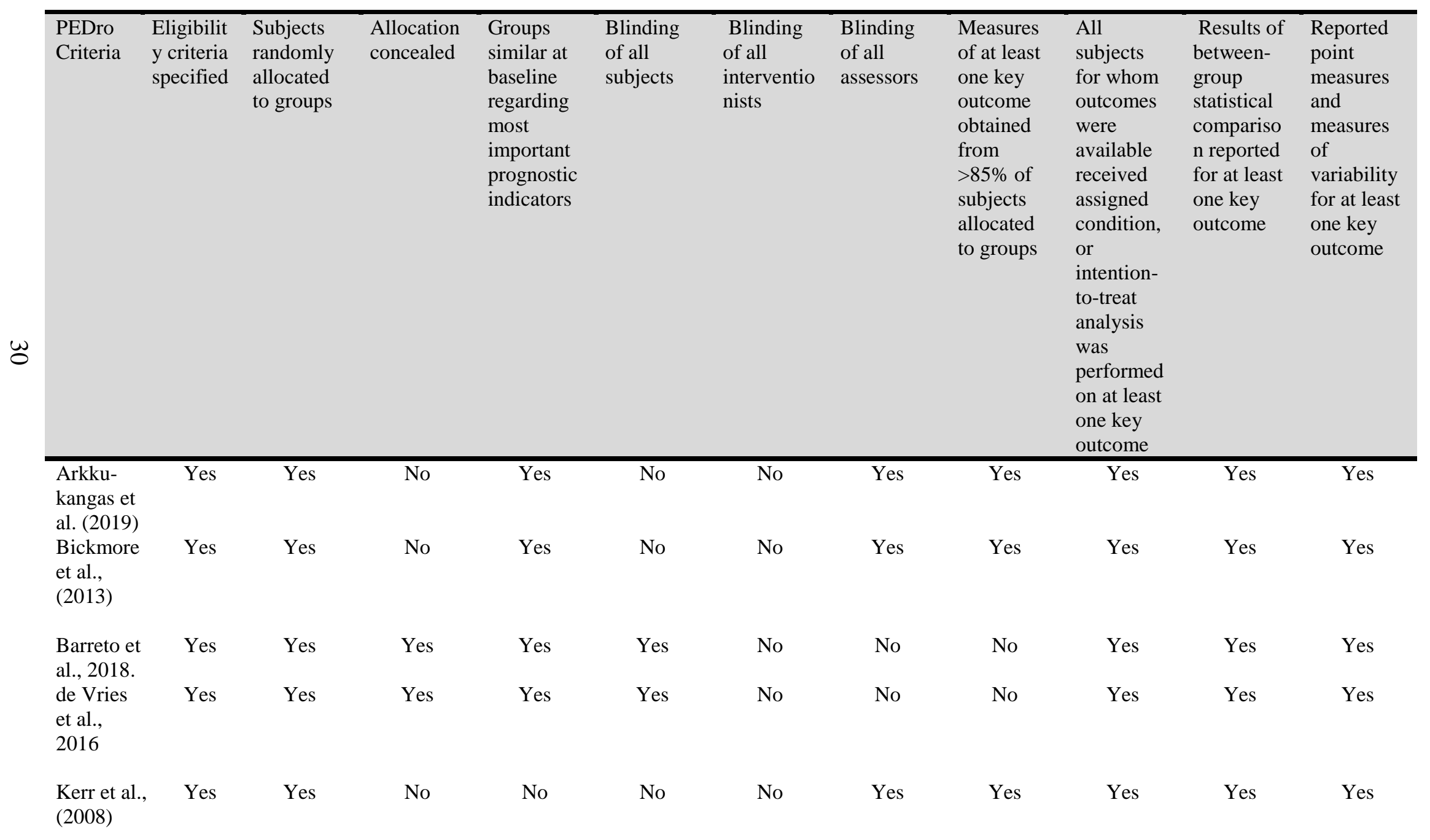




\begin{tabular}{|c|c|c|c|c|c|c|c|c|c|c|c|}
\hline $\begin{array}{l}\text { Kolt et al., } \\
(2012)\end{array}$ & Yes & Yes & No & Yes & No & No & Yes & No & No & Yes & Yes \\
\hline $\begin{array}{l}\text { Herhelegi } \\
\text { u et al., } \\
\text { (2017) }\end{array}$ & Yes & Yes & No & No & No & Yes & Yes & Yes & No & Yes & Yes \\
\hline $\begin{array}{l}\text { McMurdo, } \\
\text { et al., } \\
\text { (2010) }\end{array}$ & Yes & Yes & No & Yes & No & No & Yes & Yes & Yes & Yes & Yes \\
\hline $\begin{array}{l}\text { Mutrie et } \\
\text { al., 2012) }\end{array}$ & Yes & Yes & No & Yes & No & No & Yes & Yes & Yes & Yes & Yes \\
\hline $\begin{array}{l}\text { Rasinaho } \\
\text { et al., } \\
2011\end{array}$ & Yes & Yes & No & Yes & No & No & Yes & Yes & Yes & Yes & Yes \\
\hline $\begin{array}{l}\text { Robare et } \\
\text { al. }(2011)\end{array}$ & Yes & Yes & No & Yes & No & No & No & Yes & No & Yes & Yes \\
\hline $\begin{array}{l}\text { Thompson } \\
\text { et al., } \\
\text { (2014) }\end{array}$ & Yes & Yes & No & Yes & No & No & No & Yes & No & Yes & Yes \\
\hline $\begin{array}{l}\text { Purat et } \\
\text { al., (2013) }\end{array}$ & Yes & & & Yes & & & & & No & & \\
\hline
\end{tabular}




\section{Table 2.3}

Resources for Recommending Physical Activity

American College of Sports Medicine (2019). Health care providers' action guide. Retrieved from

https://www.exerciseismedicine.org/assets/page_documents/EIM\%20Health\%20Care\%20Pr oviders\%20Action\%20Guide\%20clickable\%20links.pdf

Lee, P.G., Jackson, E.A., Richardson, C.R. (2017). Exercise prescription in older adults. American Academy of Family Physicians, 97(7), 425-432

National Institute on Aging. (2018). Exercise and physical activity guide. Retrieved from https://order.nia.nih.gov/publication/exercise-physical-activity-your-everyday-guide-from-thenational-institute-on-aging

National Institute on Aging. (2018). Go4Life. Sample workouts: Getting fit for life. Retrieved from https://go4life.nia.nih.gov/workout-videos/

National Institute on Aging. (2018). Work out to go mini exercise guide. Retrieved from https://order.nia.nih.gov/publication/workout-to-go-mini-exercise-guide

United States Department of Health and Human Services (2018). Physical activity guidelines for Americans (2nd ed). Retrieved from https://health.gov/paguidelines/secondedition/pdf/Physical_Activity_Guidelines_2nd_edition.pdf 
Figure 2.1

\section{PRISMA 2009 Flow Diagram}
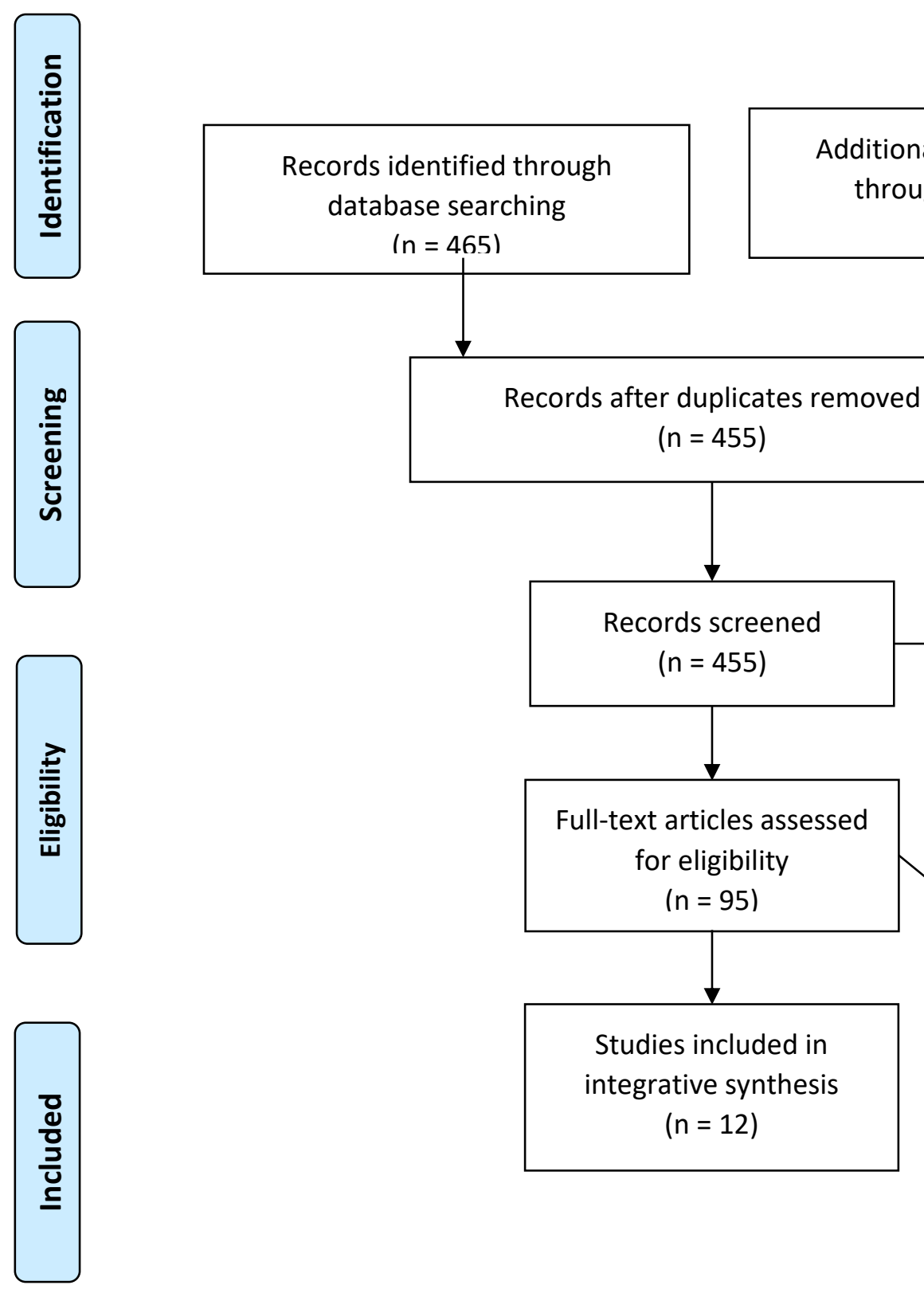

Records excluded

$$
(n=360)
$$

Full-text articles excluded, with reasons

$$
(n=83)
$$

Participant's wrong age

$$
(n=36)
$$

No PA outcome 


\section{Reference}

American College of Sports Medicine (2019). Health care providers' action guide. Retrieved from https://www.exerciseismedicine.org/assets/page_documents/EIM\%20Health\%20Care\%2 0Providers\%20Action\%20Guide\%20clickable\%20links.pdf

Aoyama, M. , Suzuki, Y., Kuzuya, M. (2015). Muscle strength of lower extremities related to incidence falls in community dwelling older adults. Gerontology and Geriatric Research, 4(2). DOI: $10.4172 / 2167-7182$

Arkkukangas, M., Söderlund, A., Eriksson, S., \& Johansson, A.C. (2019). Fall preventive exercise with or without behavior change support for community-dwelling older adults: A randomized controlled trial with short-term follow-up. Journal of Geriatric Physical Therapy, 42(1), 9-17. https://doi.org/10.1519/JPT.0000000000000129

August, K. J., \& Sorkin, D. H. (2011). Racial/ethnic disparities in exercise and dietary behaviors of middle-aged and older adults. Journal of general internal medicine, 26(3), 245-250. doi:10.1007/s11606-010-1514-7

Bachman, A.S., Wilson, R.S., Yu, L., James, B.D., Boyle, P.A. \& Bennett, D. A. (2014). Total daily activity declines more rapidly with increasing age in older adults. Archives of Gerontology and Geriatrics, 58, 74-79. https://doi.org/10.1016/j.archger.2013.08.001

Baert, V., Gorus, E., Mets, T., Geerts, C., \& Bautmans, I. (2011). Motivators and barriers for physical activity in the oldest old: A systematic review. Ageing Research Reviews, 10(4), 464-474. https://doi.org/10.1016/j.arr.2011.04.001

Bandura, A. (1997). Self-efficacy: The Exercise of Control. New York, New York: Freeman. 
Barreto, P. de S., Rolland, Y., Cesari, M., Dupuy, C., Andrieu, S., Vellas, B., \& MAPT study group. (2018). Effects of multidomain lifestyle intervention, omega-3 supplementation or their combination on physical activity levels in older adults: Secondary analysis of the Multidomain Alzheimer Preventive Trial (MAPT) randomised controlled trial. Age and Ageing, 47(2), 281-288. https://doi.org/10.1093/ageing/afx164

Bean, J., Vora, A., \& Frontera, W. (2004). Benefits of exercise for community dwelling older adults. Archives of Physical Medicine and Rehabilitation, 85(Supp 3), S31-42. doi: 10.1016/j.apmr.2004.03.010

Bickmore, T. W., Silliman, R. A., Nelson, K., Cheng, D. M., Winter, M., Henault, L., \& Paasche-Orlow, M. K. (2013). A randomized controlled trial of an automated exercise coach for older adults. Journal of the American Geriatrics Society, 61(10), 1676-1683. https://doi.org/10.1111/jgs.12449

Blair S, Sallis R, Hutber A.\& Archer, E. (2012). Exercise therapy-the public health message. Scandinavian Journal of Medicine and Science in Sports, 22(4), 24-28. doi: 10.1111/j.1600-0838.2012.01462.x

Bland, V., \& Sharma, M. (2017). Physical activity interventions in African American women: A systematic review. Health promotion perspectives, 7(2), 52-59. doi:10.15171/hpp.2017.11

Brenen, M. (2018). Nurses again outpace other professions for honesty, ethics. Gallup. Retrieved from https://news.gallup.com/poll/245597/nurses-again-outpace-professionshonesty-ethics.aspx

Center for Disease Control (2019). STEADI Older adult fall prevention. Retrieved from https://www.cdc.gov/steadi/patient.html 
Center for Disease Control (2017). Health and economic costs of chronic disease. Retrieved from https://www.cdc.gov/chronicdisease/about/costs/index.htm

Center for Medicare and Medicaid (2019). Original Medicare and Medicaid (Part A and Part B Eligibility and Enrollment. Retrieved from https://www.cms.gov/Medicare/Eligibilityand-Enrollment/OrigMedicarePartABEligEnrol

Chase, J. D. (2015). Interventions to increase PA among older adults: A meta-analysis, The Gerontologist,55(4), 706-718. doi: 10.1093/geront/gnu090

Conn, V.S., Valentine, J.C., \& Cooper, H.M. (2002). Interventions to increase physical activity among aging adults: a meta-analysis. Annals of Behavioral Medicine, 24, 190-200. PubMed doi:10.1207/S15324796ABM2403_04

Cowper, P., Peterson, M., Pieper, C., Sloan, R., Hall, K.... Morey, M. (2017). Economic nalysis of primary care based physical activity counseling in older men: The VA-LIFE trial. Journal of the American Geriatrics Society, 65(3), 533-539. doi:10.1111/jgs.14567.

Dasso, N. (2018). How is exercise different than PA? A concept analysis. Nursing Forum: An Independent Voice for Nursing, 54(1), 45-52. doi: 10.1111/nuf.12296.

de Morton, N.A. (2009). The PEDro scale is a valid measure of the methodological quality of clinical trials: A demographic study. Australian Journal of Physiotherapy, 55(2), 129133. https://doi.org/10.1016/S0004-9514(09)70043-1

de Vries, N. M., Staal, J. B., van der Wees, P. J., Adang, E. M. M., Akkermans, R., Olde Rikkert, M. G. M., \& Nijhuis-van der Sanden, M. W. G. (2016). Patient-centred physical therapy is (cost-) effective in increasing physical activity and reducing frailty in older adults with mobility problems: A randomized controlled trial with 6 months follow-up. Journal of Cachexia, Sarcopenia and Muscle, 7(4), 422-435. https://doi.org/10.1002/jcsm.12091 
Guure, C.B., Ibrahim, N.A., Adam, M.B. \& Sai, S.M. (2017). Research article impact of physical activity on cognitive decline, dementia, and its subtypes: Meta-analysis of prospective studies. Hindawi: BioMed Research International, 2017. https://doi.org/10.1155/2017/9016924

Hébert, E., Caughy, M. \& Shuval, K. (2012). Primary care providers' perceptions of physical activity counseling in a clinical setting: A systematic review. British Journal of Sports Medicine,46(9), 625-631. doi:10.1136/bjsports-2011-090734

Herghelegiu, A. M., Moser, A., Prada, G. I., Born, S., Wilhelm, M., \& Stuck, A. E. (2017). Effects of health risk assessment and counselling on physical activity in older people: A pragmatic randomised trial. PloS One, 12(7), e0181371. https://doi.org/10.1371/journal.pone.0181371

Kanfer, R. \& Kanfer, F. (1991). Goal and self-regulation: Applications of theory to work settings. In M.L. Maehr \& P.R. Pintrich (Eds). Advances in Motivation and Achievement, (vol 7), 287-326. Greenwich,CT: JAI Press.

Kerr, J., Rosenberg, D., Millstein, R. A., Bolling, K., Crist, K., Takemoto, M., Godbole, S., Moran, K., Natarajan, L., Castro-Sweet, C., \& Buchner, D. (2018). Cluster randomized controlled trial of a multilevel physical activity intervention for older adults. The International Journal of Behavioral Nutrition and Physical Activity, 15(1), 32. https://doi.org/10.1186/s12966-018-0658-4

Knowles, M. (2018). Number of nurse practitioners in U.S. hits record high. Becker's Hospital Review. Retrieved from https://www.beckershospitalreview.com/workforce/number-ofnurse-practitioners-in-us-hits-record-high.html

Kojima, G. (2018). Frailty of a predictor of nursing home placement among community dwelling 
older adults: A systematic review and meta-analysis. Journal of Geriatric Physical Therapy, 42(1), 42-48. doi: 10.1519/JPT.0000000000000097

Kolt, G. S., Schofield, G. M., Kerse, N., Garrett, N., Ashton, T., \& Patel, A. (2012). Healthy steps trial: Pedometer-based advice and physical activity for low-active older adults. Annals of Family Medicine, 10(3), 206-212. Scopus. https://doi.org/10.1370/afm.1345

Kredlow, M.A., Capozzoli, M.C., Hearon, B. A., Calkins, A.W., Otto, M.W.(2015). The effects of physical activity on sleep: A meta-analytic review. Journal of Behavioral Medicine, 38, 427-449. DOI 10.1007/s10865-015-9617-6

Langlois, F. Vu, T. T. M. , Chasse, K. , Dupuis, G. Kergoat, M. J. (2012). Benefits of physical activity training on cognition and quality of life in frail older adults. Journal of Gerontology Series B: Psychological Services and Social Sciences, 68(3), 400-404. doi:10. 1093/geronb/gbs069.

Li, I., Shiroma, E.J., Lobelo, F., Puska, P., Blair, S.N., \& Katzmarzyk, P.T. (2012). Effects of physical inactivity on major non-communicable diseases worldwide: An analysis of burden of disease and life expectancy. The Lancet, 380(9838). DOI: https://doi.org/10.1016/S0140-6736(12)61031-9

Kyu, H., Bachman, V.F., Alexander,L.T., Mumford, J.E., Afshin,A., Estep, K., Veerman, J.L., Delwiche, K., Iannarone, M.L., Moyer, M.L., Cercy, K., Vos, T., Murray, C.J.L., Forouzanfar, M.H. (2016). Physical activity and risk of breast cancer, colon cancer, diabetes, ischemic heart disease, and ischemic stroke events: systematic review and doseresponse meta-analysis for the Global Burden of Disease Study 2013. BMJ 354(i3857). doi: 10.1136/bmj.i3857 
Langlois, F. Vu, T. T. M. , Chasse, K. , Dupuis, G. Kergoat, M. J. (2012). Benefits of physical activity training on cognition and quality of life in frail older adults. Journals of Gerontology Series B: Psychological Services and Social Sciences, 68(3), 400-404. doi:10. 1093/geronb/gbs069.

Lee, P.G., Jackson, E.A., Richardson, C.R. (2017). Exercise prescription in older adults. American Academy of Family Physicians, 97(7), 425-432Lilienthal, K. R., Pignol, A. E., Holm, J. E., \& Vogeltanz-Holm, N. (2014). Telephone-based motivational interviewing to promote PA and stage of change progression in older adults. Journal of Physical Activity, 22(4), 527-535. doi. Org/10.1123/JAPA.2013-0056

Lion, A., Vuillemin, A., Thornton, F., Theisen, D., Stranges, S. \& Ward, M. (2018). Physical activity promotion in primary care: A utopian quest? Health Promotion International, 34, 877-886. doi: 10.1093/heapro/day038.

Maher, C.G., Sherrington, C., Herbert, R.D., Moseley, A.M., Elkins, A. (2003). Reliability of the PEDro scale for rating quality of randomized controlled trials, Physical Therapy, 83(8), 713-721. https://doi.org/10.1093/ptj/83.8.713

McMurdo, M. E. T., Sugden, J., Argo, I., Boyle, P., Johnston, D. W., Sniehotta, F. F., \& Donnan, P. T. (2010). Do pedometers increase physical activity in sedentary older women? A randomized controlled trial. Journal of the American Geriatrics Society, 58(11), 20992106. https://doi.org/10.1111/j.1532-5415.2010.03127.x

Moher, D., Liberati, A., Tetzlaff, J., \& Altman, D.G. (2009). Preferred reporting items for systematic reviews and meta-analyses: The PRISMA statement. Annals of Internal Medicine, 151(4), 264-269. doi: 10.7326/0003-4819-151-4-200908180-00135 
Mosen D, Glauber H, Stoneburner A, Feldstein A, Fortmann S. (2017). Assessing the association between exercise status and poor glycemic control. Journal of Patient Centered Research and Reviews, 4(3).

Mutrie, N., Doolin, O., Fitzsimons, C. F., Grant, P. M., Granat, M., Grealy, M., ... Skelton, D. A. (2012). Increasing older adults' walking through primary care: Results of a pilot randomized controlled trial. Family practice, 29(6), 633-642. doi:10.1093/fampra/cms038

National Institute on Aging. (2018). Exercise and physical activity guide. Retrieved from https://order.nia.nih.gov/publication/exercise-physical-activity-your-everyday-guidefrom-the-national-institute-on-aging

Newson, R. S., \& Kemps, E. B. (2007). Factors that promote and prevent exercise engagement in older adults. Journal of Aging and Health, 19(3), 470-481. https://doi.org/10.1177/0898264307300169

Olanrewaju, O., Kelly, S., Cowan, A., Brayne, C., \& Lafortune, L. (2016). Physical activity in community dwelling older people: A systematic review of reviews of interventions and Context. PLOS ONE, 11(12), 1-19. doi: 10.1371/journal.pone.0168614

Oliveira, J.S., Sherrington, C., Amorim, A., Dario, A., Tiedemann, A. (2017). What is the effect of health coaching on physical activity participation in people aged 60 years and over? A systematic review of randomized controlled trials. British Journal of Sports Medicine, 51, 1425-1432, doi.org/10.1136/bjsports-2016-096943

Ou, S., Chen, Y., Shih, C. \& Tarng, D. (2017). Impact of physical activity on the association between lipid profiles and mortality among older people. Scientific Reports 7. https://doi.org/10.1038/s41598-017-07857-7 
Patel, A., Schofield, G., Kolt, G. \& Koegh, J. (2011). General practitioners' views and experiences of counseling for PA through the New Zealand Green Prescription program. BMC Family Practice, 12(119). doi: 10.1186/1471-2296-12-119

Paulo, T.R.S., Tribess, S., Sasaki, J.E., Meneguci, J., Martins, C.A., Freitas, I.F., Roma-Perez, V., Virtuoso, J.S.(2016). A cross-sectional study of the relationship of physical activity with depression and cognitive deficits in older adults. Journal of Aging \& Physical Activity, 24(2), 311-324. https//doi.org/10.1123/japa.2014.0253

Prochaska, J.O., Redding, C.A., \& Viswanath, K. (2015). The transtheoretical model and stages of change. In K. Glanz, B.K. Rimer \& F.M. Lewis, (Eds.) Health Behavior: Theory, Research, and Practice (3rd Ed.). San Francisco, CA: Jossey-Bass, Inc.

Rasinaho, M., Hirvensalo, M., Törmäkangas, T., Leinonen, R., Lintunen, T., \& Rantanen, T. (2012). Effect of physical activity counseling on physical activity of older people in Finland (ISRCTN 07330512). Health Promotion International, 27(4), 463-474. https://doi.org/10.1093/heapro/dar057

Robare, J. F., Bayles, C. M., Newman, A. B., Williams, K., Milas, C., Boudreau, R., McTigue, K., Albert, S. M., Taylor, C., \& Kuller, L. H. (2011). The "10 keys" to healthy aging: 24month follow-up results from an innovative community-based prevention program. Health Education \& Behavior, 38(4), 379-388. https://doi.org/10.1177/1090198110379575

Ryan, R. M. \& Deci, E. L. (2000). Self-determination theory and the facilitation of intrinsic motivation, social development, and well-being. American Psychologist, 55, 6878. https://dx.doi.org/10.1037/0003-066X.55.1.68 
Saaksjarvi, K., Knelt, P., Mannisto, S., Lyytinen, J. , Kanerva, N., Heliovaara, M. (2014). (2014).

Reduced risk of Parkinson's disease associated with lower body mass index and heavy leisure-time physical activity. European Journal of Epidemiology, 29, 285-292.

Sallis, J. F. \& Saelens, B. E. (2000). Assessment of physical activity by self-report: Status, limitations, and further directions. Research Quarterly for Exercise and Sport, 71(2), S1.doi: $10.1080 / 02701367.2000 .11082780$

Shirley, D., van der Ploeg, H., Bauman, A. (2010). Physical activity promotion in the physical therapy setting: Perspectives from practitioners and students, Physical Therapy, 90,(9), 1311-1322. https://doi.org/10.2522/ptj.20090383

Stathokostas, L., Theou, O., Little, R.M.D., Vandervoort, A.A, Raina, R..(2013). Physical activity-related injuries in older adults: A scoping review. Sports Medicine, 83(10), 955963.

Swinburn, B., Walter, L., Arroll, B., Tilyare, M., \& Russell, D. (1998). The green prescription study: A randomized controlled trial of written exercise counseling provided by general practitioners. American Journal of Public Health, 88(2), 288-291. doi:

10.2105/AJPH.88.2.288.

Thompson, W. G., Kuhle, C. L., Koepp, G. A., McCrady-Spitzer, S. K., \& Levine, J. A. (2014). "Go4Life" exercise counseling, accelerometer feedback, and activity levels in older people. Archives of Gerontology and Geriatrics, 58(3), 314-319. https://doi.org/10.1016/j.archger.2014.01.004

United States Department of Health and Human Services (2018). Physical activity guidelines for Americans $\left(2^{\text {nd }}\right.$ ed). Retrieved from https://health.gov/paguidelines/secondedition/pdf/Physical_Activity_Guidelines_2nd_edition.pdf 
United States Department of Health and Human Services (2018). Facts and statistics: Physical Activity. Retrieved from https://www.hhs.gov/fitness/resource-center/facts-andstatistics/index.html\#footnote-4

Verhagen A.P., de Vet, H.C., de Bie, R.A., Kessels, A.G., Boers, M., Bouter, L.M. \& Knipschild, P.G. (1998). The Delphi list: a criteria list for quality assessment of randomised clinical trials for conducting systematic reviews developed by Delphi consensus. Journal of Clinical Epidemiology, 51(12):1235-41)._10.1016/s08954356(98)00131-0

Walsh, J., Swangard, D., Davis, T., McPhee, S. (1999). Exercise counseling by primary care physicians in the era of managed care. American Journal of Preventive Medicine, 16(4), doi:10.1016/S0749-3797(99)00021-5

Watson, K.B., Carolson, S.A., Gunn, J.P., Galuska, D.A., O'Connor, A., Greenlund, K.J., \& Fulton, J.E. (1999). Physical inactivity among adults aged 50 years and older - United Stated, 2014. Morbidity and Mortality Weekly Report, 65, 954-958. Doi: http://dx.doi.org/10.15585/mmwr.mm6536a3.

World Health Organizations (2018). Global Action Plan for the Prevention of Noncommunicable Diseases 2013-2020, Retrieved from http://africahealthforum.afro.who.int/firstedition/IMG/pdf/global_action_plan_for_the_prevention_and_control_of_ncds_20132020.pdf

World Health Organization. (2013). Physical activity a global world health problem. Retrieved from _https://www.who.int/dietphysicalactivity/factsheet_inactivity/en/ 
World Health Organization. (2010). Global recommendations on physical activity for health. Retrieved from https://www.ncbi.nlm.nih.gov/books/NBK305048/

Xue Q. L. (2011). The frailty syndrome: definition and natural history. Clinics in geriatric medicine, 27(1), 1-15. https://doi.org/10.1016/j.cger.2010.08.009

Zenko, Z., Willis, E. A., \& White, D. A. (2019). Proportion of adults meeting the 2018 physical activity guidelines for Americans according to accelerometers. Frontiers in Public Health, 7, 135. doi:10.3389/fpubh.2019.00135 


\section{CHAPTER 3}

\section{RESEARCH PROPOSAL \\ Specific Aims}

Older adults are living longer and with more chronic diseases that threaten their independence and quality of life (United Nations: Department of Economic and Social Affairs, 2019). The impact of physical inactivity can have serious implications for the older adult, leading to loss of muscle mass, decline in strength, endurance and function, increased fall risk, and the inability to live independently (Aoyama, Suzuki, Kuzuya, 2015). According to the World Health Organization, physical inactivity is associated with 3.2 million deaths per year(2008). Negative health outcomes associated with physical inactivity strain the United States healthcare system, with $90 \%$ of healthcare dollars going to the management of chronic diseases that can be prevented or treated by physical activity (PA). Participating in recommended levels of PA can prevent four of the costliest diseases: cardiac disease, diabetes, cancer, and Alzheimer's disease (Center for Disease Control (CDC), 2017).

Recently, organizations such as the National Institute on Aging (NIH) (2018) and the American College of Sports Medicine (2019) have focused on the role of primary care in promoting PA. This is consistent with the goals of the National Institute of Aging (NIA) and the goal of the (NIH) to improve the well-being of the older adult, (2018). Primary care providers also recognize the importance of recommending PA to their older adult patients, but struggle with barriers such as time constraints, lack of training, and lack of confidence in the effectiveness of their interventions (Hébert, Caughy, \& Shuval, 2012; Walsh, Swangard, Davis, McPhee, 1999). Diverse interventions have been shown to improve PA behavior in the older adult population (Arkkukangas, Söderlund, Eriksson, \& Johansson, 2019; Bickmore, et al., 
2013). Interventions include exercise prescriptions, counseling, patient education, exercise classes, and motivational interviewing. There is an urgent need to identify effective interventions for promoting PA in older adults in primary care. However, determining the best approach to promoting PA in older adults in the primary care setting is difficult due to the diversity of interventions and the inconsistency of intervention effects in the PA literature.

This systematic review and meta-analysis synthesizes the existing body of literature related to primary care-based PA interventions among older adults age $\geq 65$. An extensive literature search was conducted to identify studies that determine a PA outcome, are focused on primary care interventions among community dwelling adults $\geq 65$, are written in English, and include data to calculate an effect as well as sample size data. In addition to database searching, ancestry searches of pertinent articles and a thorough search for grey literature was completed. Data was extracted from each article using a detailed codebook. A random-effects model was used to synthesize effects and calculate the standardized mean difference effect size (Cohen's d) between treatment and control groups. Heterogeneity was explored using the Q statistic and $I^{2}$. Moderator analyses, using subgroup analysis and meta-regression, were conducted to determine variations in effects by theoretically relevant variables. The proposed study aims were to: Specific Aim 1 Determine the overall effect size of primary care-based PA interventions on physical activity in older adults.

Research Question 1: What is the overall effect size for primary care interventions on PA behavior in older adults?

Specific Aim 2 Determine factors that moderate primary care-based PA intervention effects in older adults. 
Research question 2: How do intervention effects vary based on study design characteristics (e. g., randomization technique, blinding)?

Research Question 3: How do intervention effects vary based on participant characteristics (e. g., demographics)?

Research Question 4: How do intervention effects vary based on interventions characteristics (e. g., use of theory, intervention duration, and interventionist)?

Findings from this meta-analysis provides information for primary providers in planning PA interventions for their patients. Additionally, meta-analysis findings will inform future primary research in PA interventions in the older adult population.

\section{Significance}

\section{Effects of Inactivity on the Older Adult}

The population of adults age 65 and older is expected to double globally, reaching two billion by 2050 and is the least active of any age group (Bauman et al., 2016; Watson et al., 2016). Older adults are a vulnerable population with $85 \%$ living with at least one chronic condition and at least $60 \%$ living with two or more chronic conditions (USDHHS, 2017). Additionally, 7.7 million older adults live below the poverty line which increases their susceptibility to chronic conditions (US Census Bureau, 2018). Levels of PA decline as people age with less than $60 \%$ of older adults engaging in PA (USDHHS, 2020). The current recommendations from the United States Department of Health and Human Services are 150 minutes to 300 minutes of moderate aerobic activity a week or 75 to 100 minutes of vigorous aerobic activity with at least two days that include a muscle strengthening activity (USDHHS, 
2018). Only $16.3 \%$ of adults $65-75$ meet the recommended guidelines for PA and an even smaller number, only $9.9 \%$ of adults 75 and older meet the guidelines (CDC, 2018).

Increasing PA levels is vitally important for the older adult, as declines in strength, balance, endurance and an increase in falls are profoundly linked to the older adult's ability to live independently (Aoyama et al., 2015). Physical activity can lower an individual's risk of cardiovascular disease, diabetes and several cancers including breast and colon cancers (Bauman, 2016; Olanrewaju, 2016). Additionally, older adults who are physically active have higher levels of cognition and quality of life than those who are inactive (Langlois, 2012). The economic benefits of increasing levels of PA in older adults were demonstrated with findings from Cowper et al., (2017), who found a medical cost savings of $\$ 1,634$ per year for participants who reached their target exercise levels. Ninety percent of healthcare dollars are used for the management of chronic diseases, many of which can be prevented or modified by PA (Center for Disease Control, 2017).

\section{Role of Primary Care Providers in Promoting PA among Older Adults}

Many clinicians recognize the importance of recommending PA to their older adult patients and $60 \%$ of patients state that they would be more likely to begin exercising if it was recommended by their physician (Blair et al., 2012). However, providers encounter many barriers to providing PA counseling including time constraints and lack of knowledge regarding efficacious interventions. Adults over 75 visit their physician an average of 5.5 times per year, advantageously positioning physicians and other primary care providers to recommend and promote PA to older adults (CDC, 2018).

\section{Diversity of Interventions for Increasing PA among Older Adults}


Several primary care-based PA interventions such as motivational interviewing, follow up phone calls, and exercise prescriptions have been demonstrated to be effective in the short term (Arkkukangas et al., 2019, Kolt et al., 2012; Herghelegiu, 2012). Armit et al. (2009) compared brief physician counseling to more extensive interventions including pedometer and follow up calls and found no significant difference between the groups. Märki et al. (2006) were able to improve time spent in PA with only a brief physician counseling session. Two studies using nurses as interventionists have demonstrated increases in PA behavior (Mutrie et al., 2012; Dubbert, et al., 2008). Other intervention studies have demonstrated no significant changes in the treatment group and even declines in PA behavior (Robare et al., 2011; Thompson et al., 2014). In other studies, women benefited from the intervention more than men (Petrella et al., 2010). These studies demonstrate the inconsistency in research results that make it difficult to determine the type and delivery of effective PA interventions.

\section{Meta-analysis Research and Primary Care-Based PA Interventions among Older Adults}

Recent meta-analyses have found PA interventions for older adults to be effective, but these prior meta-analyses were not focused on interventions delivered in primary care or those delivered to the oldest older adults (Olanrewaju et al., 2016; Chase, 2015). Another recent metaanalysis on PA intervention for older adults focused on long term interventions and their effect of fall rates and physical functioning, but did not analyze a PA outcome or perform moderator analysis of PA interventions (García-Hermoso et al., 2020). A 2014 systematic review of primary care-based interventions included only six studies and found significant results $(p \leq 0.007)$ in only one study, leaving practitioners wondering about the value of adding PA interventions into their practice (Stevens et al., 2014). An integrative review by Neidrick, Fick, and Loeb (2012) 
examined eleven studies of primary care-based interventions and found the interventions to be efficacious at least in the short term, but the authors did not complete a meta-analysis.

While most reviews on PA interventions have included community-based interventions, this systematic review and meta-analysis is unique in that it focuses on primary care-based PA interventions and seeks to support an underutilized resource for increasing PA in older adults, primary care. Additionally, the last 10 years have seen an explosion in research related to PA interventions with the number of articles written about primary care-based PA interventions doubling between 2012 and 2014 (Lion et al., 2018). Furthermore, interventionists in primary care represent a wide range of disciplines. The proposed study would add to the body of knowledge of how providers can incorporate PA interventions efficiently into their practices utilizing an interdisciplinary team.

Evaluating the effectiveness of primary care interventions to increase PA among older adults directly addresses the Healthy 2020 mission to "measure the impact of health interventions," and "improve practices that are driven by the best available evidence," as well as the goal of improving health at all stages of life (USDHHS, 2020). This meta-analysis summarizes the body of primary care-based PA interventions among adults $\geq 65$ years old to determine efficacious interventions to be utilized in primary care. Quantitatively synthesizing data across many studies produced an overall effect size of primary care-based interventions to increase PA. Using moderator analyses to determine factors that impact primary care-based PA intervention effects identified evidence-based PA behavior strategies that primary care providers can employ to make efficient use of their time. For example, increasing PA in the oldest old adults may require different interventions than the interventions that increase PA in younger adults. The oldest old face different barriers to PA including fear of falling and fear of over doing 
(Baert et al., 2011). Additionally, older adults belonging to minorities are less likely to participate in PA (August \& Sorkin, 2011; Bland \& Sharma, 2017). Finding effective interventions are essential in this group since low levels of PA contribute significantly to chronic conditions in this population (González et al., 2017).

\section{Innovation}

A recent article exploring factors that influence PA counseling by physicians note that effective strategies for encouraging PA among different populations and medical conditions is essential (Goldberg et al., 2019). The study also found low rates of PA counseling among primary care providers. Overall, PA counseling rates are declining, and when rates are compared with age groups of patients, rates of counseling declines with advancing age (Goldberg et al., 2019). While research has been done to determine the effectiveness of PA interventions for older adults, these interventions are not being utilized in primary care. Using meta-analysis to combine studies of various sample sizes and patient populations can increase generalizability to a larger population and settle disputes from studies with inconsistent results making the choice of which interventions to use easier for primary care providers (Lee, 2019). This meta-analysis builds on previous work by Chase (2015) to determine effective interventions to increased PA and work by Conn et al. (2008) to determine effective educational interventions to increase PA among chronically ill adults. This meta-analysis focuses on interventions to increase PA in primary care and includes healthy older adults as well as those with chronic diseases. Findings from this work will inform future researchers in PA interventions regarding potentially efficacious interventions for different patient populations. Moderate analysis allows for more specific inferences about intervention type, dose, and duration. Practitioners can use the research to determine how to implement PA interventions into their practices. This meta-analysis is also relevant to physical 
therapists, nurses, health coaches, exercise specialists, and anyone who desires to impact PA behavior in their older patients.

\section{Approach}

The study aimed to: 1) determine the overall effect size of primary care-based PA interventions on physical activity in older adults; and 2) determine factors that moderate primary care-based PA intervention effects in older adults. The Preferred Reporting Items for Systematic Reviews and Meta-Analysis (PRISMA) provided the guideline for this meta-analysis. The PRISMA statement is a 27 -item checklist that helps researchers follow a systematic process in meta-analysis research (Moher et al., 2009).

\section{Sampling}

Eligible published and unpublished reports : 1) tested an intervention to increase PA; 2) included an outcome measure of PA or exercise behavior (e. g. pedometer, accelerometer readings, survey or questionnaire); 3) used a one-group pre- post-test design or a two-group postintervention comparison experimental design; 4) included adequate data to calculate and effect size, including outcome and sample size (e. g. mean with measure of variability, t-statistic, p value from t-statistic or success rate; 5) were written in English; 6) included communitydwelling participants age $\geq 65$, with a mean age of participants of $\geq 70$,); and7) were based in primary care. Primary care referred to an initial or first point of contact for outpatient, nonspecialized care. There were no restrictions on date of publication.

\section{Literature Search}

A health science research librarian was consulted to aid in a comprehensive search of library databases. Databases utilized for this search included CINAHL, PsycINFO, PubMed, 
Scopus, SPORTDiscus, and Dissertation Abstracts International/Proquest. Google Scholar was also included per suggestion of the librarian. The following is an example of a search utilized in PubMed: “Clinical trial” OR “clinical study” OR "randomized controlled trial” OR “comparative study” OR “meta-analysis” OR synthesis OR review AND exercise OR “physical activity” OR “physical inactivity” OR “physically inactive” OR exercise AND “primary care” AND “older adult" OR geriatric* OR “senior citizens" AND “green prescription" OR “exercise prescription" OR intervention OR interventions. The "view related works" feature in Web of Science was utilized to find additional articles. Additional search avenues included: 1) contact with authors who publish PA literature for unpublished research; 2) bibliography search of applicable studies and review articles; 3) search of content page of relevant journals, including American Journal of Health Behavior, International Journal of Behavioral Nutrition and Physical Activity, Journal of Aging and Health, and Journal of Aging and Physical Activity; 4) locating and review unpublished manuscripts by searching the DAI data base for unpublished studies; and 5) reviewing conference programs, including The Gerontological Society, American Society of Aging, and International Conference on Active Aging, for applicable presentation and poster abstracts.

\section{Codebook Development}

A codebook was developed based on the primary investigator's knowledge of the literature and after reviewing a random selection of 15 articles for common outcomes and variables. Types of variables included were related to study design, study quality, participant characteristics, interventions, and outcomes. A comprehensive list of variables was included in the codebook and it was pilot tested on 15 studies and missing characteristics were added. Detailed coding is required to analyze patterns of interventions characteristics that are associated 
with increases in PA, as well as characteristics of participants that respond best to specific interventions.

\section{Procedure}

Citations from the database search were loaded into Zotero. Other unpublished articles and dissertations were also added to Zotero. Duplicate articles were removed using the duplicate article function in Zotero. Citations were reviewed for inclusion by the principle investigator (PI) by reading the title and abstract. Existing synthesis and meta-analysis works were reviewed by the PI for an ancestry search of bibliography entries. Eligible studies were assigned a study number along with any corresponding articles and coding of the studies was complete. Once the PI had coded all the articles, an experienced and doctorally-prepared second coder coded $20 \%$ of the studies, as well as $100 \%$ of the outcome data. Outcome data were entered into Comprehensive Meta-analysis Software (CMA) for analysis. Moderator analyses were completed on available variables to determine effect size related to study design, sample, and intervention characteristics.

\section{Data Collection}

Each variable was operationally and theoretically defined for the development of the code book to guide the coding procedure. This detailed code book helped ensure intracoder and intercoder reliability. All outcome data was coded by the principal investigator and $20 \%$ of the studies and all the outcomes was double-coded by the experienced coder. Any discrepancies in how a variable should be coded was discussed until an agreement had been reached. Examples of characteristics included in the codebook are shown in Table 3.1. 


\section{Data Management}

As the PI reviewed each study, notes were made using the note function of Zotero. Coding was completed on eligible studies on paper and then duplicate-entered in Excel. Data was then compared and cleaned to ensure accuracy of data entry prior to entering data into CMA (Borenstein, 2005). When questionable data were found, the original studies were reviewed by the PI to resolve the questionable data.

\section{Data Analysis}

Analyses were conducted using CMA software developed especially for meta-analysis (Borenstein, 2005). Due to the heterogeneity of the primary care-based PA interventions, a random-effects model was used to account for the sampling error within studies and the true variation of effect sizes between studies (Borenstein et al., 2009). Homogeneity of effects was assessed using heterogeneity statistics, Q and $\mathrm{I}^{2}$. The Q statistic tests the null hypothesis that all the studies share a mutual effect size. The $\mathrm{I}^{2}$ represents the percentage of between study heterogeneity that is not related to chance (Borenstein et al., 2009).

\section{- Aim 1: Determine the overall effect size of primary care-based PA interventions} physical activity in older adults. The summary effect size of interventions is represented by the standard mean difference (SMD) or Cohen's $d$. The SMD is the mean difference between the treatment and control group divided by the pooled standard deviation of the participant outcomes. Cohen's $d$ is used to combine a variety of designs and outcome measures when they address the same central question (Cooper, 2017). Study effect sizes will be synthesized using a random-effects model which considers the within-study variance, as well as the between-study variance or the true effect size across studies. Study 
weights are allocated to reduce the effect of the two sources of variance (Borenstein et al., 2009). It was not possible to convert the effect size to an original metric, such as minutes of PA per week due to the heterogeneity of outcome measures (Lipsey \& Wilson, 2000). Data from pre- post-test designs and two-group designs were analyzed separately.

- Aim 2: Determine the factors that moderate the effect size of primary care-based PA intervention in older adults. Moderator analysis was used to determine which interventions are more effective for improving PA levels. The data was analyzed using meta-regression to test the impact of the continuous variables on PA levels and subgroup analysis was used to test the impact of the dichotomous variables (Borenstein et al., 2009).

\section{Anticipated Difficulties}

\section{Sampling}

Most of the time designated for this project was devoted to the search for eligible studies. It is essential that tremendous effort be committed to the endeavor of finding all possible eligible studies. While attempts were made to locate unpublished studies, some studies may have been missed. Publication bias may have occurred as the result of specific within-study issues that result in outcome bias or issues with the entire study that results in dissemination bias. There is evidence that effect size can influence the likelihood of a study getting published with studies with smaller effect size less likely to be published (Thornton \& Peter, 1999). Three methods were utilized to detect and adjust for publication bias. The first method was evaluation of the symmetry of the funnel plot. If there was publication bias, we would expect the funnel plot to have a gap in one corner of the funnel indicating that smaller, less favorable studies are missing (Borenstein, 2019). Another method was the Classic Fail-safe N. This test determines the number of studies with a mean risk ratio of 1.0 which would need to be included in the analysis for the 
results to be considered insignificant (Borenstein, 2019). The last method was Egger's regression test which regresses the standard normal deviations by their standard errors on precision. This resulted in a regression intercept that determined the amount and direction of asymmetry of the funnel plot (Borenstein, 2019).

\section{Missing data}

Missing data could be the result of missing studies due to publication bias, as discussed above. Missing data may also occur when outcomes are incompletely reported. Authors may selectively report outcomes that are favorable (Hutton, \& Williamson, 2000). Studies may also be missing predictors that could be used for moderator analysis (Cooper, 2017). Pigott (2019) notes that predictor variables may be missing because of the way variables are defined in the different disciplines. Patterns were explored as to how missing data impacted the results (Piggot, 2019). Authors were contacted when data for calculating an effect size were missing. If data were not received, the study was removed from the meta-analysis.

\section{Coding}

The process of coding multiple studies can introduce the potential problem of coding mistakes. To minimize coding errors, the code book included specific instructions and descriptions of each coded item. To ensure that all necessary variables were included in the code book, the code book was pilot tested on 15 studies and revised throughout the coding process. If a coding issue was identified after studies had been coded, steps were taken to retroactively implement the change in the coding of the previous studies. Additionally, two coders coded the outcome variables. Disagreements between the coders was discussed until a consensus was reached. Another potential coding issue was that authors are not always consistent about how 
they report different items. For example, some studies reported mean body weight while others reported mean body mass. When data were missing, attempts were made to reach the researcher to obtain results.

\section{Study Quality}

Internal and external validity of eligible studies was assessed using the PEDro scale developed by Physiotherapy Evidence Database (Verhagen et al., 1998). The PEDro scale has been found to be a valid instrument for establishing the methodological quality of clinical trials (de Morton, 2009, Maher et al., 2003). Some of the studies included in the meta-analysis contained methodological issues, such as small sample size and imprecise measures. Other studies have conceptual problems related to operational definitions. Two studies were removed due to methodological issues. While it is necessary to evaluate study quality, it is also important to try not to eliminate studies unnecessarily and to include as much data as possible (Conn \& Rantz, 2003). The relationship between study quality indicators and effect sizes was statistically tested using a moderator analysis.

\section{Limitations Related to Primary Study Reporting}

Although the PI had the assistance of a health science librarian, the selected search criteria may have inadvertently missed relevant studies due to the variability in terms used in PA literature (Glanville, 2019). Additionally, studies involving non-white older adults, as well as the oldest old adults, were limited. Some descriptions of interventions were not detailed enough to allow for accurate moderator analysis. Another limitation of primary studies was related to the lack of inclusion of studies written in languages other than English. 


\section{Inclusion of Women and Minorities}

Women were well represented. Attempts were made to include studies that included participants of underrepresented racial/ethnic groups. However, studies inconsistently reported racial/ethnic demographics and less physical activity research has been conducted among underrepresented racial/ethnic groups, limiting generalizability of study findings to more diverse groups. 


\section{References}

American College of Sports Medicine (2019). Health care providers' action guide. https://www. exerciseismedicine.

org/assets/page_documents/EIM\%20Health\%20Care\%20Providers\%20Action\%20Guide $\% 20$ clickable\%20links. pdf

Aoyama, M., Suzuki, Y., \& Kuzuya, M. (2015). Muscle strength of lower extremities related to incidence falls in community dwelling older adults. Gerontology and Geriatric Research, 4(2). DOI: 10. 4172/2167-7182.

Arkkukangas, M., Söderlund, A., Eriksson, S., \& Johansson, A.C. (2019). Fall preventive exercise with or without behavior change support for community-dwelling older adults: A randomized controlled trial with short-term follow-up. Journal of Geriatric Physical Therapy, 42(1), 9-17. https://doi. org/10. 1519/JPT. 0000000000000129

Armit, C.M., Brown, W.J., Marshall, A.L., Ritchie, C.B., Trost, S.G., Green, A., Bauman, A.E. (2009). Randomized trial of three strategies to promote physical activity in general practice. Preventive Medicine, 48(2), 156-163

August, K. J. \& Sorkin, D. H. (2011). Racial/ethnic disparities in exercise and dietary behaviors of middle-aged and older adults. Journal of General Internal Medicine, 26(3), 245-250. doi:10. 1007/s11606-010-1514-7

Bachman, A. S., Wilson, R.S., Yu, L., James, B. D., Boyle, P. A., \& Bennett, D. A. (2014). Total daily activity declines more rapidly with increasing age in older adults. Archives of Gerontology and Geriatrics, 58, 74-79. https://doi. org/10. 1016/j. archger. 2013. 08. 001 
Baert, V., Gorus, E., Mets, T., Geerts, C., \& Bautmans, I. (2011). Motivators and barriers for physical activity in the oldest old: A systematic review. Aging Research Review, 10(4), 464-474.

Bauman, A., Merom, D., Bull, F. C., Buchner, D. M., Fiatarone, \& Singh, M. A. (2016). Updating the evidence for physical activity: summative reviews of the epidemiological evidence, prevalence, and interventions to promote "active aging", The Gerontologist, 56, (Supp 2), S268-280. https://doi. org/10. 1093/geront/gnw031

Bickmore, T. W., Silliman, R. A., Nelson, K. , Cheng, D. M., Winter, M., Henault, L., \& Paasche-Orlow, M. K. (2013). A randomized controlled trial of an automated exercise coach for older adults. Journal of the American Geriatrics Society, 61(10), 1676-1683. https://doi. org/10. 1111/jgs. 12449

Blair, S, Sallis, R, Hutber, A. \& Archer, E. (2012). Exercise therapy - the public health message. Scandinavian Journal of Medicine and Science in Sports, 22(4), 24- doi: 10. 1111/j. 1600-0838. 2012. 01462. X

Bland, V. \& Sharma, M. (2017). Physical activity interventions in African American women: A systematic review. Health Promotion Perspectives, 7(2), 52-59. doi:10. 15171/hpp. 2017. 11

Borenstein, M. (2019). Heterogeneity in meta-analysis. In Cooper, H., Hedges, L. \& Valentine, J. C. (eds.). The Handbook of Research and Meta-analysis. Russel Sage Foundation

Borenstein, M., Hedges, L.V., Higgins, J., \& Rothstein, H. (2005). Comprehensive metaanalysis, version 2. Englewood, NJ: Biostat. 
Borenstein, M., Hedges, L., Higgins, J., \& Rothstein, H. (2009). Introduction to Meta-analysis. Wiley.

Center for Disease Control (2017). Health and economic costs of chronic disease. https://www. cdc. gov/chronicdisease/about/costs/index. htm

Center for Disease Control (2018). Summary health statistics: National health interview survey. https://ftp. cdc.gov/pub/Health_Statistics/NCHS/NHIS/SHS/2018_SHS_Table_C-8.pdf

Chase, J. D. (2015). Interventions to increase physical activity among older adults: A metaanalysis, The Gerontologist, 55(4), 706-718. https://doi. org/10. 1093/geront/gnu090

Conn, V. S., Hafdahl, A. R., Brown, S. A., \& Brown, L. M. (2008). Meta-analysis of patient education interventions to increase physical activity among chronically ill adults. Patient education and counseling, 70(2), 157-172. https://doi.org/10.1016/j.pec.2007.10.004

Conn, V. \& Rantz, M.J. (2003). Research methods: Managing primary study quality in meta analyses. Research in Nursing \& Health, 26, 322.

Cooper, H. (2017). Research synthesis and meta-analysis (5th ed). Sage Publications.

Cowper, P., Peterson, M., Pieper, C., Sloan, R., Hall, K.... Morey, M. (2017). Economic nalysis of primary care based physical activity counseling in older men: The VA-LIFE trial. Journal of the American Geriatrics Society, 65(3), 533-539. doi:10.1111/jgs.14567

de Morton, N.A. (2009). The PEDro scale is a valid measure of the methodological quality of clinical trials: A demographic study. Australian Journal of Physiotherapy, 55(2), 129133. https://doi.org/10.1016/S0004-9514(09)70043-1 
Dubbert, P., Morey, M., Kirchner, K., Meydrech, E. \& Grothe, K. (2008). Counseling for homebased waking and strength exercise in older primary care patients. Archives of Internal Medicine, 168(9), 979-986. doi:10.1001/archinte.168.9.979

García-Hermoso, A. Ramirez-Vélez, R., Sález de Asteasu, M.L. Martínez-Velilla, N., ZambomFerraresi, Valenzuela, P.L., Lucia, A., \& Izquierdo, M. (2020). Safety and effectiveness of long term exercise interventions in older adults: A systematic review and metaanalysis of randomized controlled trials. Sports Medicine, 50, 1095-1106. https://doi.org/10.1007/s40279-020-01259-y

Glanville, J. (2019). Searching bibliographical databases In H. Cooper, L. Hedges, L., \& J.C. Valentine (Eds). The Handbook of research and meta-analysis (pp 73-99). Russel Sage Foundation.

Goldberg, D., Cho, B., \& Lin, H. (2019). Factors influencing U.S. physicians’ decision to provide behavioral counseling. Preventive Medicine, 119, 70-76. https://doi.org/10.1016/j.ypmed.2018.12.015

González, K., Fuentes, J., \& Márquez, J. L. (2017). Physical inactivity, sedentary behavior, and chronic disease. Korean Journal of Family Medicine, 38, 111-115. https://doi. org/10. 4082/kjfm. 2017. 38. 3. 111

Hébert, E., Caughy, M., \& Shuval, K. (2012). Primary care providers' perceptions of physical activity counseling in a clinical setting: A systematic review. British Journal of Sports Medicine,46(9), 625-631. doi:10. 1136/bjsports-2011-090734 
Kolt, G. S., Schofield, G. M., Kerse, N., Garrett, N., Ashton, T., \& Patel, A. (2012). Healthy steps trial: Pedometer-based advice and physical activity for low-active older adults. Annals of Family Medicine, 10(3), 206-212. https://doi. org/10. 1370/afm. 1345

Langlois, F. Vu, T. T. M., Chasse, K. , Dupuis, G. Kergoat, M. J. (2012). Benefits of physical activity training on cognition and quality of life in frail older adults. Journals of Gerontology Series B: Psychological Services and Social Sciences, 68(3), 400-404. doi:10. 1093/geronb/gbs069.

Lee, Y. H. (2019). Strengths and limitations of meta-analysis. Korean Journal of Medicine, 94(5). DOI: https://doi.org/10.3904/kjm.2019.94.5.391

Lion, A., Vuillemin, A., Thornton, F., Theisen, D., Stranges, S. \& Ward, M. (2018). Physical activity promotion in primary care: A utopian quest? Health Promotion International, 34, 877-886. doi: 10.1093/heapro/day038.

Lipsey, M.W., \& Wilson, D.B. (2000). Practical Meta-Analysis. Sage Publications.

Märki, A., Bauer, G., Angst, F., Nigg, C., Gillmann, G., \& Gehring, T. (2006). Systematic counseling by general practitioners for promoting PA in elderly patients: A feasibility study. Swiss Medical Weekly, 136, 482-488. doi.org/10.1007/s00038-006-5065-y

Moher, D., Liberati, A., Tetzlaff, J. , \& Altman, D. G. (2009). Preferred reporting items for systematic reviews and meta-analyses: The PRISMA statement. Annals of Internal Medicine, 151(4), 264-269. doi: 10. 7326/0003-4819-151-4-200908180-00135

Mutrie, N., Doolin, O., Fitzsimons, C. F., Grant, P. M., Granat, M., Grealy, M., ... Skelton, D. A. (2012). Increasing older adults' walking through primary care: Results of a pilot 
randomized controlled trial. Family practice, 29(6), 633-642.

doi:10.1093/fampra/cms038

National Institute on Aging (2018). Exercise and physical activity: Your everyday guide from the National Institute on Aging. https://order.nia.nih.gov/sites/default/files/2018-04/niaexercise-guide.pdf

Neidrick, T. J., Fick, D. M., \& Loeb, S. J. (2012). Physical activity promotion in primary care targeting the older adult. Journal of the American Academy of Nurse Practitioners, 24(7), 405-416. https://doi.org/10.1111/j.1745-7599.2012.00703.x

Office of Disease Prevention and Health Promotion (2018). Physical activity. https://www. healthypeople. gov/2020/data-search/Search-the-Data\#topic-area=3504

Olanrewaju, O., Kelly, S., Cowan, A., Brayne, C., \& Lafortune, L. (2016). Physical activity in community dwelling older people: A systematic review of reviews on intervention and context. PLOSone, 11(12). doi:10.1371/journal.pone.0168614

Petrella, R. J., Lattanzio, C. N., Shapiro, S., \& Overend, T. (2010). Improving aerobic fitness in older adults: effects of a physician-based exercise counseling and prescription program. Canadian family physician,56(5), e191-e200.

Piggot, T.D. (2019). Missing data in meta-analysis. In H. Cooper, L. Hedges, \& J.C. Valentine, (eds). The Handbook of research and meta-analysis. Russel Sage Foundation: New York.

Robare, J. F., Bayles, C. M., Newman, A. B., Williams, K., Milas, C., Boudreau, R., McTigue, K., Albert, S. M., Taylor, C., \& Kuller, L. H. (2011). The “10 keys” to healthy aging: 24- 
month follow-up results from an innovative community-based prevention program. Health Education \& Behavior, 38(4), 379-388.

https://doi.org/10.1177/1090198110379575

Thompson, W. G., Kuhle, C. L., Koepp, G. A., McCrady-Spitzer, S. K., \& Levine, J. A. (2014). "Go4Life" exercise counseling, accelerometer feedback, and activity levels in older people. Archives of Gerontology and Geriatrics, 58(3), 314-319. https://doi.org/10.1016/j.archger.2014.01.004

Thornton, A., \& Peter, L. (1999). Publication bias in meta-analysis: its causes and consequences. Journal of Clinical Epidemiology, 53, 207-216.

United States Department of Health and Human Services (2020). About healthy people. Office of Disease Promotion and Health. https://www. healthypeople. gov/2020/About-HealthyPeople

United States Department of Health and Human Services (2018). Physical activity guidelines for Americans (2nd ed). Retrieved from https://health. Gov/paguidelines/secondedition/pdf/Physical_Activity_Guidelines_2nd_edition.Pdf

U.S. Department of Health and Human Services. (2017). Supporting older adults with chronic conditions. National Institute on Aging. https://www.nia.nih.gov/health/supporting-olderpatients-chronic-conditions

United States Census Bureau (2018). Income and poverty in the United States: 2018. https://www. census. gov/library/publications/2019/demo/p60-266. html 
United Nations: Department of Economic and Social Affairs (2019). World population ageing. https://www.un.

Org/en/development/desa/population/publications/pdf/ageing/WorldPopulationAgeing20 19-Highlights. Pdf

Valentine, J.C. (2019). Incorporating judgments about study quality into research synthesis. In H. Cooper, L. Hedges, \& J.C. Valentine, (Eds). The Handbook of research and metaanalysis. Russel Sage Foundation.

Verhagen, A. P., de Vet, H. C., de Bie, R. A., Kessels, A. G. , Boers, M., Bouter, L. M. \& Knipschild, P. G. (1998). The Delphi list: A criteria list for quality assessment of randomised clinical trials for conducting systematic reviews developed by Delphi consensus. Journal of Clinical Epidemiology,51(12):1235-41). 10. 1016/s08954356(98)00131-0

Walsh, J., Swangard, D. , Davis, T. , \& McPhee, S. (1999). Exercise counseling by primary care physicians in the era of managed care. American Journal of Preventive Medicine, 16(4). doi:10. 1016/S0749-3797(99)00021-5

Watson, K., Carlson, S., Gunn, J., Galuska, D., O’Connor, A., Greenlund, K. , \& Fulton, J. (2016). Physical Inactivity Among Adults Aged 50 Years and Older — United States, 2014. Morbidity and Mortality Weekly Report, 65(36), 954-958. doi:10. 2307/24858967

World Health Organization (2008). Global strategy on diet, physical activity, and health. Retrieved from https://www.who.int/dietphysicalactivity/physical_activity_intensity/en/ 


\section{CHAPTER 4}

\section{FINDINGS}

\section{SYSTEMATIC REVIEW AND META-ANALYSIS OF PRIMARY CARE-BASED PHYSICAL ACTIVITY INTERVENTIONS AMONG OLDER ADULTS}

\section{Manuscript in preparation for Journal of Aging and Physical Activity}

Physical inactivity impacts many aspects of the lives of older adults. Lack of physical activity is associated with many diseases such as cancer, diabetes, and hypertension (Center for Disease Control (CDC), 2017). Older adults who are inactive have higher rates of hospitalizations and nursing home placements (Aoyama et al., 2015). Overall, older adults who exercise regularly are more resilient and experience less depression (Avila et al., 2016; Overdof et al., 2016). While most healthcare providers agree that increasing physical activity (PA) in older adults is beneficial, providers face many barriers to delivering interventions including time constraints and the complex medical issues of their patients (Fowles et al., 2018). Additionally, some health care providers believe that efforts to motivate their patient to increase physical activity do not result in any real changes in their patient's behavior (Mathews et al., 2017). Unfortunately, a lack of discussion around PA by the health provider can be misinterpreted by the patient as a lack of the need to make any changes in their lifestyle (Bardach \& Schoenberg, 2018).

Despite the challenges associated with motivating older adults to increase their PA, interventions to increase PA can be effective and even a small increase in PA can be beneficial (Marques et al., 2019; CDC, 2018). A meta-analysis by Chase (2015) found that PA interventions for the older adult had an overall mean effect size of 0.18 for two-group post-test comparisons which represents an increase of 73 minutes of PA per week. Compared with younger adults, the average older adult values and respects their health provider's advice, 
(Schutzer \& Graves, 2004). Older adults visit their physician's office an average of 5.5 times per year, giving primary care providers opportunities to deliver PA interventions (CDC, 2018).

Meta-analysis research offers the opportunity to explore variations in intervention types, doses, and delivery methods (Deeks, Higgins, Altman, 2019). Recent meta-analyses have found PA interventions for older adults to be effective, but these prior meta-analyses were not focused on interventions delivered in primary care (Olanrewaju et al., 2016; Chase, 2015). Meta-analyses of primary care PA interventions by Orrow et al. (2012) and Pavey et al. (2011) were not restricted by age of participant, so did not capture the effects of interventions on the older adult. Another recent meta-analysis on PA intervention for older adults was not restricted to primary care interventions and focused on long term interventions and their effect of fall rates and physical functioning, rather than a PA outcome (García-Hermoso et al., 2020). Orrow et al. (2012) found small-to-medium effects of primary interventions, while a 2014 systematic review of primary care-based interventions found significant results $(p \leq 0.007)$ in only one out of six studies, leaving practitioners wondering about the value of adding PA interventions into their practice (Stevens et al., 2014). The present systematic review and meta-analysis integrated primary care-based studies designed to increase PA in the older adult to determine the overall effect of PA interventions, and aimed to identify and resolve divergences within the literature of primary care interventions for increasing PA, as well as highlight areas for further research. This research is guided be the following research questions:

1. What is the overall effect size for primary care interventions on PA behavior in older adults?

2. How do intervention effects vary based on study design characteristics (e. g., randomization technique, blinding)? 
3. How do intervention effects vary based on participant characteristics (e. g., demographics)?

4. How do intervention effects vary based on interventions characteristics (e. g., use of theory, intervention duration, and interventionist)?

\section{Methods}

This systematic review meta-analysis adheres to reporting guidelines for the Preferred Reporting Items for Systematic Reviews and Meta-Analysis (PRISMA) (Moher et al., 2009).

\section{Inclusion Criteria}

Eligible study designs were two-group pre- post-test designs in which control groups received usual care and single group pre-posttest. Two-group designs where one group was compared to another group receiving a different PA intervention, rather than compared to a control group receiving usual care, were treated as pre/post study design analysis. Eligible studies were conducted in a primary care setting. Primary care was defined as a patient's main source of healthcare, providing holistic care, rather than care focused on a specific disease process (World Health Organization, 2019). Only studies written in English were included, but studies were not restricted based on geography. There was no restriction on date of publication. Primary care-based interventions were defined as activities utilized in primary care aimed at increasing the time older adults spend in PA. PA was defined as any skeletal movement that produces increased energy expenditure and can include planned exercise, as well as movement throughout the day (World Health Organization, 2018). Participants were community dwelling older adults ages $\geq 65$ or with a mean age of $\geq 70$. Included studies had a PA outcome measured either subjectively or objectively, and studies were not restricted by the length of follow up. Studies were not limited to the number of participants, as long as the study included data to 
calculate an effect size (e.g. mean with measure of variability, t-statistic, and p value from tstatistic or success rate).

\section{Search Strategies}

A research librarian experienced in meta-analysis procedures assisted with the search strategy for this study. The search strategy included a search of databases including Pubmed, CINAHL, PsycINFO, Scopus, SportDiscus, Dissertation Abstracts International (DAI)/Proquest, and Google Scholar. The "view related works" feature in Web of Science, which, lists the number of shared references from high to low, was utilized to find additional articles (Cooper, 2017). An ancestry searching was completed for relevant articles. Bibliographies of relevant previous systematic reviews were reviewed after locating systematic reviews via Prospero. Researchers who have published work in physical activity and older adults were contacted to inquire about unpublished works. The DAI data base was searched for unpublished studies. Research by Chan and Altman (2005) reviewed 519 trials and found that unreported outcomes were a common occurrence and present in over one third of trials. Relevant journals were hand searched for applicable articles with dates varying due to availability. Conference programs from The Gerontological Society, American Society of Aging, and the International Conference of Active Aging were reviewed for podium or poster presentation fitting the inclusion criteria. Because studies with positive effect sizes are more likely to be published, attempts were made to find unpublished, as well as published literature, to avoid over exaggeration of the effectiveness of interventions (McAuley et al., 2000). Search strategy for Medline consisted of the following, “Clinical trial” OR “clinical study" OR "randomized controlled trial” OR “comparative study" OR “meta-analysis” OR synthesis OR review AND exercise OR “physical activity” OR “physical inactivity" OR "physically inactive” OR exercise AND “primary care” AND “older 
adult" OR geriatric* OR "senior citizens" AND "green prescription" OR "exercise prescription" OR intervention OR interventions.

\section{Coding and Data Extraction}

Data were extracted from the eligible studies using a codebook developed by reviewing the literature related to PA interventions. The codebook was tested using 15 eligible articles and necessary adjustments were made. All studies were coded by the principal investigator. To reduce coding errors (Buscemi et al., 2007), a second, experienced, doctorally-prepared coder coded $100 \%$ of PA outcome data and $20 \%$ of entire studies. The studies included in the $20 \%$ were chosen using a random number generator. Both coders met and coding discrepancies were resolved once coding was completed. Adjustments were made to the codebook throughout the coding process and studies coded previously were recoded. Study quality variables such as randomization and intention to treat were collected, as well as participant characteristics and interventions used. Authors were contacted for missing data. After coding on paper, codes were added to excel by the primary investigator and another person, after which the excel sheets were compared using a comparison application. Codes were checked for accuracy prior to data entry.

\section{Risk of Bias}

Publication bias was examined using three methods. A funnel plot was used as a visual representation to check for publications bias. Studies with high precision should fall near the edges and those with less precision should spread evenly on both sides of the funnel shape (Borenstein et al., 2009). Additionally, Egger's regression test which regresses the standard normal deviations by their standard errors on precision and quantifies the amount and direction of symmetry was used (Vevea et al., 2019). Finally, the Classic fail-safe N was used to examine 
the number of studies which would need to be included in the analysis for the results to be considered inconsequential (Borenstein et al., 2009).

The PEDro scale, developed by Physiotherapy Evidence Database, was used to assess the internal and external validity of the included studies (Verhagen et al., 1998). The PEDro scale has been found to be a valid instrument for determining the methodological quality of clinical trials (de Morton, 2009; Maher, Sherrington, Herbert, Moseley \& Elkins, 2003). Table 4.8 is the results for the PEDro scale for the two-group design studies.

\section{Data Analysis}

Data analysis was conducted using Comprehensive Meta-Analysis software (CMA) (Borenstein et al., 2005). A random-effects model was used to synthesize study effects due to the expected heterogeneity of physical activity studies. The random-effects model takes into account the differences of effects within studies, as well as between-study variance. PA interventions studies include participants with a wide mix of characteristics, as well as interventions with a variety of features, making the random effects model particularly useful (Borenstein et al., 2010. The overall effect size (ES) was calculated by calculating the mean of the treatment group minus the mean of the control group and dividing by the pooled standard deviation. To adjust for bias, studies were weighted by the inverse of the variance. The effect sizes for two-group design studies and pre/post design studies were calculated separately using a statistical significance level of alpha $\leq 0.5 \%$. None of the pre/post design studies included the correlational data needed to associate a pre- and post- score, so a moderate correlation of 0.6 was used. Because a correlation is required to use the standard deviation difference to determine the standard deviation within groups, this correlation was estimated (Cooper et al., 2019). For studies that collected data at multiple time points, the most distal collection point was used to calculate effect 
sizes to better capture a longer term effect of interventions. When multiple outcomes were given, moderate PA was used for analysis. When more than one outcome measure was collected, the objective measure was used followed by the subjective tool that was most specific for the older adult population. According to Cohen (1988), ES may be described as small $(\leq 0.20)$, medium $(=0.50)$, or large $(\geq 0.80)$. Analysis of potential moderators of the effect size is particularly important in PA intervention research where the interventions often vary between the studies (Conn \& Rantz, 2003). Descriptions of the moderators used in this analysis are in Table 4.5. Heterogeneity of effects were examined using Cochran's Q and $\mathrm{I}^{2}$ statistics. The Q statistic tests the null hypothesis that all the studies share a mutual effect size and is determined by taking the sum of the weighted squared deviation of each study. $\mathrm{I}^{2}$ represents the percentage of between-study heterogeneity that is not related to chance and is a measure of inconsistencies across the true effects (Borenstein et al., 2009). Subgroup analysis of potential moderators were completed to determine what study characteristics associated with better outcomes. To maintain rigor, moderator analysis was completed on only the two-group study designs. Meta-regression was used to evaluate the impact of the continuous variables. Analysis of variance (ANOVA) was used to evaluate the impact of the dichotomous variables.

\section{Results}

The comprehensive data base search identified 4,123 potential studies. Hand searching of

journals, bibliography search, and the "view related works" feature in Web of Science yielded 13 more potential studies. After removal of duplicates, 3,022 studies were screened for inclusion. The flow of study selection is shown in Figure 4.1. The 28 studies selected for inclusion in this meta-analysis are described in Table 4.2. Four of the studies had two comparison groups. A total 
of 5,685 participants were included in the effect size calculations, 4,685 in the two-group analysis $(k=25)$ and 940 in the pre/post group analysis $(k=11)$.

\section{Overall Intervention Effects}

The overall mean effect size for the two-group comparison was 0.27 (95\% CI 0.15-0.39, $p=0.00)$ which represents a small-to-medium effect size of primary care PA interventions on PA behavior. Figure 4.2 shows the forest plot for this analysis. For the two-group comparison, results demonstrated significant heterogeneity: $\mathrm{Q}=117.56(\mathrm{P}=0.00)$ and $\mathrm{I}^{2}=80.435$. One study (Tarazone-Santabalbina, 2016) with a large effect size $d=2.83$ (95\% CI 2.22-3.44, $p=0.00$ ) focused on all frail patients and involved a nurse and a physiotherapist who led five sessions per week of 65 minutes of strengthening, endurance, and balance activities that increased patients' overall levels of PA. When this study is removed from the analysis, the effect size is somewhat smaller: $d=0.10(95 \%$ CI 0.012-0.27, $p=0.00)$.

The funnel plot in Figure 4.3 may be indicative of publication bias with individual studies asymmetrically placed about the mean effect size (Borenstein et al., 2009). Egger's regression was not statistically significant $(t=1.6, p=0.12)$. Classic Fail-safe N suggests 451 studies would be needed to yield an insignificant $p$ value.

\section{Study Design Characteristics}

Studies ranged in date of publication from 1999 to 2019. Studies included 25 randomized controlled trials and 3 pre- post-test, single-group studies. In four of the randomized controlled trials, the control group received an alternative intervention, so these studies were analyzed as pre- post-test studies. Five of the studies had a primary outcome of fall prevention (TarazonaSantabalbina, 2016; Mackenzie \& Clemson, 2014; Perula et al., 2012; Campbell et al., 1999). 
Studies represented seven different countries: Australia $(n=3)$, Canada $(n=3)$, New Zealand $(n=2)$, Romania $(n=1)$, Spain $(n=2)$, Switzerland $(n=1)$, United Kingdom (7), and the United States of America $(n=9)$. All 28 studies identified a funding source.

Overall, the two-group design studies met most of the PEDro scale criteria (Table 4.8). Intention-to-treat analysis was used in 14 of the comparisons. There was no significant difference in effect size between the studies that used intention-to-treat analysis $(d=0.32)$ and those that did not $(d=0.2)(p=0.32)$. Assessors were blinded in 11 of the comparisons. There was no significant difference in effect size between comparisons with blinded assessors $(d=0.17)$ and those without $(d=0.33)(p=0.23)$. Seven of the comparisons used objective measures of PA. There was no significant difference in effect size between those studies with objective measures $(d=0.17)$ and those with subjective measures $(d=0.29)(p=0.45)$. These results are for two group studies and can be found in Table 4.6.

\section{Participant Characteristics}

The mean age of all participants was 75.08 years. Both men and women were well represented with $55.8 \%$ or participants female. Many studies did not document race or ethnicity and non-Caucasian groups were not well represented. One study enrolled only participants with heart failure (Witham, et al., 2011); one study enrolled participants with chronic obstructive pulmonary disease (Coultas et al., 2018); and one study enrolled only frail participants (Tarazona-Santabalbina, 2016). Overall, participant's health characteristics were not well documented. Study and participant characteristics for single-group studies are included in Table 4.2. Study and participant characteristics for two-group studies are included in Table 4.3. The 
age of the participants and the number of women included were not significant moderators Continuous moderator analyses are displayed in Table 4.7.

\section{Intervention Characteristics}

Intervention characteristics were explored to determine if effects varied based on strategies, duration and interventionist. Intervention characteristics include strategies used by the interventionists as well as the extent of the intervention, such as the length of interventions and the number of sessions. A variety of interventionists were used to deliver the interventions.

\section{Strategies}

Results from the moderator analysis for the dichotomous variables are listed in Table 4.6. Barrier management $(k=14)$ and problem-solving $(k=10)$ were the most common interventions in the 25 comparisons of randomized controlled trials. There was no significant difference in effect between studies that used barrier management $(d=0.36)$ and those studies that did not use barrier management $(d=0.23)(p=0.35)$. Similarly, studies that used problem solving $(d=0.33)$ versus studies that did not use problem-solving $(d=0.25)$ did not have significantly different effects $(p=0.6)$. Other interventions strategies such as goal-setting, feedback, actionplanning, decisional balance, education and risk assessment, pedometer, and diary use, did not significantly impact the effect size. Studies using counseling $(d=0.17)$ were less effective, compared with studies that used counseling $(d=0.60)(p=0.00)$. Studies employing exercise referral initiated in primary care $(d=0.70)$ had significantly greater effects compare to those studies that did not use exercise referral $(d=0.18)(p=0.00)$. Transtheoretical model of change (TTM) was the most used theory $(k=8)$, followed by social cognitive theory $(k=5)$. TTM had a 
positive effect on overall effect size $(d=0.36)$; however, there was no significant difference in effects over studies that did not use TTM $(0.24)(p=0.41)$.

\section{Intervention Dose}

While counseling was not shown to have a positive effect on PA activity, in those studies that did utilize counseling, more counseling sessions were associated with an increased effect size $(B=0.02, p=0.01)$. Other continuous moderators including the length of the intervention, number of phone calls, and the number of face-to-face interactions were not significant. The mean length of the intervention in days was 329.

\section{Interventionists}

PA interventions were provided by a variety of interventionists including physical and occupational therapists, physicians, nurses, exercise trainers, health counselors, volunteers, and peers. Studies that included physical or occupational therapists as interventionists demonstrated greater effects (0.53) than studies without these disciplines' involvement $(d=0.21)(p=0.05)$.

Multiple studies utilizing physician involvement in PA interventions yielded positive effect sizes $(\mathrm{n}=16)(d=0.21, p=0.00)$. Studies with positive effect sizes not involving the physician in the primary care office often involved the nurse $(k=9)$ and, in some studies, both were involved $(k=6)$. Studies utilizing nurse interventionists $(d=0.40)$ were not significantly more effective than studies not using nurse interventionists $(d=0.2)(p=0.12)$.

\section{Discussion}

The overall effect size of $0.27(p=0.00)$ represents a small-to-moderate positive effect for interventions used in primary care to facilitate PA. This effect size is consistent with a previous primary care intervention meta-analysis that found a 0.25 effect size in interventions provide for 
adults ages 17-92 (Orrow et al., 2012). Though the effect size was small-to-moderate, small changes in PA can positively impact the health of older adults. The single group pre/post studies had an effect size of $0.14(p=0.00)$. Marques et al. (2019) found that older adults who participated in even low-to-moderate levels of PA at least one time per week reduced their risk of chronic diseases including diabetes and hypertension. Exercising three times per week for only 15 minutes at time is associated with a lower risk of depression in the older adults (Chang, 2017). Results from this meta-analysis are similar, but slightly larger than effect sizes for intervention to facilitate PA in older adults found by Chase $(d=0.18)$ and found by Conn et al. $(d=0.19)$ (Chase, 2015; Conn et al., 2011). The slightly larger effect size found in this current meta-analysis may represent a positive effect of the primary care setting for delivering PA interventions.

A variety of delivery methods may be used ranging from in-person sessions to automated phone calls (Dubbert et al., 2008; Morey et al., 2009; Coultas et al., 2018). More counseling sessions are more effective, but these can be provided in person or by phone. Older adults may experience many barriers to participation in PA, so it is not surprising that barrier management can be an effective strategy for increasing PA and was used in 14 out of 25 studies. The positive effects of barrier management and problem-solving techniques did not reach statistical significance in this meta-analysis, which is inconsistent with prior research (Chase, 2015). A systematic review of studies addressing older adult's barriers to PA identified poor health as the most common barrier (Baert et al., 2011). Perhaps more counseling sessions give more opportunities to address and resolve barriers as they arise. Interventions do not need to require an extensive amount of time. Kerse et al. (2005) increased PA in participants $(d=0.245)$ by using an exercise prescription which took an average of 7 minutes to deliver. 
The use of theory-based interventions did not positively modify PA effect size. Chase (2015) found that the use of theory-based interventions is positively associated with effect sizes, while Conn (2002) found no association. The use of theory was not consistently described in all included articles; thus, it is difficult to say how closely the constructs of each theory were applied. Theories that are more consistently applied may lead to more effective interventions (Mitchie et al., 2013). Future research utilizing theory-based interventions should strive to closely apply the theoretical constructs, as well as describe how the constructs were used in their reports.

Only seven of the included studies used objective measures of PA. While objective measures can be more accurate the subjective measures, pedometers and accelerometer sometimes do not record the variety of functional activities older adults participate in. Additionally, they can be worn incorrectly or not worn consistently. When studies rely on only self-report, accuracy can be decreased due to misinterpretation of the questions, memory impairments of the participant, as well as the effect of the older adult choosing responses that are viewed to be more socially desirable (Banda et al., 2010; Sallis \& Saelens, 2000). Future research should include studies with objective measures of PA outcomes.

The use of technology in providing interventions is a growing area of research. The search for this meta-analysis found only two studies utilizing technology to promote PA (Bickmore et al., 2013; Weinstock et al., 2011) meeting the inclusion criteria. There is limited research in the use of technology in older adults to promote PA, especially in adults $\geq 65$. Parker and Ellis (2016) found that text messages were effective in increasing levels on PA in older adults age $\geq 50$ over a four-week period. Currently, $53 \%$ of adults $\geq 65$ in the United States own a smart phone and $73 \%$ use the internet (Livingston, 2019). As older adults are using cell phones 
and the internet more often, more research will be needed to identify effective interventions utilizing technology. Using technology-based interventions can be efficient and economical. More research is needed analyzing the cost of providing PA interventions to older adults versus the savings in healthcare expenditures when older adults are active.

Primary care-based interventions can be provided by an interdisciplinary team without putting the entire burden on the primary care provider. In a quantitative study of barriers and facilitators for exercise, older adults listed their physician support and encouragement as motivating factors (Costello et al., 2011). Although involvement of the physician did not positively moderate the overall effect size in this meta-analysis, all of the PA interventions delivered in primary care may be viewed by patients as being backed by the provider and thus confounding the effect of the moderator of the physician as the interventionist.

The nurse alone or in conjunction with the physician was the interventionist in many of the studies. Unfortunately, none of the studies reported the educational level of the nurse interventionist. Other interventionists included health counselors, exercise specialists, and volunteers, supporting the finding by Chase (2015) that a variety of personnel can be utilized to deliver interventions. Utilizing ancillary personnel to deliver PA interventions can free up time for the primary care provider.

Physical and occupational therapists, as well as exercise specialists or trainers as interventionists, have the advantage of being able to demonstrate exercise to the older adult and provide recommendations on the different types of exercise, strengthening, balance, and aerobic training that are recommended for the adult population (CDC, 2018). This can help alleviate another barrier that older adults face, lack of knowledge about types of exercise (Baert et al., 2011). In quantitative research by Huffman and Amireault (2020), the authors found that the 
older adults value help from trainers and other fitness experts because they gave them confidence that they were doing the exercises correctly. While physical and occupational therapist interventionists in this meta-analysis were more effective, general supervised exercise provided by a variety of interventionists was not associated with an increase in effect size. This fits the assumption that older adults prefer exercise experts to lead them in PA. Older adults with chronic conditions face greater challenges to increasing PA. Studies involving those with chronic conditions had negative or small effect sizes (Coultas et al., 2018; Witham et al., 2011), and results are consistent with prior meta-analysis work (Chase, 2015). More research on the role of physical or occupational therapists in promoting PA in primary care is needed. Furthermore, studies incorporating exercise specialists, exercise trainers, and health coaches are needed to demonstrate the effectiveness of these ancillary personnel for providing PA interventions.

\section{Limitations}

Moderator analyses are intended to be exploratory in nature and are useful for generating hypotheses to guide further research (Borenstein et al., 2009). The limitations of this metaanalysis are related to the limited ability to complete moderator analysis due to the number of studies, as well as missing data within studies. Many studies collected very minimal participant data. Some potential moderators, such as objective outcome measurements, peer support, types of exercise recommended, and exercise prescription, were present in numbers too small to use moderator analysis. The primary studies contained limited information about interventions so information about the interventions should be interpreted with caution. Although some studies enrolled participants with diabetes, heart disease, and other conditions, many only reported aggregate data across these groups, limiting the ability to identify effect size within specific 
populations. Sufficient information about specific chronic illnesses would have been valuable information for moderator analysis.

Despite attempts to locate all applicable studies published and published, some studies may have been missed. Several studies were located that did not contain the outcome data needed to perform meta-analysis. PA research is needed that explores the unique needs of ethnic and racial minority groups. Further research is also needed to explore the unique needs of ethnic and racial minorities groups. Researchers should strive to enroll more people of color and document characteristics of racial/ethnic diversity, as these groups participate less frequently in health-promoting behaviors compared to non-Hispanic White counterparts (August \& Sorkin, 2011). By setting a mean age of $\geq 70$, it was hoped to capture a greater percentage of the oldest old population. This represents a significantly older population than other PA intervention metaanalyses in primary care (Orrow et al., 2012; Pavey et al., 2011). Yet, the mean age of participants was only 75.0. Few of the studies included participants older than 85 . There were not enough participants in this older age to detect any differences in response to intervention based on an oldest old population. This study only included studies of community-dwelling participants; thus, results cannot be generalized to vulnerable older adults in facilities. Finally, all meta-analyses should be interpreted based on the quality of the studies that go into the analysis (da Costa \& Juni, 2014). Study quality was addressed through adherence to inclusion criteria and analyzing single-group studies separately from two-group studies. Meta-analyses are observational studies and are useful for synthesizing research and providing directions for future research. However, meta-analysis and moderator analysis findings do not establish cause-andeffect relationships between and among variables. 


\section{Conclusion}

Primary care providers are often a respected information resources for patients and a valuable source of motivation to improve their health. Primary care providers can provide interventions that increase PA levels in their older adult patients, significantly impacting their overall health. Taking a team approach to these interventions can help to manage the extra time required to facilitate effective interventions. While this research demonstrates that promoting PA in primary care for older adults is feasible, the most effective means to achieve this goal continues to be a challenge for researchers. Adding to this challenge is the difficulty with enrolling the more vulnerable older adults $\geq 85$, as well as older adults representative of minority populations. 


\section{Table 3.1.}

Categories of data collection

\begin{tabular}{|c|c|c|c|c|}
\hline Design & $\begin{array}{c}\text { Participant } \\
\text { Characteristics }\end{array}$ & Interventions & Interventionist & $\begin{array}{l}\text { Use of } \\
\text { Theory }\end{array}$ \\
\hline -Allocation & -Age & -Automated & -Physicians & -Social \\
\hline to group & -Number of & phone calls & -Nurses & cognitive theory \\
\hline -PA outcome & comorbidities & -Journaling & -Personal & -Health belief \\
\hline measure & -Gender & -Motivational & Trainers & model \\
\hline -Pre-, post-test & -Prior PA level & interviewing & -Physical and & -Behavioral \\
\hline design & -Educational & -Exercise & Occupational & choice theory \\
\hline -Experimental & level & prescriptions & Therapists & -Empowerment \\
\hline design & -Race/ethnicity & & -Peer Leaders & theory \\
\hline -Type of control & -Use of assistive & & & -Theory of \\
\hline group & device & & & planned \\
\hline
\end{tabular}


Table 4.1

Included Two-group Studies

\begin{tabular}{|c|c|c|c|c|c|}
\hline $\begin{array}{l}\text { Author, Year, } \\
\text { Location }\end{array}$ & Design & Theory & $\begin{array}{c}\text { Sample } \\
\text { Characteristics }\end{array}$ & Intervention & Results \\
\hline $\begin{array}{l}\text { Coultas et al., } 2018 \\
\text { United States }\end{array}$ & $\begin{array}{l}\text { Randomized } \\
\text { controlled } \\
\text { trial }\end{array}$ & $\begin{array}{l}\text { Transtheoretical } \\
\text { Model } \\
\text { Social } \\
\text { Cognitive } \\
\text { Theory }\end{array}$ & $\begin{array}{l}\text { Mean age of } \\
\text { all } \\
\text { participants: } \\
70.3 \\
\mathrm{~N}=205\end{array}$ & $\begin{array}{l}\text { Intervention Duration } \\
\text { (Months): } 18 \\
\text { Interventionist: } \\
\text { Intervention: Phone } \\
\text { Counseling, workbook, } \\
\text { pedometer }\end{array}$ & $\begin{array}{l}\text { Outcome Measure: RAPA } \\
\text { Results: Greater percentage of } \\
\text { participants in the treatment } \\
\text { group were persistently active } \\
\text { at } 18 \text { months }\end{array}$ \\
\hline $\begin{array}{l}\text { Dolovich et al., } 2019 \\
\text { Canada }\end{array}$ & $\begin{array}{l}\text { Randomized } \\
\text { controlled } \\
\text { trial }\end{array}$ & None Noted & $\begin{array}{l}\text { Tx Mean age: } \\
79.06 \\
\text { Con Mean } \\
\text { age: } 78.06 \\
\mathrm{~N}=312\end{array}$ & $\begin{array}{l}\text { Intervention Duration } \\
\text { (Months): } 6 \\
\text { Interventionist: } \\
\text { Physicians, Trained } \\
\text { Community Volunteers } \\
\text { Intervention: home } \\
\text { visits }\end{array}$ & $\begin{array}{l}\text { Outcome Measure: IPAQ } \\
\text { No difference between } \\
\text { groups on goal attainment } \\
\text { Intervention group did have } \\
\text { fewer hospitalizations }\end{array}$ \\
\hline $\begin{array}{l}\text { Dubbert et al. (2008) } \\
\text { United States }\end{array}$ & $\begin{array}{l}\text { Randomized } \\
\text { controlled } \\
\text { trial }\end{array}$ & $\begin{array}{l}\text { Social } \\
\text { Cognitive } \\
\text { Theory }\end{array}$ & $\begin{array}{l}\text { Mean age: } \\
71.7 \\
\mathrm{~N}=224\end{array}$ & $\begin{array}{l}\text { Intervention Duration } \\
\text { (Months): } 10 \\
\text { Interventionist: Nurse } \\
\text { Intervention: } \\
\text { In-person exercise } \\
\text { counseling provided by } \\
\text { nurse (EXC) } \\
\text { vs another health topic } \\
\text { provided by a nurse } \\
\text { (EDUC) }\end{array}$ & $\begin{array}{l}\text { Outcome Measures: } \\
\text { Accelerometer } \\
\text { Results: } \\
\text { More EXC participants ( } 64 \% \\
\text { vs } 46 \% \text { ) EDUC participants } \\
\text { who averaged } 30 \text { min/day of } \\
\text { moderate or higher intensity } \\
\text { physical activity ( } p=.03)\end{array}$ \\
\hline
\end{tabular}




\begin{tabular}{|c|c|c|c|c|c|}
\hline $\begin{array}{l}\text { Author, Year, } \\
\text { Location }\end{array}$ & Design & Theory & $\begin{array}{c}\text { Sample } \\
\text { Characteristics }\end{array}$ & Intervention & Results \\
\hline $\begin{array}{l}\text { Herghelegiu } \\
\text { et al., (2017) } \\
\text { Romania }\end{array}$ & $\begin{array}{l}\text { Randomized } \\
\text { controlled } \\
\text { trial }\end{array}$ & $\begin{array}{l}\text { Transtheoretical } \\
\text { Model }\end{array}$ & $\begin{array}{l}\text { Tx Mean age: } \\
74.8, \mathrm{n}=100 \\
\text { Con Mean age: } \\
75, \mathrm{~N}=100\end{array}$ & $\begin{array}{l}\text { Intervention Duration } \\
\text { (Months): } 6 \\
\text { Interventionist: } \\
\text { Geriatrician } \\
\text { Intervention: Monthly } \\
\text { 15-30-minute } \\
\text { counseling sessions }\end{array}$ & $\begin{array}{l}\text { Outcome Measures: } \\
\text { International PA } \\
\text { Questionnaire (IPAQ) } \\
\text { Intervention: PA increased by } \\
\text { a median of } 180.0 \mathrm{MET} \\
\text { minutes/week }(95 \% \\
\text { confidence interval }(\mathrm{CI}) \\
43.4 \pm 316.6, p=0.01) \\
\text { Control group: PA decreased } \\
\text { by a median of } 346.5 \mathrm{MET} \\
\text { minutes/week }(95 \% \mathrm{CI} \\
\text { 178.4 } \pm 514.6, p<0.001) \text { due to } \\
\text { seasonal effect }\end{array}$ \\
\hline
\end{tabular}

Illife et al., 2014 United Kingdom
Randomized None Noted controlled trial
Mean age: 71 $\mathrm{N}=1256$
Intervention Duration

(Months): 12

Interventionist:

Physician, peer

Intervention: Falls

Management Exercise

(FaME) program,

home-based exercise

Otago Exercise

Programme (OEP)

\section{Outcome Measures:}

\section{CHAMPS}

Results: FaME arm

increased time spent in PA.

Both arms had

improvements in balance

confidence 


\begin{tabular}{|c|c|c|c|c|c|}
\hline $\begin{array}{l}\text { Author, Year, } \\
\text { Location }\end{array}$ & Design & Theory & $\begin{array}{c}\text { Sample } \\
\text { Characteristics }\end{array}$ & Intervention & Results \\
\hline $\begin{array}{l}\text { Kerse et al., } 1999 \\
\text { New Zealand }\end{array}$ & $\begin{array}{l}\text { Randomized } \\
\text { controlled } \\
\text { trial }\end{array}$ & None Noted & $\begin{array}{l}\text { Intervention: } \\
\text { Tx Mean age: } \\
72.9 \\
\text { Con Mean } \\
\text { Age: } 74.2 \\
\mathrm{~N}=233\end{array}$ & $\begin{array}{l}\text { Intervention Duration } \\
\text { (Months): } 2-3 \\
\text { Interventionist: } \\
\text { General Practitioners } \\
\text { Intervention: } \\
\text { Educational Program }\end{array}$ & $\begin{array}{l}\text { Outcome Measures: Survey } \\
\text { Results: Increase of } 88 \mathrm{~min} \\
\text { of PA/2 weeks }\end{array}$ \\
\hline $\begin{array}{l}\text { Kolt et al., } 2007 \\
\text { Australia }\end{array}$ & $\begin{array}{l}\text { Randomized } \\
\text { controlled } \\
\text { trial }\end{array}$ & $\begin{array}{l}\text { Social } \\
\text { Cognitive } \\
\text { Theory }\end{array}$ & $\begin{array}{l}\text { Intervention: } \\
\text { Tx Mean age: } \\
74.1 \\
\text { Con Mean } \\
\text { Age: } 74.3 \\
\mathrm{~N}=186\end{array}$ & $\begin{array}{l}\text { Intervention Duration } \\
\text { (Months): } 6 \\
\text { Interventionist: } \\
\text { Physician, counselor } \\
\text { Intervention: } \\
\text { Telephone counseling, } \\
\text { goal setting, rewards }\end{array}$ & $\begin{array}{l}\text { Outcome Measures: Aukland } \\
\text { Heart Study PA } \\
\text { Results: More participants in } \\
\text { the intervention group reached } \\
2.5 \text { hours of PA per week than } \\
\text { in the control group }\end{array}$ \\
\hline $\begin{array}{l}\text { McMurdo, et al., } \\
(2010) \\
\text { United Kingdom }\end{array}$ & $\begin{array}{l}\text { Randomized } \\
\text { controlled } \\
\text { trial }\end{array}$ & $\begin{array}{l}\text { Self-regulation } \\
\text { Theory }\end{array}$ & $\begin{array}{l}\text { Mean age of } \\
\text { all } \\
\text { groups: } 77.3 \\
\text { BCI } n=68 \\
\text { BCI + } \\
\text { pedometer } \\
\mathrm{N}=68 \\
\text { Con } \mathrm{N}=68\end{array}$ & $\begin{array}{l}\text { Intervention Duration } \\
\text { (Months): } 6 \\
\text { Interventionist: } \\
\text { Trained study } \\
\text { coordinators } \\
\text { Intervention: } \\
\text { Group1: Behavioral } \\
\text { Change Intervention } \\
\text { (BCI) } \\
\text { Group 2: } \\
\text { (BCI) plus pedometer } \\
\text { Group 3: CON }\end{array}$ & $\begin{array}{l}\text { Outcome Measure: } \\
\text { Accelerometer reading } \\
\text { Results: PA at } 3 \text { months was } \\
\text { higher in the BCI group than in } \\
\text { the control group ( } p=.002) \text { and } \\
\text { the pedometer plus group } \\
(p=.04) \text {. } \\
\text { No significant difference } \\
\text { between BCI group and BCI + } \\
\text { pedometer }\end{array}$ \\
\hline
\end{tabular}




\begin{tabular}{|c|c|c|c|c|c|}
\hline $\begin{array}{l}\text { Author, Year, } \\
\text { Location }\end{array}$ & Design & Theory & $\begin{array}{c}\text { Sample } \\
\text { Characteristics }\end{array}$ & Intervention & Results \\
\hline $\begin{array}{l}\text { Morey et al., } 2006 \\
\text { United States }\end{array}$ & $\begin{array}{l}\text { Randomized } \\
\text { controlled } \\
\text { trial }\end{array}$ & $\begin{array}{l}\text { Social- } \\
\text { Cognitive } \\
\text { Theory }\end{array}$ & $\begin{array}{l}\text { Tx Mean age: } \\
78.5 \\
\text { Con Mean } \\
\text { age: } 78.1 \\
\mathrm{~N}=179\end{array}$ & $\begin{array}{l}\text { Intervention Duration } \\
\text { (Months): } 6 \\
\text { Interventionist: } \\
\text { Physician and Health } \\
\text { Counselor } \\
\text { Intervention: } \\
\text { Identified stages of } \\
\text { Change, Counseling }\end{array}$ & $\begin{array}{l}\text { Outcome Measures: } \\
\text { CHAMPS } \\
\text { Results: Significant increase } \\
\text { in PA }\end{array}$ \\
\hline $\begin{array}{l}\text { Morey et al., } \\
2009 \\
\text { United States }\end{array}$ & $\begin{array}{l}\text { Randomized } \\
\text { controlled } \\
\text { trial }\end{array}$ & $\begin{array}{l}\text { Transtheoretical } \\
\text { Model of } \\
\text { Change } \\
\text { and Social } \\
\text { Cognitive } \\
\text { Theory }\end{array}$ & $\begin{array}{l}\text { Mean age: } 77.7 \\
\mathrm{~N}=398\end{array}$ & $\begin{array}{l}\text { Intervention Duration } \\
\text { (Months): } \mathbf{2 4} \\
\text { Interventionist: } \\
\text { Counselor } \\
\text { Intervention: } \\
\text { In-person and phone } \\
\text { counseling }\end{array}$ & $\begin{array}{l}\text { Outcome Measures: } \\
\text { CHAMPS } \\
\text { Results: } \\
\text { Participants in the intervention } \\
\text { group increased their exercise } \\
\text { frequency from } 15.9 \text { per week } \\
\text { to } 112.4 \text { per week }\end{array}$ \\
\hline $\begin{array}{l}\text { Morgan et al., } 2019 \\
\text { United Kingdom }\end{array}$ & $\begin{array}{l}\text { Randomized } \\
\text { controlled } \\
\text { trial }\end{array}$ & $\begin{array}{l}\text { Self- } \\
\text { Determination }\end{array}$ & $\begin{array}{l}\text { Mean } \\
\text { age: } 74.1 \\
\mathrm{~N}=51\end{array}$ & $\begin{array}{l}\text { Intervention Duration } \\
\text { (Months): } \\
\text { Interventionist: } \\
\text { Trained community } \\
\text { member } \\
\text { Intervention: Phone } \\
\text { calls, Motivational } \\
\text { Interviewing }\end{array}$ & $\begin{array}{l}\text { Outcome Measures: } \\
\text { Accelerometer } \\
\text { Results: }\end{array}$ \\
\hline
\end{tabular}




\begin{tabular}{|c|c|c|c|c|c|}
\hline $\begin{array}{l}\text { Author, Year, } \\
\text { Location }\end{array}$ & Design & Theory & $\begin{array}{c}\text { Sample } \\
\text { Characteristics }\end{array}$ & Intervention & Results \\
\hline $\begin{array}{l}\text { Mutrie et al., } \\
\text { (2012) } \\
\text { United Kingdom }\end{array}$ & $\begin{array}{l}\text { Randomized } \\
\text { controlled } \\
\text { trial }\end{array}$ & $\begin{array}{l}\text { Social } \\
\text { Cognitive } \\
\text { Theory }\end{array}$ & $\begin{array}{l}\text { Intervention } \\
\text { mean } \\
\text { age: } 71.6 \\
\text { Con mean } \\
\text { age of } 70.0 \\
\mathrm{~N}=41\end{array}$ & $\begin{array}{l}\text { Intervention Duration } \\
\text { (Months): } 3 \\
\text { Interventionist: Nurse } \\
\text { Intervention: } \\
\text { Two 30-minute nurse } \\
\text { led counseling sessions, } \\
\text { use of pedometer } \\
\text { Control group: received } \\
\text { intervention } 12 \text { weeks } \\
\text { later }\end{array}$ & $\begin{array}{l}\text { Outcome Measures: Sealed } \\
\text { pedometers and an activPAL }{ }^{\mathrm{tm}} \\
\text { Monitor. } \\
\text { Results: } \\
12 \text { Weeks: Intervention } \\
\text { increased step counts } \\
\text { by } 2119 \text { steps/day }(p=.001)\end{array}$ \\
\hline
\end{tabular}

¿ Pérula et al., 2012 Spain
Randomized None Noted controlled

trial
Tx Mean age:

76.30

Con Mean

age: 76.48

$\mathrm{N}=404$
Intervention Duration

(Months): 12

Interventionist: Nurse,

Physician,

Physiotherapist

Intervention:

Counseling, Supervised

exercise session,

Workbook
Outcome Measures: IPAQ

short

\section{Results: Tx group:}

66.2\% increased

their PA and $73.6 \%$ continued

with the exercise program 


\begin{tabular}{|c|c|c|c|c|c|}
\hline $\begin{array}{l}\text { Author, Year, } \\
\text { Location }\end{array}$ & Design & Theory & $\begin{array}{c}\text { Sample } \\
\text { Characteristics }\end{array}$ & Intervention & Results \\
\hline $\begin{array}{l}\text { Sims et al., } 1999 \\
\text { United Kingdom }\end{array}$ & $\begin{array}{l}\text { Pre/Post- } \\
\text { Test }\end{array}$ & None Noted & $\begin{array}{l}\text { Mean age: } 72.3 \\
\mathrm{~N}=20\end{array}$ & $\begin{array}{l}\text { Intervention Duration } \\
\text { (Months): } 2 \\
\text { Interventionist: Nurse } \\
\text { Intervention: Nurse } \\
\text { and patient developed } \\
\text { and activity schedule } \\
\text { and plan }\end{array}$ & $\begin{array}{l}\text { Outcome Measure: Minutes } \\
\text { with heart } \\
\text { rate> } 100 \mathrm{bpm} \\
\text { Results: } \\
\text { Increase in moderate activity } \\
\text { was significant with } \\
\text { Mean baseline: } 3.05 \\
\text { Mean at outcome: } 5.0 \\
(p=0.015)\end{array}$ \\
\hline $\begin{array}{l}\text { Stuck et al., } 2015 \\
\text { Switzerland }\end{array}$ & $\begin{array}{l}\text { Randomized } \\
\text { controlled } \\
\text { trial }\end{array}$ & $\begin{array}{l}\text { Transtheoretical } \\
\text { Model of } \\
\text { Change } \\
\text { Self-Efficacy }\end{array}$ & $\begin{array}{l}\text { Tx Mean age: } \\
74.5 \\
\text { Con Mean } \\
\text { age: } 74.5 \\
\mathrm{~N}=2284\end{array}$ & $\begin{array}{l}\text { Intervention Duration } \\
\text { (Months): } 24 \\
\text { Interventionist: Nurse } \\
\text { and Physician } \\
\text { Intervention: Health } \\
\text { Risk Assessment } \\
\text { Questionnaire used to } \\
\text { motivate participants } \\
\text { nurse counseling }\end{array}$ & $\begin{array}{l}\text { Outcome Measures: } \\
\text { Lifestyle Questionnaire } \\
\text { Results: } 70 \% \text { of the } \\
\text { intervention group were } \\
\text { physically active compared to } \\
62 \% \text { of control group }\end{array}$ \\
\hline $\begin{array}{l}\text { Tarazona- } \\
\text { Santabalbina et al., } \\
2016 \\
\text { Spain }\end{array}$ & $\begin{array}{l}\text { Randomized } \\
\text { controlled } \\
\text { trial }\end{array}$ & None Noted & $\begin{array}{l}\text { Tx Mean age: } \\
79.7 \\
\text { Con Mean } \\
\text { age: } 80.3 \\
\mathrm{~N}=100\end{array}$ & $\begin{array}{l}\text { Intervention Duration } \\
\text { (Months): } 6 \\
\text { Interventionist: Nurse } \\
\text { or Physiotherapist } \\
\text { Intervention: } \\
\text { Supervised exercise }\end{array}$ & $\begin{array}{l}\text { Outcome Measures: } \\
\text { Previously validated tool } \\
\text { adapted for this study } \\
\text { Results: } \\
77.5 \% \text { of participants in } \\
\text { intervention group } \\
\text { performed 3-6 hours/week of } \\
\text { PA. } 90 \% \text { of control group } \\
\text { performed } 3 \text { hours or less PA. } \\
\text { Reduction of primary care } \\
\text { visits was significantly } \\
\text { reduced in the exercise group }\end{array}$ \\
\hline
\end{tabular}




\begin{tabular}{|c|c|c|c|c|c|}
\hline $\begin{array}{l}\text { Author, Year, } \\
\text { Location }\end{array}$ & Design & Theory & $\begin{array}{c}\text { Sample } \\
\text { Characteristics }\end{array}$ & Intervention & Results \\
\hline $\begin{array}{l}\text { Weinstock et al., } \\
2011\end{array}$ & $\begin{array}{l}\text { Randomized } \\
\text { controlled }\end{array}$ & None noted & $\begin{array}{l}\text { Tx Mean age: } \\
70.8\end{array}$ & $\begin{array}{l}\text { Intervention Duration } \\
\text { (Months): } 60\end{array}$ & $\begin{array}{l}\text { Outcome Measures: DSC- } \\
\text { PA }\end{array}$ \\
\hline United Kingdom & trial & & $\begin{array}{l}\text { Con Mean } \\
\text { age: } 70.9 \\
\mathrm{~N}=1650\end{array}$ & $\begin{array}{l}\text { Interventionist: Nurse } \\
\text { Intervention: } \\
\text { Telehealth visits, } \\
\text { pedometer }\end{array}$ & $\begin{array}{l}\text { Results: Less decline in PA } \\
\text { over time with telehealth visits } \\
\text { Pedometers introduced after } \\
\text { two years contributed to long } \\
\text { term effects of intervention }\end{array}$ \\
\hline
\end{tabular}


Table 4.2

Included Single-group Studies

\begin{tabular}{|c|c|c|c|c|c|}
\hline $\begin{array}{l}\text { Author, Year, } \\
\text { Location }\end{array}$ & Design & Theory & $\begin{array}{c}\text { Sample } \\
\text { Characteristics }\end{array}$ & Intervention & Results \\
\hline $\begin{array}{l}\text { Bickmore, } \\
\text { et al., (2013) } \\
\text { United States }\end{array}$ & $\begin{array}{l}\text { Randomized } \\
\text { controlled } \\
\text { trial }\end{array}$ & None noted & $\begin{array}{l}\text { Mean age of } \\
\text { all } \\
\text { participants: } \\
71.3 \\
\text { Treatment } \\
\mathrm{N}=263\end{array}$ & $\begin{array}{l}\text { Intervention Duration } \\
\text { (Months): } 12 \\
\text { Interventionist: } \\
\text { Embodied } \\
\text { Conversational Agent } \\
\text { Intervention: } \\
\text { Coaching daily for } 2 \\
\text { Months, then } \\
\text { intermittently for } 10- \\
\text { month } \\
\text { maintenance }\end{array}$ & $\begin{array}{l}\text { Outcome measure: Steps via } \\
\text { pedometer } \\
\text { Statistically significant } \\
\text { increase at } 2 \text { months }(p=.01) \\
\text { No longer significant at } 12 \\
\text { months }(p=.09)\end{array}$ \\
\hline $\begin{array}{l}\text { Gibbs et al., } 2019 \\
\text { Canada }\end{array}$ & Pre/Post test & None noted & $\begin{array}{l}\text { Mean age: } 81 \\
\mathrm{~N}=44\end{array}$ & $\begin{array}{l}\text { phase } \\
\text { Intervention Duration } \\
\text { (Months): } 6 \\
\text { Interventionist: } \\
\text { Physical Therapist } \\
\text { Intervention: } \\
\text { Integrating strength and } \\
\text { balance into normal } \\
\text { routines }\end{array}$ & $\begin{array}{l}\text { Outcome Measure: IPAQ } \\
\text { Results: No significant } \\
\text { changes in moderate to } \\
\text { vigorous PA outcomes }\end{array}$ \\
\hline
\end{tabular}




\begin{tabular}{|c|c|c|c|c|c|}
\hline $\begin{array}{l}\text { Author, Year, } \\
\text { Location }\end{array}$ & Design & Theory & $\begin{array}{c}\text { Sample } \\
\text { Characteristics }\end{array}$ & Intervention & Results \\
\hline $\begin{array}{l}\text { Kolt et al. (2012) } \\
\text { New Zealand }\end{array}$ & $\begin{array}{l}\text { Cluster } \\
\text { randomized } \\
\text { controlled } \\
\text { trial }\end{array}$ & None noted & $\begin{array}{l}\text { Intervention: } \\
\text { Tx Mean age: } \\
73.9, \\
\mathrm{n}=165 \\
\text { Con Mean } \\
\text { age: } \\
74.3, \mathrm{~N}=165\end{array}$ & $\begin{array}{l}\text { Intervention Duration } \\
\text { (Months): } 3 \\
\text { Interventionist: } \\
\text { Physician } \\
\text { Intervention: } \\
\text { Group 1: Green } \\
\text { Prescription (exercise } \\
\text { prescription)/ } \\
\text { Pedometer/telephone } \\
\text { counseling sessions } \\
\text { Group 2: Green/ } \\
\text { Prescription/telephone } \\
\text { counseling sessions } \\
\text { No pedometer }\end{array}$ & $\begin{array}{l}\text { Outcome Measure: Aukland } \\
\text { Heart Study PA } \\
\text { Results: Group } 1 \text { (pedometer- } \\
\text { based) increased leisure } \\
\text { walking by } 63.0 \mathrm{~min} / \mathrm{wk} \text { on } \\
\text { average, more than double the } \\
\text { increase in Group } 2 \text { (no } \\
\text { pedometer) of } 30.9 \mathrm{~min} / \mathrm{wk} \text { at } \\
3-4 \text { months }\end{array}$ \\
\hline $\begin{array}{l}\text { Mackenzie \& } \\
\text { Clemson, } 2014 \\
\text { Australia }\end{array}$ & Pre/Post test & None noted & $\begin{array}{l}\text { Mean age: } \\
81.3 \\
\mathrm{~N}=8\end{array}$ & $\begin{array}{l}\text { Intervention Duration } \\
\text { (Months): } 2 \\
\text { Interventionist: } \\
\text { Occupational, } \\
\text { Physical Therapists and } \\
\text { Physician } \\
\text { Intervention: Home } \\
\text { visits using Otago } \\
\text { exercise program }\end{array}$ & $\begin{array}{l}\text { Outcome Measures: PASE } \\
\text { Results: Minimal } \\
\text { improvements in PASE score; } \\
\text { however, there were } \\
\quad \text { significant } \\
\text { improvements in physical } \\
\text { functioning }\end{array}$ \\
\hline
\end{tabular}




\begin{tabular}{|c|c|c|c|c|c|}
\hline $\begin{array}{l}\text { Author, Year, } \\
\text { Location }\end{array}$ & Design & Theory & $\begin{array}{c}\text { Sample } \\
\text { Characteristics }\end{array}$ & Intervention & Results \\
\hline $\begin{array}{l}\text { Marki et al. } \\
(2006) \\
\text { Switzerland }\end{array}$ & $\begin{array}{l}\text { Pre/Post } \\
\text { Test }\end{array}$ & $\begin{array}{l}\text { Transtheoretical } \\
\text { Model of } \\
\text { Change }\end{array}$ & $\begin{array}{l}\text { Mean age: } \\
74.1 \\
\mathrm{~N}=29\end{array}$ & $\begin{array}{l}\text { Intervention Duration } \\
\text { (Months): } 2 \\
\text { Interventionist: } \\
\text { Physician } \\
\text { Intervention: Baseline } \\
\text { PA assessment followed } \\
\text { by counseling session }\end{array}$ & $\begin{array}{l}\text { Outcome Measures: } \\
\text { Physician interview } \\
\text { Results: } \\
\text { Minutes PA at baseline: } \\
\text { M=247, SD }=275 \\
\text { Minutes PA at Follow up: } \\
\text { M=436 ( } \mathrm{SD}=361 \text { ) } \\
\text { Counseling led to increase in } \\
\text { PA }\end{array}$ \\
\hline $\begin{array}{l}\text { Pfeiffer et al., } \\
2001 \\
\text { United States }\end{array}$ & $\begin{array}{l}\text { Randomized } \\
\text { controlled } \\
\text { trial }\end{array}$ & None noted & $\begin{array}{l}\text { Mean age: } 74 \\
N=76\end{array}$ & $\begin{array}{l}\text { Intervention Duration } \\
\text { (Months): } 1.5 \\
\text { Interventionist: } \\
\text { Physician } \\
\text { Intervention: } \\
\text { Verbal advice or verbal } \\
\text { advice plus prescription }\end{array}$ & $\begin{array}{l}\text { Outcome Measures: } \\
\text { Researcher-designed } \\
\text { questionnaire } \\
\text { Results } \\
\text { No significant difference } \\
\text { between verbal advice or } \\
\text { verbal advice plus prescription }\end{array}$ \\
\hline $\begin{array}{l}\text { Sugden et al., } 2008 \\
\text { United Kingdom }\end{array}$ & $\begin{array}{l}\text { Randomized } \\
\text { controlled } \\
\text { trial }\end{array}$ & $\begin{array}{l}\text { Self-regulation } \\
\text { theory }\end{array}$ & $\begin{array}{l}\text { Mean age: } 76 \\
N=54\end{array}$ & $\begin{array}{l}\text { Intervention Duration } \\
\text { (Months): } \\
\text { Interventionist: } \\
\text { Physician, Nurse } \\
\text { Intervention: } \\
\text { Pilot study-Pedometer } \\
\text { plus theory; } \\
\text { Theory-based } \\
\text { intervention alone }\end{array}$ & $\begin{array}{l}\text { Outcome Measures: } \\
\text { Accelerometer } \\
\text { Results: Non-significant } \\
\text { increase in PA in only one } \\
\text { subgroup with the goal to } \\
\text { increase PA by } 20 \% \text {. The } \\
\text { groups with lower goals did } \\
\text { not increase PA }\end{array}$ \\
\hline
\end{tabular}


Table 4.3

Characteristics

\begin{tabular}{lcc}
\hline \multicolumn{1}{c}{ Characteristic } & Number of Comparisons & Mean (SD) \\
\hline Age & 27 & $75.08(3.50)$ \\
Percentage Women & 25 & $55.80(27.4)$ \\
Percentage Minority & 11 & $22.05(21.42)$ \\
Percentage Married & 14 & $50.54(14.09)$ \\
Length of Intervention in days & 36 & $278.99(329.34)$ \\
Sample Size & 28 & $187.4(283.21)$ \\
\hline
\end{tabular}


Table 4.4

Effect Sizes

\begin{tabular}{|c|c|c|c|c|c|c|c|}
\hline Group & $k$ & $d$ & $95 \% \mathrm{CI}$ & $\mathrm{SE}$ & Q & $\mathrm{I}^{2}$ & $p$ \\
\hline $\begin{array}{l}\text { Two-group Treatments versus } \\
\text { Control, Post Intervention }\end{array}$ & 24 & 0.27 & $0.15,0.39$ & 0.06 & 117.56 & 80.44 & 0.00 \\
\hline Two-group Pre- and Post- & 24 & 0.27 & $0.14,0.40$ & 0.07 & 121.58 & 81.08 & 0.00 \\
\hline \multicolumn{8}{|l|}{ Intervention } \\
\hline Single-Group Pre- Post- & 9 & 0.14 & $0.04,0.23$ & 0.05 & 13.09 & 38.89 & 0.00 \\
\hline
\end{tabular}


Table 4.5

Description of variables

\begin{tabular}{ll}
\hline \multicolumn{1}{c}{ Variables for Moderator Analysis } & \multicolumn{1}{c}{ Description } \\
\hline Use of Theory & $\begin{array}{l}\text { Study-based interventions on a behavioral or } \\
\text { cognitive theory }\end{array}$ \\
Goal Setting & $\begin{array}{l}\text { PA goals were either set for the participant by } \\
\text { the interventionist or the participant set their } \\
\text { own goals }\end{array}$ \\
Problem Solving & $\begin{array}{l}\text { Making available a variety of response to deal } \\
\text { with problems that prevent participation in } \\
\text { PA. Report must say problem-solving }\end{array}$ \\
In-person counseling & $\begin{array}{l}\text { Includes an in-person two-way conversation } \\
\text { or discussion between participant and } \\
\text { interventionist with the goal of increasing PA }\end{array}$ \\
Barrier Management & $\begin{array}{l}\text { Assisting the participant to overcome } \\
\text { challenges or barriers to PA }\end{array}$ \\
Feedback & Participants given feedback based on their PA \\
performance
\end{tabular}

Action Planning

Process where participants are asked to plan the steps required to accomplish their PA goals. Report must say action planning

Diary

Participants keep track of their time spent in PA

Decisional Balance

Assisting the participant to weigh the pros and cons of participation in PA

Use of risk assessment

Health risk appraisal, lifestyle risk or safety assessment completed by the interventionist and results are shared with the participant

Education

Participant educated regarding the recommendations of PA levels for older adults

Supervised Exercise

Interventionist-supervised or -led group PA sessions 
Variables for Moderator Analysis

Physician Interventionist

Physician Recruited

Nurse Interventionist

Therapist Interventionist

Length of Intervention

\# fact-to-face counseling sessions

\# phone calls

\# counseling sessions

\section{Description}

Physician provided education, demonstration of exercises, counseling, encouraging phone calls, prescription, risk assessment or encouraged participation in study

Physician asked patients to participate in study or sent letters asking for participation

Nurse provided education, demonstration of exercises, counseling, encouraging phone calls, prescription, risk assessment or encouraged participation in study

Physical or Occupational therapist provided education, demonstration of exercises, counseling, encouraging phone calls, prescription, risk assessment or encouraged participation in study

Number of total days over which intervention was delivered

Number of counseling sessions delivered face-to-face

Number of total phone calls made includes automated or video phone calls

Number of sessions including face-to-face counseling or phone calls 
Table 4.6.

Moderator analysis of dichotomous variables.

\begin{tabular}{|c|c|c|c|c|c|c|}
\hline Variable & $\begin{array}{c}k \\
\text { studies } \\
\text { containing } \\
\text { the } \\
\text { variable }\end{array}$ & $\begin{array}{c}k \\
\text { studies } \\
\text { missing } \\
\text { the } \\
\text { variable }\end{array}$ & $\begin{array}{c}d \\
\text { studies } \\
\text { containing } \\
\text { the } \\
\text { variable }\end{array}$ & $\begin{array}{c}d \\
\text { studies } \\
\text { missing } \\
\text { the } \\
\text { variable }\end{array}$ & $\begin{array}{c}\mathrm{Q} \\
\text { between }\end{array}$ & $p$ value \\
\hline Use of Theory & 15 & 10 & 0.24 & 0.30 & 0.33 & 0.57 \\
\hline Use of Counseling & 20 & 5 & 0.17 & 0.60 & 8.26 & 0.00 \\
\hline Goal Setting & 13 & 12 & 0.23 & 0.32 & 0.47 & 0.50 \\
\hline Problem Solving & 6 & 19 & 0.33 & 0.25 & 0.28 & 0.60 \\
\hline $\begin{array}{l}\text { In-person } \\
\text { counseling }\end{array}$ & 13 & 12 & 0.16 & 0.41 & 3.70 & 0.05 \\
\hline Phone Calls & 14 & 11 & 0.27 & 0.30 & 0.03 & 0.85 \\
\hline Pedometer & 6 & 19 & 0.16 & 0.30 & 0.73 & 0.40 \\
\hline $\begin{array}{l}\text { Barrier } \\
\text { Management }\end{array}$ & 8 & 17 & 0.36 & 0.23 & 0.88 & 0.35 \\
\hline Feedback & 3 & 22 & 0.12 & 0.30 & 0.57 & 0.45 \\
\hline Action Planning & 6 & 19 & 0.26 & 0.28 & 0.02 & 0.89 \\
\hline Diary & 6 & 19 & 0.24 & 0.29 & 0.14 & 0.71 \\
\hline Decisional Balance & 2 & 23 & 0.16 & 0.28 & 0.12 & 0.72 \\
\hline $\begin{array}{l}\text { Use of Risk } \\
\text { Assessment }\end{array}$ & 8 & 17 & 0.11 & 0.33 & 2.37 & 0.12 \\
\hline Education & 11 & 14 & 0.26 & 0.29 & 0.05 & 0.83 \\
\hline $\begin{array}{l}\text { Supervised } \\
\text { Exercise }\end{array}$ & 3 & 22 & 0.18 & 0.29 & 0.33 & 0.57 \\
\hline Exercise Referral & 4 & 21 & 0.70 & 0.18 & 10.87 & 0.00 \\
\hline $\begin{array}{l}\text { Physician } \\
\text { Interventionist }\end{array}$ & 17 & 8 & 0.22 & 0.42 & 1.96 & 0.16 \\
\hline $\begin{array}{l}\text { Physician } \\
\text { Recruited }\end{array}$ & 12 & 13 & 0.24 & 0.30 & 0.22 & 0.64 \\
\hline $\begin{array}{l}\text { Nurse } \\
\text { Interventionist }\end{array}$ & 9 & 16 & 0.40 & 0.20 & 2.89 & 0.12 \\
\hline $\begin{array}{l}\text { Therapist } \\
\text { Interventionist }\end{array}$ & 5 & 20 & 0.52 & 0.20 & 4.145 & 0.04 \\
\hline Intention to treat & 14 & 11 & 0.32 & 0.2 & 0.99 & 0.32 \\
\hline Assessors Blinded & 11 & 14 & 0.17 & 0.33 & 1.44 & 0.23 \\
\hline Objective Measure & 7 & 18 & 0.17 & 0.29 & 0.58 & 0.45 \\
\hline
\end{tabular}

Note. $k=$ number of studies, $d=$ standardized mean difference 


\section{Table 4.7.}

Moderator Analysis of Continuous Variables

\begin{tabular}{|c|c|c|c|c|}
\hline Variable & $k$ & $\begin{array}{l}\text { Standardized } \\
\text { Meta- } \\
\text { regression } \\
\text { Coefficient }\end{array}$ & $\begin{array}{l}\text { Standard } \\
\text { Error (SE) }\end{array}$ & $\mathrm{P}$ value \\
\hline Age & 22 & 0.03 & 0.02 & 0.10 \\
\hline $\begin{array}{l}\text { Length of } \\
\text { Intervention }\end{array}$ & 24 & -0.00 & 0.00 & 0.18 \\
\hline $\begin{array}{l}\# \text { face-to-face } \\
\text { interactions }\end{array}$ & 13 & 0.02 & 0.03 & 0.51 \\
\hline \# phone calls & 12 & 0.01 & 0.01 & 0.09 \\
\hline $\begin{array}{l}\text { Percentage of } \\
\text { women }\end{array}$ & 22 & 0.00 & 0.00 & 0.66 \\
\hline $\begin{array}{l}\text { \# counseling } \\
\text { sessions }\end{array}$ & 18 & 0.02 & 0.01 & 0.01 \\
\hline
\end{tabular}

Note. $k=$ number of studies 


\section{Table 4.8.}

Assessment of Bias Using the PEDro Scale

\begin{tabular}{|c|c|c|c|c|c|c|c|c|c|c|c|}
\hline PEDro Criteria & $\begin{array}{l}\text { Eligibility } \\
\text { criteria } \\
\text { specified }\end{array}$ & $\begin{array}{l}\text { Subjects } \\
\text { randomly } \\
\text { allocated } \\
\text { to groups }\end{array}$ & $\begin{array}{l}\text { Allocation } \\
\text { concealed }\end{array}$ & $\begin{array}{l}\text { Groups } \\
\text { similar } \\
\text { at } \\
\text { baseline }\end{array}$ & $\begin{array}{l}\text { Subjects } \\
\text { blinded }\end{array}$ & $\begin{array}{l}\text { Interventionist } \\
\text { blinded }\end{array}$ & $\begin{array}{l}\text { Assessors } \\
\text { blinded }\end{array}$ & $\begin{array}{l}>85 \% \text { of } \\
\text { key } \\
\text { outcome } \\
\text { measured }\end{array}$ & $\begin{array}{l}\text { Intention- } \\
\text { to-treat } \\
\text { analysis } \\
\text { on } \\
\text { outcome }\end{array}$ & $\begin{array}{l}\text { Between- } \\
\text { group } \\
\text { comparison } \\
\text { outcome }\end{array}$ & $\begin{array}{l}\text { Point } \\
\text { measures/ } \\
\text { measure } \\
\text { variability }\end{array}$ \\
\hline $\begin{array}{l}\text { Burton et al., } \\
1995\end{array}$ & Yes & Yes & No & Yes & No & No & No & Yes & No & Yes & Yes \\
\hline $\begin{array}{l}\text { Campbell et } \\
\text { al., } 1999\end{array}$ & Yes & Yes & No & Yes & No & No & No & Yes & Yes & Yes & Yes \\
\hline $\begin{array}{l}\text { Coultas et } \\
\text { al., (2018) }\end{array}$ & Yes & Yes & Yes & Yes & No & No & Yes & No & No & Yes & Yes \\
\hline $\begin{array}{l}\text { Dolovich et } \\
\text { al., (2019) }\end{array}$ & Yes & Yes & Yes & Yes & No & No & No & Yes & Yes & Yes & Yes \\
\hline $\begin{array}{l}\text { Dubbert et } \\
\text { al., (2008) }\end{array}$ & Yes & Yes & No & Yes & No & No & Yes & Yes & Yes & Yes & Yes \\
\hline $\begin{array}{l}\text { Herghelegiu } \\
\text { et al., } \\
(2017)\end{array}$ & Yes & Yes & No & Yes & No & Yes & Yes & Yes & No & Yes & Yes \\
\hline $\begin{array}{l}\text { Illife et al., } \\
\text { (2014) }\end{array}$ & Yes & Yes & No & Yes & No & No & No & Yes & Yes & Yes & Yes \\
\hline $\begin{array}{l}\text { Kerse et al., } \\
(2005)\end{array}$ & Yes & Yes & No & Yes & No & No & No & Yes & Yes & Yes & Yes \\
\hline $\begin{array}{l}\text { Kerse et al., } \\
\text { (1999) }\end{array}$ & Yes & Yes & No & Yes & No & No & Yes & Yes & Yes & Yes & Yes \\
\hline $\begin{array}{l}\text { Kolt et al., } \\
\text { (2007) }\end{array}$ & Yes & Yes & No & Yes & No & No & No & Yes & No & Yes & Yes \\
\hline $\begin{array}{l}\text { McMurdo, et } \\
\text { al., (2010) }\end{array}$ & Yes & Yes & No & Yes & No & No & Yes & Yes & Yes & Yes & Yes \\
\hline $\begin{array}{l}\text { Morey et } \\
\text { al., (2009) }\end{array}$ & Yes & Yes & No & Yes & No & No & No & Yes & No & Yes & Yes \\
\hline Morey et & Yes & Yes & No & Yes & No & No & Yes & Yes & No & Yes & Yes \\
\hline
\end{tabular}




\begin{tabular}{|c|c|c|c|c|c|c|c|c|c|c|c|}
\hline \multirow{2}{*}{$\begin{array}{l}\text { al., (2006) } \\
\text { PEDro Criteria }\end{array}$} & \multirow[b]{2}{*}{$\begin{array}{l}\text { Eligibilit } \\
\text { y criteria } \\
\text { specifie } \\
\text { d }\end{array}$} & \multirow[b]{2}{*}{$\begin{array}{l}\text { Subjects } \\
\text { randoml } \\
y \\
\text { allocated } \\
\text { to } \\
\text { groups }\end{array}$} & \multirow[b]{2}{*}{$\begin{array}{l}\text { Allocatio } \\
n \\
\text { conceale } \\
d\end{array}$} & \multirow[b]{2}{*}{$\begin{array}{l}\text { Groups } \\
\text { similar } \\
\text { at } \\
\text { baselin } \\
\text { e }\end{array}$} & \multirow[b]{2}{*}{$\begin{array}{l}\text { Subject } \\
\text { s } \\
\text { blinded }\end{array}$} & \multirow[b]{2}{*}{$\begin{array}{l}\text { Interventionis } \\
\mathrm{t} \text { blinded }\end{array}$} & \multirow[b]{2}{*}{$\begin{array}{l}\text { Assessor } \\
\text { s blinded }\end{array}$} & \multirow[b]{2}{*}{$\begin{array}{l}>85 \% \text { of } \\
\text { key } \\
\text { outcome } \\
\text { measure } \\
\text { d }\end{array}$} & \multirow[b]{2}{*}{$\begin{array}{l}\text { Intention } \\
\text {-to-treat } \\
\text { analysis } \\
\text { on } \\
\text { outcome }\end{array}$} & \multirow[b]{2}{*}{$\begin{array}{l}\text { Between- } \\
\text { group } \\
\text { compariso } \\
\text { n outcome }\end{array}$} & \multirow[b]{2}{*}{$\begin{array}{l}\text { Point } \\
\text { measures } \\
\text { / measure } \\
\text { variability }\end{array}$} \\
\hline & & & & & & & & & & & \\
\hline $\begin{array}{l}\text { Morgan et } \\
\text { al., (2019) }\end{array}$ & Yes & Yes & No & Yes & No & No & Yes & Yes & Yes & Yes & Yes \\
\hline $\begin{array}{l}\text { Mutrie et } \\
\text { al., (2012) }\end{array}$ & Yes & Yes & No & Yes & No & No & Yes & Yes & Yes & Yes & Yes \\
\hline $\begin{array}{l}\text { Pérula et } \\
\text { al., } 2012\end{array}$ & Yes & Yes & No & Yes & No & No & No & Yes & No & Yes & Yes \\
\hline $\begin{array}{l}\text { Sims, et al., } \\
\text { (1999) }\end{array}$ & Yes & Yes & No & Yes & No & No & No & Yes & No & Yes & Yes \\
\hline $\begin{array}{l}\text { Tarazona et } \\
\text { al., (2016) }\end{array}$ & Yes & Yes & Yes & Yes & No & No & No & No & Yes & Yes & Yes \\
\hline $\begin{array}{l}\text { Weinstock } \\
\text { et al., 2011) }\end{array}$ & Yes & Yes & No & Yes & No & No & No & Yes & No & Yes & Yes \\
\hline $\begin{array}{l}\text { Witham et } \\
\text { al., (2012) }\end{array}$ & Yes & Yes & No & Yes & No & No & Yes & No & Yes & Yes & Yes \\
\hline
\end{tabular}


Figure 4.1

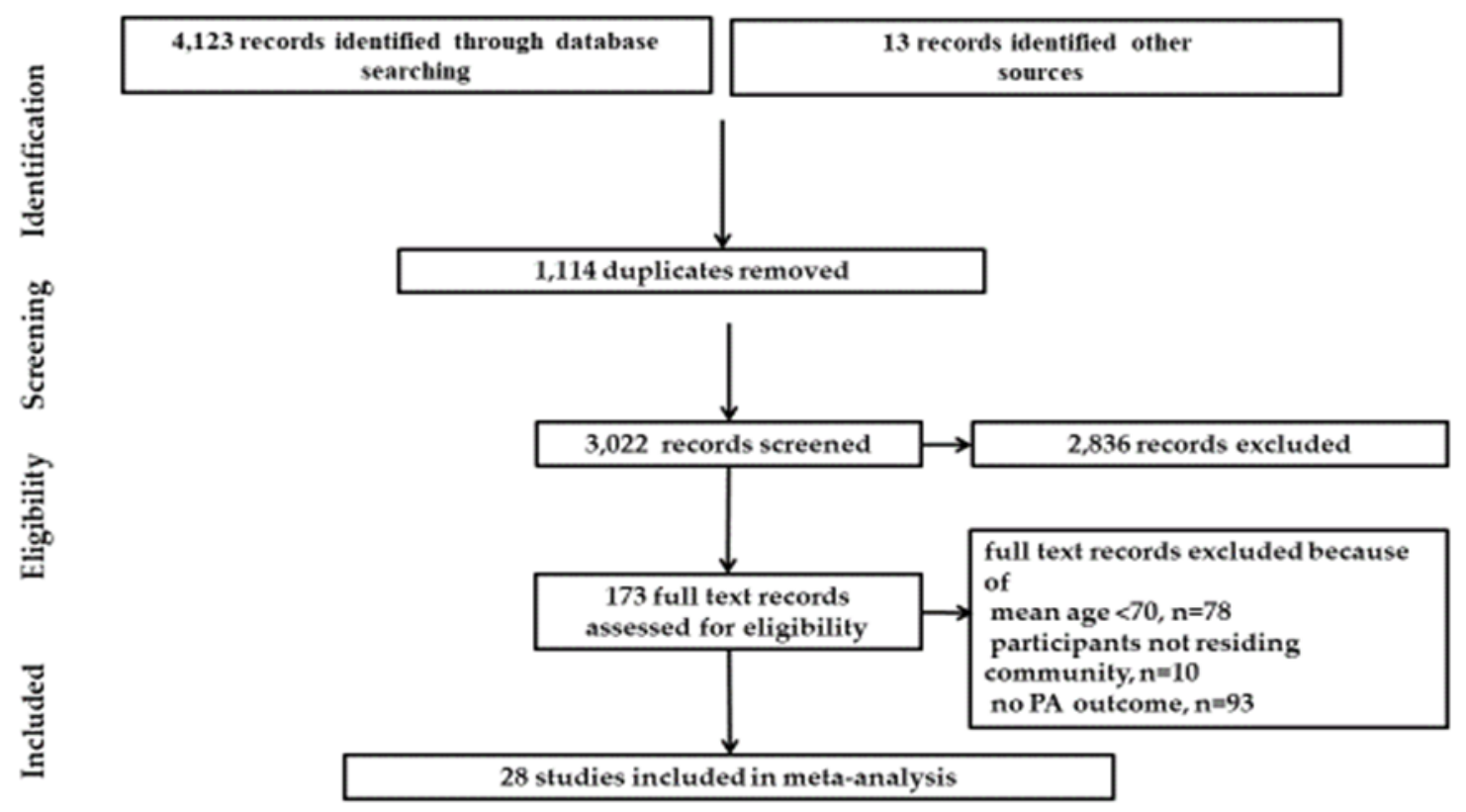

Flow diagram of meta-analysis study selection.

Note: PA=physical activity. Adapted from Moher D, Liberati A, Tetzlaff J, Atman DG, PRISMA

Group (2009). Preferred Reporting Items for Systematic Reviews and Meta-Analyses: The

PRISMA Statement. PLoS Medicine, 6(6), e1000097. doi:10.1371/journal.pmed1000097dapted 
Figure 4.2

Forest Plot

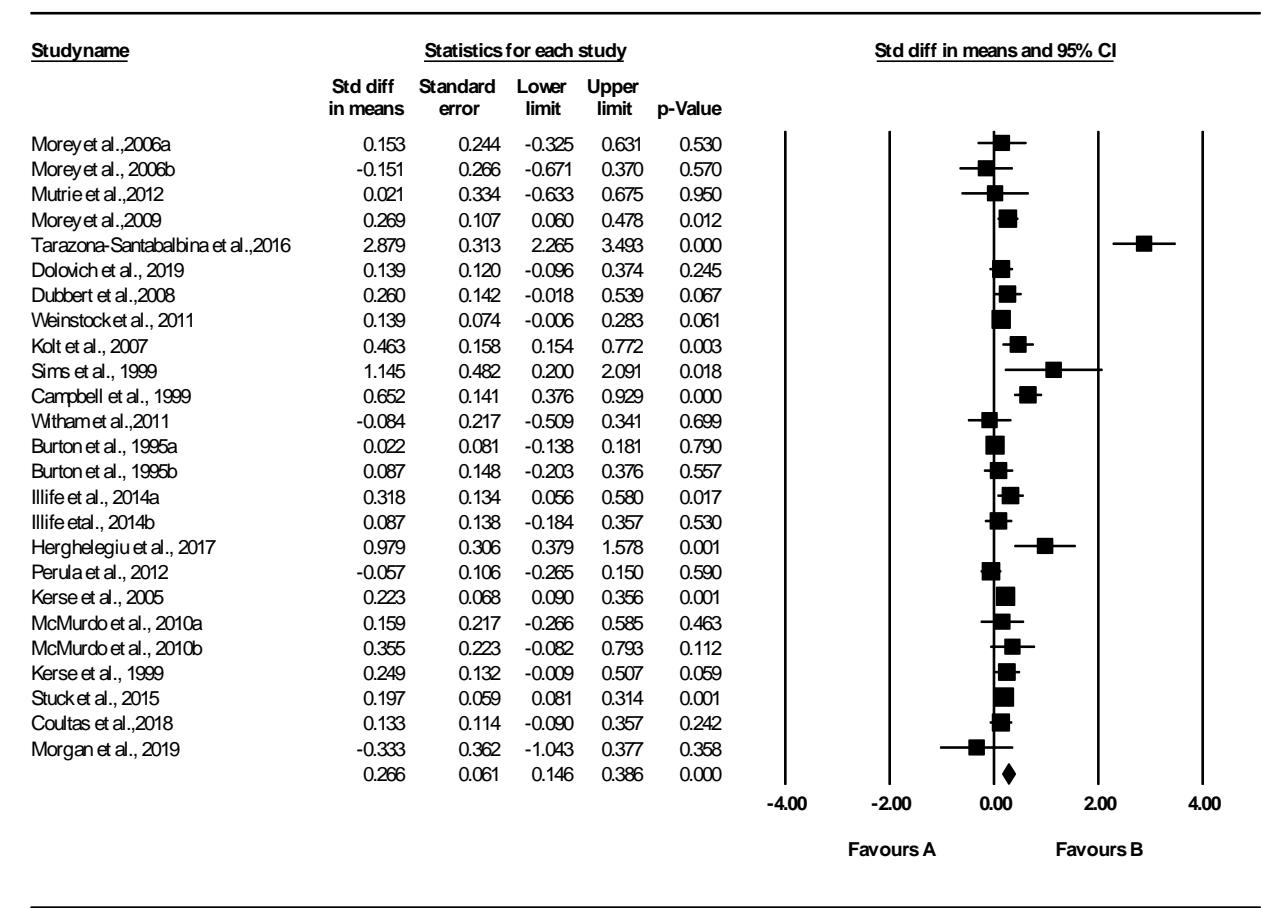

Meta Analysis

Note. Forest plot of 2-group post-test physical activity outcomes. Random effects size model used for calculation. Rectangles denote proportion of study weight. Table 4.3 details effect size for the two-group comparisons, as well as the pre-post comparisons. 
Figure 4.3

Funnel Plot of Publication Bias.

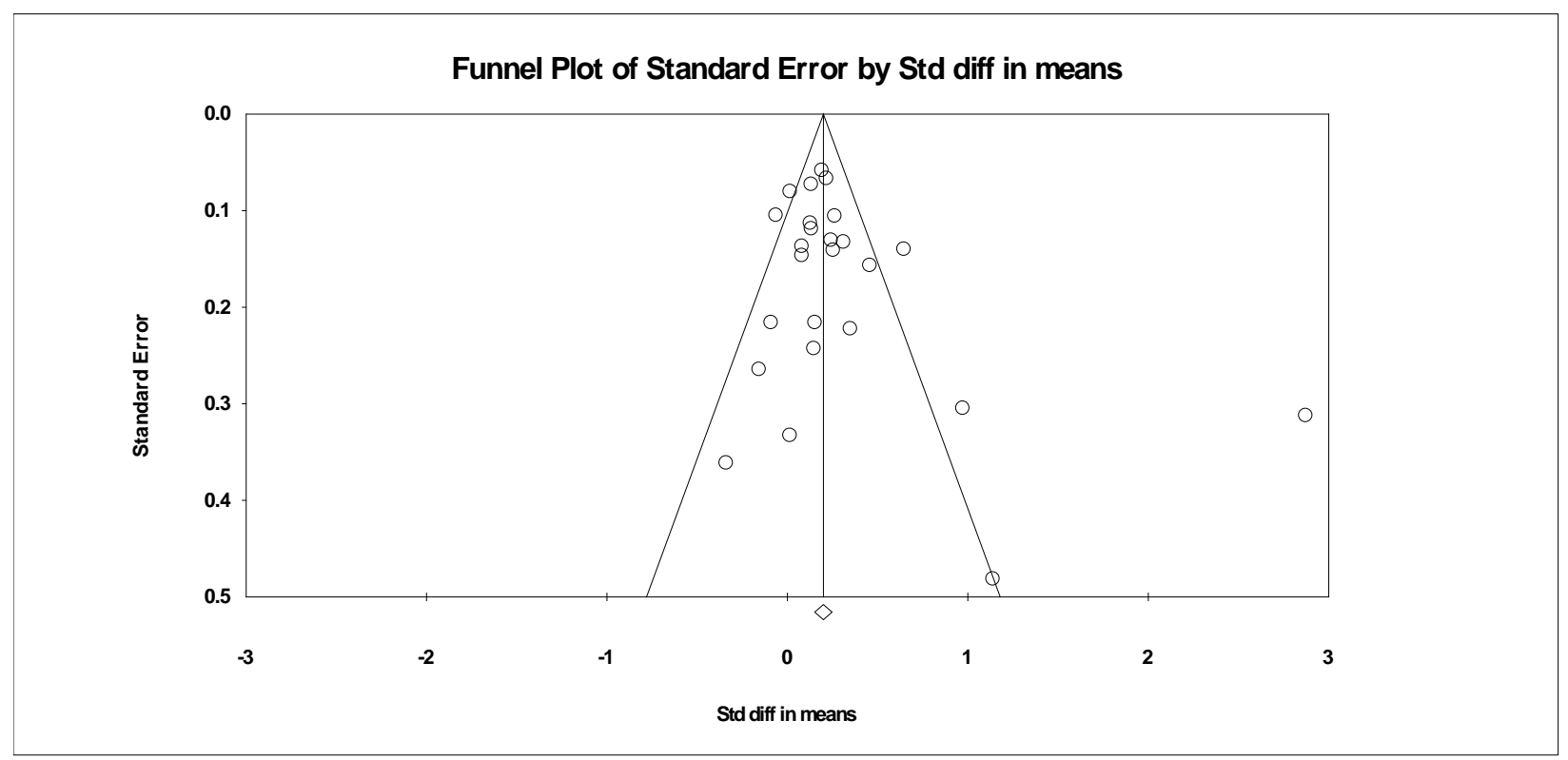

Note. Funnel plot indicates the presence of publication bias. Egger's regression was not statistically significant $(t=1.6, p<0.12)$. Classic Fail-safe $\mathrm{N}$ reports that 451 studies would be needed to yield an insignificant $\mathrm{p}$ value. 


\section{References}

Aoyama, M., Suzuki, Y., \& Kuzuya, M. (2015). Muscle strength of lower extremities related to incidence falls in community dwelling older adults. Gerontology and Geriatric Research, 4(2). DOI: 10. 4172/2167-7182.

August, K. J. \& Sorkin, D. H. (2011). Racial/ethnic disparities in exercise and dietary behaviors of middle-aged and older adults. Journal of general internal medicine, 26(3), 245-250. doi:10.1007/s11606-010-1514-7

Avilia, M.P.W., Correa, J.C., Lucchetti, A.L.G. \& Lucchetti, G. (2016). The role of physical activity in the association between resilience and mental health in older adults. Journal of Aging and Physical Activity, 26(2), 248-253. https://doi.org/10.1123/japa.2016-0332

Baert, V., Gorus, E., Mets, T., Geerts, C., \& Bautmans, I. (2011). Motivators and barriers for physical activity in the oldest old: A systematic review. Ageing Research Reviews, 10(4), 464-474. https://doi.org/10.1016/j.arr.2011.04.001

Banda, J. A., Hutto, B., Feeney, A., Pfeiffer, K. A., McIver, K., Lamonte, M. J., Blair, S. N., Vena, J., \& Hooker, S. P. (2010). Comparing physical activity measures in a diverse group of midlife and older adults. Medicine and science in sports and exercise, 42(12), 2251-2257. https://doi.org/10.1249/MSS.0b013e3181e32e9a

Bardach, S. \& Schoenberg, N. (2018). The role of primary care providers in encouraging older patients to change their lifestyle behavior. Clinical Gerontologist, 41(4), 326-334. Doi: $10.1080 / 07317115.2017 .1376029$ 
Bickmore, T. W., Silliman, R. A., Nelson, K., Cheng, D. M., Winter, M., Henault, L., \& Paasche-Orlow, M. K. (2013). A randomized controlled trial of an automated exercise coach for older adults. Journal of the American Geriatrics Society, 61(10), 1676-1683. https://doi.org/10.1111/jgs.12449

Borenstein, M., Hedges, L., Higgins, J., \& Rothstein, H. (2010). A basic introduction to fixedeffect and random-effects models for meta-analysis. Research Synthesis Methods, 1, 97111.

Borenstein, M., Hedges, L.V., Higgins, J., \& Rothstein, H. (2005). Comprehensive metaanalysis, version 2. Englewood, NJ: Biostat.

Borenstein, M., Hedges, L., Higgins, J., \& Rothstein, H. (2009). Introduction to meta-analysis. West Sussex: Wiley.

Buscemi, N., Hartling, L., Vandermeer, B., Tjosvold, L., \& Klassen, T. P. (2006). Single data extraction generated more errors than double data extraction in systematic reviews. Journal of Clinical Epidemiology, 59(7), 697-703.

Campbell, A.J., Robertson, M.C., Gardner, M.M., Norton, R.N., Buchner, D.N. (1999). Fall prevention over two years: A randomized controlled trial in women 80 years and older. Age and Ageing, 28, 513-518.

Center for Disease Control (2018). Summary health statistics: National health interview survey. Retrieved from https://ftp. cdc. gov/pub/Health_Statistics/NCHS/NHIS/SHS/2018_SHS_Table_C-8.pdf 
Center for Disease Control (2017). Health and economic costs of chronic disease. Retrieved from https://www. cdc. gov/chronicdisease/about/costs/index. htm

Chase, J.D. (2015). Interventions to increase physical activity among older adults: A metaanalysis, The Gerontologist, 55(4), 706-718. https://doi. org/10. 1093/geront/gnu090

Chan, A. W. \& Altman, D. G. (2005). Identifying outcome reporting bias in randomised trials on PubMed: review of publications and survey of authors. BMJ (Clinical research ed.), 330(7494), 753. https://doi.org/10.1136/bmj.38356.424606.8F

Cohen J. (1988). Statistical power analysis for the behavioral sciences (2nd ed.). Hillsdale, NJ: Lawrence Earlbaum Associates.

Conn, V., Hafdahl, A.R., Mehr, D.R. (2011). Interventions to increase physical activity among healthy adults: Meta-analysis of outcomes, American Journal of Public Health 101(4) 751-758. https://doi.org/10.2105/AJPH.2010.194381Conn, V. S., \& Rantz, M. J. (2003). Focus on research methods. Research methods: Managing primary study quality in metaanalyses. Research in Nursing and Health, 26(4), 322-333

Conn, V.S., Valentine, J.C., \& Cooper, H.M. (2002). Interventions to increase physical activity among aging adults: a meta-analysis. Annals of Behavioral Medicine, 24, 190-200. PubMed doi:10.1207/S15324796ABM2403_04

Conn, V. S., \& Rantz, M. J. (2003). Focus on research methods. Research methods: Managing primary study quality in meta-analyses. Research in Nursing and Health, 26(4), 322-333.

Cooper, H. (2017). Research synthesis and meta-analysis. 5th Ed. Thousand Oaks, CA: Sage Publications. 
Cooper, H., Hedges, L., \& Valentine, J. C. (2019). Research synthesis as a scientific process. In Cooper, H., Hedges,L. \& Valentine, J. C.(eds). The Handbook of research and metaanalysis. Russel Sage Foundation: New York.

Costello, E., Kafchinski, M.,Vrazel, J. Sullivan, P. (2011). Motivators, barriers, and beliefs regarding physical activity in an older adult population, Journal of Geriatric Physical Therapy,34( 3),138-147 doi: 10.1519/JPT.0b013e31820e0e71

Coultas, D. B., Jackson, B. E., Russo, R., Peoples, J., Singh, K. P., Sloan, J., Uhm, M., Ashmore, J. A., Blair, S. N., \& Bae, S. (2018). Home-based physical activity coaching, physical activity, and health care utilization in chronic obstructive pulmonary disease. Chronic obstructive pulmonary disease self-management activation research trial secondary outcomes. Annals of the American Thoracic Society, 15(4), 470-478. https://doi.org/10.1513/AnnalsATS.201704-308OC

da Costa, B.R., Jüni, P., (2014)Systematic reviews and meta-analyses of randomized trials: principles and pitfalls, European Heart Journal, 35(47) 33363345, https://doi.org/10.1093/eurheartj/ehu424

Deeks, J. J, Higgins, J.P.T., Altman, D.G. (2019). Chapter 10: Analysing data and undertaking meta-analyses. In Higgins, J.P.T., Thomas, J., Chandler, J., Cumpston, M., Li, T., Page, M.J., Welch, V.A. (editors). Cochrane Handbook for Systematic Reviews of Interventions version 6.0. www.training.cochrane.org/handbook

de Morton, N.A. (2009). The PEDro scale is a valid measure of the methodological quality of clinical trials: A demographic study. Australian Journal of Physiotherapy, 55(2), 129133. https://doi.org/10.1016/S0004-9514(09)70043-1 
Dubbert, P., Morey, M., Kirchner, K., Meydrech, E. \& Grothe, K. (2008). Counseling for homebased waking and strength exercise in older primary care patients. Archives of Internal Medicine, 168(9), 979-986. doi:10.1001/archinte.168.9.979

Fowles, J., O’Brien, M.W., Solmundson, K., Oh, P.I., \& Shields, C.A. (2018). Exercise is Medicine Canada physical activity counselling and exercise prescription training improves counselling, prescription, and referral practices among physicians across Canada. Applied Physiology, Nutrition and Metabolism, 43, 535-539. http://doi.org/10.1139/apnm-2017-0763

García-Hermoso, A. Ramirez-Vélez, R., Sález de Asteasu, M.L. Martínez-Velilla,N., ZambomFerraresi, Valenzuela, P.L., Lucia, A., \& Izquierdo, M. (2020). Safety and effectiveness of long term exercise interventions in older adults: A systematic review and metaanalysis of randomized controlled trials. Sports Medicine, 50, 1095-1106. https://doi.org/10.1007/s40279-020-01259-y

Gibbs, J.C., McArthur, C., Milligan, J., Clemson, L., Lee, L., Boscart, V.M., Heckman, G., Stolee, P., Giangregorio,, L.M. (2019). Measuring the implementation of lifestyle-integrated functional exercise in primary care for older adults: Results of a feasibility study. Canadian Journal of Aging, 38(3), 350-366. https://www.muse.jhu.edu/article/731700.

Huffman, M.K., Amireault, S. (2020). What Keeps Them Going, and What Gets Them Back? Older Adults’ Beliefs About Physical Activity Maintenance, The Gerontologist, gnaa087, https://doi-org.proxy.mul.missouri.edu/10.1093/geront/gnaa087 
Iliffe, S., Kendrick, D., Morris, R., Masud, T., Gage, H., Skelton, D., Dinan, S., Bowling, A., Griffin, M., Haworth, D., Swanwick, G., Carpenter, H., Kumar, A., Stevens, Z., Gawler ,S., Barlow, C., Cook, J., Belcher, C.(2014). Multicentre cluster randomised trial comparing a community group exercise programme and home-based exercise with usual care for people aged 65 years and over in primary care. Health Technol Assess 18(49. doi: 10.3310/hta18490. PMID: 25098959; PMCID: PMC4781144.

Kerse, N., Elley, R., Robinson, E., Arroll, B. (2005). Is physical activity counseling effective for older people? A randomized controlled trial in primary care. Journal of the American Geriatrics Society, 53(11), 1951-1956. https://doiorg.proxy.mul.missouri.edu/10.1111/j.1532-5415.2005.00466.x

Kerse, N.M., Flicker, L., Jolley, D., Arroll, B., Young, Y. (1999). Improving the health behaviours of elderly people: Randomized controlled trial of a general practice education programme. BMJ, 319, 683-687.

Kolt, G.S., Schofield, G.M., Kerse, N., Garrett, N., Ashton, T., Patel, A. (2012). Healthy steps trial: Pedometer based advice and physical activity for low active older adults. Annals of Family Medicine, 10(3).

Kolt, G.S., Schofield, G.M., Kerse, N., Garrett, N. and Oliver, M. (2007). Effect of telephone counseling on physical activity for low-active older people in primary care: A randomized controlled trial. Journal of the American Geriatrics Society, 55, 986-992. doi:10.1111/j.1532-5415.2007.01203.x

Livingston, G. (2019). Americans 60 and older are spending more time in front of their screens then a decade ago. Pew Research Center. https://www.pewresearch.org/fact- 
tank/2019/06/18/americans-60-and-older-are-spending-more-time-in-front-of-theirscreens-than-a-decadeago/?utm_source=Pew+Research+Center\&utm_campaign=041770d7ae-InternetScience_2019_06_27\&utm_medium=email\&utm_term=0_3e953b9b70-041770d7ae400310621

Mackenzie, L., \& Clemson, L. (2014). Can chronic disease management plans including occupational therapy and physiotherapy services contribute to reducing fall risk in older people? Australian Family Physician, 43(4). 211-216.

Maher, C.G., Sherrington, C., Herbert, R.D., Moseley, A.M., Elkins, A. (2003). Reliability of the PEDro scale for rating quality of randomized controlled trials, Physical Therapy, 83(8), 713-721. https://doi.org/10.1093/ptj/83.8.713

Märki, A., Bauer, G., Angst, F., Nigg, C., Gillmann, G., \& Gehring, T. (2006). Systematic counseling by general practitioners for promoting PA in elderly patients: A feasibility study. Swiss Medical Weekly, 136, 482-488. doi.org/10.1007/s00038-006-5065-y

Marques, A., Miguel, P., Martins, J., Gouveia, E., Valeiro, M. (2019). Cross-sectional and prospective relationship between low-to-moderate-intensity physical activity and chronic diseases in older adults from 13 European Countries, Journal of Human Kinetics, 27(1), 93-101. https://journals.humankinetics.com/view/journals/japa/27/1/article-p93.xml

Mathews, A., Jones, N., Thomas, A., van den Berg, P. \& Foster, C. (2017). An education programme influencing health professionasl to recommend exercise to their type 2 diabetes patients-understanding the processes: A case study from Oxfodshire, UK. BMC Health Services Research, 17(30). Doi 10.1186/s12913-017-2040-7 
McAuley, L., Pham, B., Tugwell, P., \& Moher, D. (2000). Does the inclusion of grey literature influence estimates of intervention effectiveness reported in meta-analyses? Lancet (London, England), 356(9237), 1228-1231. https://doi.org/10.1016/S01406736(00)02786-0

Michie, S., West, R., Spring, B. (2013). Moving from theory to practice and back in social and health psychology. American Psychology Association, 32(5), 581-585. https://doi.org/10.1037/a0030205

Moher, D., Liberati, A., Tetzlaff, J., \& Altman, D.G. (2009). Preferred reporting items for systematic reviews and meta-analyses: The PRISMA statement. Annals of Internal Medicine, 151(4), 264-269. doi: 10.7326/0003-4819-151-4-200908180-00135

Morey, M., Peterson, M. Pieper, C., Sloane, R., Crowley, G., Cowper, P., McConnell, E., Bosworth, H., Ekelund, C., \& Pearson, M. (2009). The veterans learning to improve fitness and function elders' study: A randomized trial of primary care-based PA counseling for older men. Journal of the American Geriatric Society, 57(7), 1166-1174

Morey, M.C., Ekelund, C., Pearson, M., Crowley, G., Peterson, M., Sloane, R., Pieper, C., McConnell, E., \& Bosworth, H. (2006). Project LIFE: A partnership to increase physical activity in elders with multiple chronic illnesses. Journal of Physical Activity and Aging, 14, 324-343.

Olanrewaju, O., Kelly, S., Cowan, A., Brayne, C., \& Lafortune, L. (2016). Physical activity in community dwelling older people: A systematic review of reviews of interventions and Context. PLOS ONE, 11(12), 1-19. doi: 10.1371/journal.pone.0168614 
Orrow, G., Kinmonth, A.L., Sanderson, S., \& Sutton, S. (2012). Effectiveness of physical activity interventions based in primary care: Systematic review and meta-analysis of randomized controlled trials. British Medical Journal, 344. doi: https://doi.org/10.1136/bmj.e1389

Overdof, V., Kollia, B., Makarec, K. \& Alleva Szeles, C. (2016). The relationship between physical activity and depressive symptoms in healthy older women. Gerontology and Geriatric Medicine, 2, 1-8. https://doi.org/10.1177/2333721415626859

Parker, C.A. \& Ellis, R. (2016). Effect of electronic messaging on physical activity participation among older adults. Journal of Aging Research, 2016, https://doi.org/10.1155/2016/6171028

Pavey, T.J., Fox, K.R., Anokye, N., Green, C., Mutrie, N., \& Trueman, P. (2011). Effect of exercise referral schemes in primary care on physical activity and improving health outcomes: Systematic review and meta-analysis. British Medical Journal, 343. doi: https://doi.org/10.1136/bmj.d6462

Pérula, L.A., Varas-Fabra, F., Rodriquez, V., Ruiz-Moral, R., Fernandez, J.A., Gonzalez, J., Perula, C.J., Roldan, A.M., \& de Dios, C. (2012). Effectiveness of a multifactorial intervention among community-living older adults: A randomized controlled trial. Archives of Physical Medicine and Rehabilitation, 93(10). 1677-1684. https://doi.org/10.1016/j.apmr.2012.03.035

Petrella, R. J., Lattanzio, C. N., Shapiro, S., \& Overend, T. (2010). Improving aerobic fitness in older adults: effects of a physician-based exercise counseling and prescription program. Canadian family physician,56(5), e191-e200. 
Pfeiffer, B., Clay, S., \& Conaster, R. (2001). A green prescription study: Does written exercise prescribed by a physician result in increased physical activity among older adults. Journal of Aging and Health, 13(4), 527-538. https://doi.org/10.1177\%2F089826430101300405

Sallis, J. F. \& Saelens, B. E. (2000). Assessment of physical activity by self-report: Status, limitations, and further directions. Research Quarterly for Exercise and Sport, 71(2), S1.doi: $10.1080 / 02701367.2000 .11082780$

Schutzer, K. \& Graves, S. (2004). Barriers and motivations to exercise in older adults. Preventive Medicine, 39, 1056-1061.

Sims, J., Smith, F., Duffy, A. \& Hilton, S. (1999). The vagaries of self-reports of physical activity: A problem revisited and addressed in a study of exercise promotion in the over 65s in general practice. Family Practice, 16(2), 152-157. Doi: 10.1093/fampra/16.2.152

Stevens, Z., Barlow, C., Kendrick, D., Masud, T., Skelton, D., Dinan-Young, S., \& Iliffe, S. (2014). Effectiveness of general practice-based physical activity promotion for older adults: Systematic review. Primary Health Care Research \& Development, 15(2), 190201. doi:10.1017/S1463423613000017

Stuck AE, Moser A, Morf U, Wirz U, \& Wyser J, et al. (2015) Effect of Health Risk Assessment and Counselling on Health Behaviour and Survival in Older People: A Pragmatic Randomised Trial. PLOS Medicine 12(10). e1001889. https://doi.org/10.1371/journal.pmed.1001889

Tarazona-Santabalina, F. J. Gómez-Cabrera, M.C., Pérez-Ros, P., Martínez-Arnau, F.M., Cabo, H., Tsaparas, K., Salvador-Pascual, A., Rodriguez-Mañas, L., \& Viña, J. (2016). A 
multicomponent exercise intervention that reverses frailty and improves cognition, emotion, and social networking in the community-dwelling frail elderly: A randomized clinical trial. JAMDA, 17(5). 426-433. http://dx.doi.org/10.1016/j.jamda.2016.01.019

United States Department of Health and Human Serviced (2018). 2017 profile of older Americans. Administration of Community Living, Administration on Aging. https://acl.gov/sites/default/files/Aging\%20and\%20Disability\%20in\%20America/2017Ol derAmericansProfile.pdf

Verhagen, A. P., de Vet, H. C., de Bie, R. A., Kessels, A. G., Boers, M., Bouter, L. M. \& Knipschild, P. G. (1998). The Delphi list: A criteria list for quality assessment of randomised clinical trials for conducting systematic reviews developed by Delphi consensus. Journal of Clinical Epidemiology,51(12):1235-41). 10. 1016/s08954356(98)00131-0

Vevea, J., Coburn, K. \& Sutton, A. (2019). Heterogeneity in meta-analysis. In Cooper, H., Hedges, L. \& Valentine, J. C. (Eds.). The Handbook of research and meta-analysis. New York: Russel Sage Foundation

Weinstock, R.S., Brooks, G., Palmas, W., Morin, P.C., Teresi, J.A., Eimicke, J.P., Silver, S/. Izquierdo, R., Goland, R., \& Shea, S. Lessened decline in physical activity and impairment of older adults with diabetes with telemedicine and pedometer use: results from the IDEATel study, Age and Ageing, 40(1)98-105 https://doi.org/10.1093/ageing/afq147

Witham, M.D., Fulton, R.L., Creig, C.A. Johnston, D.W., Lang, C.C., van der Pol, M., Boyers, D., Struthers, A.D., \& McMurdo, M.E.T. (2012). Efficacy and cost of an exercise 
program for functionally impaired older patients with heart failure: A randomized controlled trial. Circulation: Heart Failure, 5, 209-216. https://doi.org/10.1161/CIRCHEARTFAILURE.111.963132

World Health Organizations (2018). Global Action Plan for the Prevention of Noncommunicable Diseases 2013-2020, http://africahealthforum.afro.who.int/firstedition/IMG/pdf/global_action_plan_for_the_prevention_and_control_of_ncds_20132020.pdf

World Health Organization (2019). Primary Health Care. Retrieved from https://www.who.int/news-room/fact-sheets/detail/primary-health-care 


\section{CHAPTER 5}

SUMMARY

Motivating older adults to participate in PA is a global problem as evidenced by the number of countries represented in the studies reviewed for this dissertation research. Older adults should participate in 150 minutes of moderate activity, but many older adults do not meet these requirements (United States Department of Health and Human Services (USDHHS), 2018). Increasing participation in PA for the older adults has multiple physical and psychological benefits, including preventing disease, promoting independence, and maintaining cognition (Marques et al., 2019; Ramos et al., 2019; Reis et al., 2019). The results of this systematic review and meta-analysis demonstrate that PA interventions used in primary care are effective for increasing levels of PA in older adults.

\section{Effects of Primary Care Interventions}

The many benefits of participation in PA for the older adult make a compelling case for incorporating PA interventions into primary care. Primary care providers are accustomed to providing health promotion measures, as well as care based on the effects of lifestyle choices. Primary care providers have the benefit of multiple interactions with the older adult patient so interventions can be provided during care. Finding interventions that are effective and that can be provided economically are an important aspect of promoting PA in older adults.

This meta-analysis demonstrated an overall effect size of $0.27(p=0.00)$ representing a small-to-moderate positive effect for interventions used in primary care to facilitate PA. This positive effect size (ES) indicates that interventions used in primary care to promote PA are effective. This ES represents a clinically significant positive change in the health of older adults as the result of primary care intervention. Previous research has found that small increases in PA 
can have positive effects in the health of older adults (Marques et al., 2019; Orrow et al., 2012).

This meta-analysis yielded similar results to other meta-analysis describing PA interventions by Chase $(d=0.18)$ and by Conn et al. $(d=0.19)$ (Chase, 2015; Conn et al., 2011).

\section{Interventions}

Frequently used interventions include goal setting, barrier management, risk assessment tools, pedometers, motivational interviewing, action planning, feedback, and exercise diaries. Primary care providers should use a variety of interventions when promoting PA in older adults as more intensive interventions are generally more successful (Conn, et al., 2002). Receiving written materials is generally appreciated by the older adult (Pfeiffer, et al., 2001). The use of theory as a basis for interventions did not positively affect the effect size of the individual studies in this meta-analysis. However, studies often did not explicitly state how consistently or completely the theory was applied to the intervention. Unfortunately, the use of theory is often not well articulated in intervention studies and how the researchers operationalize the theory is often not described (Michie \& Prestwich, 2010). Common theories used in the studies in this meta-analysis included the transtheoretical model of change and social cognitive theory.

\section{Delivery Methods}

Researchers used a variety of delivery methods to deliver their interventions including inperson sessions, telehealth, live phone calls and automated phone calls (Dubbert et al., 2008; Morey et al., 2009; Coultas et al., 2018). When interventions involved a higher number of counseling sessions they were more effective. Fortunately, primary care providers have the flexibility of providing interventions in person or by phone to help manage time restraints. Technological advances and the increasing ability of the older adult to navigate technology may 
provide convenient, economical and effective intervention delivery options in the future. The use of technology in the future may help to reduce amount of time needed to provide interventions.

\section{Interventionists}

Another way to reduce the time burden of providing interventions is to utilize an interdisciplinary team to provide interventions. While physicians are a source of support and encouragement to their patients, referring to exercise specialists such as physical and occupational therapists is a good option. These referrals have the benefit of positive influence of physician approval combined with the expertise of providers that are experts in the field of exercise. Older adults value the expertise these exercise experts can provide. Utilizing exercise specialists can help improve the older adult's self-efficacy for exercise thus reducing another potential barrier. The most common barrier to PA is poor health (Baert et al., 2011). Understandably, this meta-analysis found that those studies than enrolled patients with chronic conditions had less of an effect on PA levels.

Nurses were interventionists in many of the studies often in conjunction with the physician. Utilizing ancillary personnel such as nurses, health counselors, exercise trainers and volunteers to deliver PA interventions can free up time for the primary care. Peer support and peer leaders hold promise as exercise interventionists and have the added benefit of improving socialization for the older adult (Gibbs et al., 2019; Kerr et al., 2018; Illife et al., 2014). Further studies are needed to explore the effectiveness of these interventionists.

\section{Conclusion}

Promoting healthy behaviors in primary care is a difficult and complicated process and, when the patient is an older adult, it adds additional challenges. The primary care provider is a 
trusted source of health information for the older adult and has the potential to provide effective PA interventions. Primary care PA intervention can improve levels of PA to impact the health of older adults and are an important part of health promotion. A variety of behavior change strategies and techniques can contribute to the overall effectiveness of interventions. Future research is needed to incorporate technological advances into PA interventions, as well as the enrollment of participants of color and adults $\geq 85$. Future research should also examine health care cost savings related to increasing PA in older adults to provide support for incentives for proving PA interventions. Interventions offered in primary have the potential to promote PA in older adults using a team approach and drawing on the primary care provider's experience and expertise in health promotion. 


\section{References}

Baert, V., Gorus, E., Mets, T., Geerts, C., \& Bautmans, I. (2011). Motivators and barriers for physical activity in the oldest old: A systematic review. Ageing Research Reviews, 10(4), 464-474. https://doi.org/10.1016/j.arr.2011.04.001

Chang, YC, Lu M-C, Hu I-H, Wu, W-C.I., \& Hu, S.C. (2017). Effects of different amounts of exercise on preventing depressive symptoms in community dwelling older adults: A prospective cohort study in Taiwan. BMJ Open, 7(e014256). doi:10.1136/ bmjopen2016-014256

Chase, J.D. (2015). Interventions to increase physical activity among older adults: A metaanalysis. The Gerontologist, 55(4), 706-718. https://doi. org/10. 1093/geront/gnu090

Conn, V., Hafdahl, A.R., \& Mehr, D.R. (2011). Interventions to increase physical activity among healthy adults: Meta-analysis of outcomes. American Journal of Public Health 101(4) 751-758. https://doi.org/10.2105/AJPH.2010.194381

Conn, V.S., Valentine, J.C., \& Cooper, H.M. (2002). Interventions to increase physical activity among aging adults: a meta-analysis. Annals of Behavioral Medicine, 24, 190-200. PubMed doi:10.1207/S15324796ABM2403_04

Coultas, D. B., Jackson, B. E., Russo, R., Peoples, J., Singh, K. P., Sloan, J., Uhm, M., Ashmore, J. A., Blair, S. N., \& Bae, S. (2018). Home-based physical activity coaching, physical activity, and health care utilization in chronic obstructive pulmonary disease. Chronic Obstructive Pulmonary Disease Self-Management Activation Research Trial Secondary Outcomes. Annals of the American Thoracic Society, 15(4), 470-478. https://doi.org/10.1513/AnnalsATS.201704-308OC 
Dubbert, P., Morey, M., Kirchner, K., Meydrech, E., \& Grothe, K. (2008). Counseling for homebased waking and strength exercise in older primary care patients. Archives of Internal Medicine, 168(9), 979-986. doi:10.1001/archinte.168.9.979

Gibbs, J.C., McArthur, C., Milligan, J., Clemson, L., Lee, L., Boscart, V.M., Heckman, G., Stolee, P., \& Giangregorio, L.M. (2019). Measuring the implementation of lifestyle-integrated functional exercise in primary care for older adults: Results of a feasibility study. Canadian Journal of Aging, 38(3), 350-366. https://www.muse.jhu.edu/article/731700.

Iliffe, S., Kendrick, D., Morris, R., Masud, T., Gage, H., Skelton, D., Dinan, S., Bowling, A., Griffin, M., Haworth, D., Swanwick, G., Carpenter, H., Kumar, A., Stevens, Z., Gawler ,S., Barlow, C., Cook, J., \& Belcher, C.(2014). Multicentre cluster randomised trial comparing a community group exercise programme and home-based exercise with usual care for people aged 65 years and over in primary care. Health Technol Assess 18(49. doi: 10.3310/hta18490. PMID: 25098959; PMCID: PMC4781144.

Kerse, N., Elley, R., Robinson, E., Arroll, B. (2005). Is physical activity counseling effective for older people? A randomized controlled trial in primary care. Journal of the American Geriatrics Society, 53(11), 1951-1956. https://doiorg.proxy.mul.missouri.edu/10.1111/j.1532-5415.2005.00466.x

Märki, A., Bauer, G., Angst, F., Nigg, C., Gillmann, G., \& Gehring, T. (2006). Systematic counseling by general practitioners for promoting PA in elderly patients: A feasibility study. Swiss Medical Weekly, 136, 482-488. doi.org/10.1007/s00038-006-5065-y

Marques, A., Miguel, P., Martins, J., Gouveia, E., \& Valeiro, M. (2019). Cross-sectional and prospective relationship between low-to-moderate-intensity physical activity and chronic 
diseases in older adults from 13 European Countries, Journal of Ageing and Physical Activity, 27(1), 93-101.

https://journals.humankinetics.com/view/journals/japa/27/1/article-p93.xml

Michie, S \& Prestwich, A. (2010) Are interventions theory-based? Development of a theory coding scheme. Health Psychology, 29 (1). 1 - 8 (8). http://eprints.whiterose.ac.uk/76353/

Morey, M.C., Ekelund, C., Pearson, M., Crowley, G., Peterson, M., Sloane, R., Pieper,C., McConnell, E., \& Bosworth, H. (2006). Project LIFE: A partnership to increase physical activity in elders with multiple chronic illnesses. Journal of Physical Activity and Aging, 14, 324-343.

Orrow, G., Kinmonth, A.L., Sanderson, S., \& Sutton, S. (2012). Effectiveness of physical activity interventions based in primary care: Systematic review and meta-analysis of randomized controlled trials. British Medical Journal, 344. doi: https://doi.org/10.1136/bmj.e1389

Pfeiffer, B., Clay, S., Conaster, R. (2001). A green prescription study: Does written exercise prescribed by a physician result in increased physical activity among older adults .Journal of Aging and Health, 13(4), 527-538. https://doi.org/10.1177\%2F089826430101300405

Ramos, M., Lamotte, M., Gerlier, L., Sangre,, P., Miquel-Cases, A., Haughney, J. (2019). Costeffectiveness of physical activity in the management of COPD patients in the UK. International Journal of Chronic Obstructive Pulmonary Disease, 14, 227-239. Doi: 10.2147/COPD.s181194. 
Reis, E., Laughlin, G., Bergstrom, J., Kritz-Silverstein, D., Richard, E., Barrett-Connor, E., McEvoy, L. (2019). Lifetime physical activity and late-life cognitive function: The Rancho Bernardo study, Age and Ageing, 48(2), 241246, https://doi.org/10.1093/ageing/afy188

United States Department of Health and Human Serviced (2018). 2017 profile of older Americans. Administration of Community Living, Administration on Aging. https://acl.gov/sites/default/files/Aging\%20and\%20Disability\%20in\%20America/2017O1 OlderAmericansProfi.pdf 


\section{References}

American College of Sports Medicine (2019). Health care providers' action guide.

https://www.exerciseismedicine.org/assets/page_documents/EIM\%20Health\%20Care\%2 0Providers\%20Action\%20Guide\%20clickable\%20links.pdf

American College of Sports Medicine (ACSM). (2018). American college of sports medicine and exercise is medicine initiative support UN commitment to reducing non-communicable disease. https://www.acsm.org/read-research/newsroom/news-releases/newsdetail/2018/09/27/ACSM-EIM-support-United-Nations-commitment-reducingnoncommunicable-disease

Aoyama, M., Suzuki, Y., Kuzuya, M. (2015). Muscle strength of lower extremities related to incidence falls in community dwelling older adults. Gerontology and Geriatric Research, 4(2). DOI: $10.4172 / 2167-7182$.

Arkkukangas, M., Söderlund, A. , Eriksson, S. , \& Johansson, A. -C. (2019). Fall preventive exercise with or without behavior change support for community-dwelling older adults: A randomized controlled trial with short-term follow-up. Journal of Geriatric Physical Therapy, 42(1), 9-17. https://doi. org/10. 1519/JPT. 0000000000000129

August, K. J., \& Sorkin, D. H. (2011). Racial/ethnic disparities in exercise and dietary behaviors of middle-aged and older adults. Journal of General Internal Medicine, 26(3), 245-250. doi:10.1007/s11606-010-1514-7 
Avilia, M.P.W., Correa, J.C., Lucchetti, A.L.G. \& Lucchetti, G. (2016). The role of physical activity in the association between resilience and mental health in older adults. Journal of Aging and Physical Activity, 26(2), 248-253. https://doi.org/10.1123/japa.2016-0332

Bachman, A.S., Wilson, R.S., Yu, L., James, B.D., Boyle, P.A. \& Bennett, D. A. (2014). Total daily activity declines more rapidly with increasing age in older adults. Archives of Gerontology and Geriatrics, 58, 74-79. https://doi.org/10.1016/j.archger.2013.08.001

Baert, V., Gorus, E., Mets, T., Geerts, C., \& Bautmans, I. (2011). Motivators and barriers for physical activity in the oldest old: A systematic review. Ageing Research Reviews, 10(4), 464-474. https://doi.org/10.1016/j.arr.2011.04.001

Balde, A., Figueras, J., Hawking, D.A., \& Miller, J.R.(2003). Physician advice to the elderly about physical activity. Journal of Aging and Physical Activity, 11(1), 90-977. https://journals.humankinetics.com/view/journals/japa/11/1/article.p90.xml.

Banda, J. A., Hutto, B., Feeney, A., Pfeiffer, K. A., McIver, K., Lamonte, M. J., Blair, S. N., Vena, J., \& Hooker, S. P. (2010). Comparing physical activity measures in a diverse group of midlife and older adults. Medicine and science in sports and exercise, 42(12), 2251-2257. https://doi.org/10.1249/MSS.0b013e3181e32e9a

Bandura, A. (1997). Self-efficacy: The Exercise of Control. Macmillin.

Bardach, S. \& Schoenberg, N. (2018). The role of primary care providers in encouraging older patients to change their lifestyle behavior. Clinical Gerontologist, 41(4), 326-334. Doi: $10.1080 / 07317115.2017 .1376029$ 
Batcir, S. \& Melzer, I. (2018). Daily bicycling in older adults may be effective to reduce fall risks-A case-control study. Journal of Aging and Physical Activity, 26(4), 579-576. https://doi.org/10.1123/japa.2017-0263

Bauman, A., Merom, D., Bull, F. C. , Buchner, D. M. , Fiatarone Singh, M. A. (2016). Updating the evidence for physical activity: Summative reviews of the epidemiological evidence, prevalence, and interventions to promote "active aging". The Gerontologist, 56, (Supp 2), S268-280. https://doi. org/10. 1093/geront/gnw031

Bickmore, T. W., Silliman, R. A., Nelson, K., Cheng, D. M., Winter, M., Henault, L., \& Paasche-Orlow, M. K. (2013). A randomized controlled trial of an automated exercise coach for older adults. Journal of the American Geriatrics Society, 61(10), 1676-1683. https://doi.org/10.1111/jgs.12449

Bean, J., Vora, A., \& Frontera, W. (2004). Benefits of exercise for community dwelling older adults. Archives of Physical Medicine and Rehabilitation, 85(Supp 3), S31-42. doi: 10.1016/j.apmr.2004.03.010

Biedenweg, K., Meischke, H., Bohl, A., Hamerback, K., Williams, B., Poe, P., Phelan, E. (2013). Understanding older adults' motivators and barriers to participating in organized programs supporting exercise behaviors. Journal of Primary Prevention, 35(1), 1-11.

Blair S, Sallis R, Hutber A.\& Archer, E. (2012). Exercise therapy-the public health message. Scandinavian Journal of Medicine and Science in Sports, 22(4), 24-28. doi: 10.1111/j.1600-0838.2012.01462.x 
Bland, V., \& Sharma, M. (2017). Physical activity interventions in African American women: A systematic review. Health Promotion Perspectives, 7(2), 52-59. doi:10.15171/hpp.2017.11

Borenstein, M (2019). Heterogeneity in meta-analysis. In H. Cooper, L .Hedges \& J.C. Valentine, (eds.). The Handbook of research and meta-analysis. Russel Sage Foundation.

Borenstein, M., Hedges, L.V., Higgins, J., \& Rothstein, H., (2005). Comprehensive metaanalysis, version 2. Biostat.

Borenstein, M., Hedges, L., Higgins, J., \& Rothstein, H. (2010). A basic introduction to fixedeffect and random-effects models for meta-analysis. Research Synthesis Methods, 1, 97111.

Borenstein, M. , Hedges, L. , Higgins, J. , \& Rothstein, H. (2009). Introduction to meta-analysis. Wiley.

Brenen, M. (2018). Nurses again outpace other professions for honesty, ethics. Gallup. Retrieved from https://news.gallup.com/poll/245597/nurses-again-outpace-professionshonesty-ethics.aspx

Buscemi, N., Hartling, L., Vandermeer, B., Tjosvold, L., \& Klassen, T. P. (2006). Single data extraction generated more errors than double data extraction in systematic reviews. Journal of Clinical Epidemiology, 59(7), 697-703.

Campbell, A.J., Robertson, M.C., Gardner, M.M., Norton, R.N., Buchner, D.N.(1999). Fall prevention over two years: A randomized controlled trial in women 80 years and older. Age and Ageing, 28, 513-518. https://doi.org/10.1093/ageing/28.6.513 
Center for Disease Control and Prevention. (2020). Behavioral risk factor surveillance system. https://www.cdc.gov/brfss/index.html

Center for Disease Control (2019). STEADI Older adult fall prevention. Retrieved from https://www.cdc.gov/steadi/patient.html

Center for Disease Control (2018). Summary health statistics: National health interview survey. Retrieved from https://ftp. cdc. gov/pub/Health_Statistics/NCHS/NHIS/SHS/2018_SHS_Table_C-8.pdf

Center for Disease Control (2017). Health and economic costs of chronic disease. Retrieved from https://www.cdc.gov/chronicdisease/about/costs/index.htm

Center for Medicare and Medicaid (2019). Original Medicare and Medicaid (Part A and Part B eligibility and Enrollment. Retrieved from https://www.cms.gov/Medicare/Eligibilityand-Enrollment/OrigMedicarePartABEligEnrol

Chan, A. W., \& Altman, D. G. (2005). Identifying outcome reporting bias in randomised trials on PubMed: review of publications and survey of authors. BMJ (Clinical research ed.), 330(7494), 753. https://doi.org/10.1136/bmj.38356.424606.8F

Chase, J. D. (2015). Interventions to increase PA among older adults: A meta-analysis. The Gerontologist,55(4), 706-718. doi: 10.1093/geront/gnu090

Cohen J . (1988). Statistical power analysis for the behavioral sciences (2nd ed.). Lawrence Earlbaum Associates.

Conn, V., Hafdahl, A.R., Mehr, D.R. (2011). Interventions to increase physical activity among healthy adults: Meta-analysis of outcomes. American Journal of Public Health 101(4) 
751-758. https://doi.org/10.2105/AJPH.2010.194381Conn, V.\& and Rantz,M.J. (2003). Research methods: Managing primary study quality in meta analyses. Research in Nursing \& Health, 26, 322. DOI: 10.1002/nur.10092

Conn, V.S., Valentine, J.C., \& Cooper, H.M. (2002). Interventions to increase physical activity among aging adults: a meta-analysis. Annals of Behavioral Medicine, 24, 190-200. PubMed doi:10.1207/S15324796ABM2403_04

Cooper, H. (2017). Research synthesis and meta-analysis. (5th Ed). Sage Publications.

Cooper, H., Hedges, L. \& Valentine, J. C. (2019). Research synthesis as a scientific process. In Cooper, H., Hedges,L. \& Valentine, J. C.(eds). The Handbook of research and metaanalysis. Russel Sage Foundation.

Costello, E. Kafchinski, M.Vrazel, J.Sullivan, P. (2011). Motivators, barriers, and beliefs regarding physical activity in an older adult population, Journal of Geriatric Physical Therapy 34,3,138-147, doi: 10.1519/JPT.0b013e31820e0e71

Coultas, D. B., Jackson, B. E., Russo, R., Peoples, J., Singh, K. P., Sloan, J., Uhm, M., Ashmore, J. A., Blair, S. N., \& Bae, S. (2018). Home-based physical activity coaching, physical activity, and health care utilization in chronic obstructive pulmonary disease. chronic obstructive pulmonary disease self-management activation research trial secondary outcomes. Annals of the American Thoracic Society, 15(4), 470-478. https://doi.org/10.1513/AnnalsATS.201704-308OC

Cowper, P., Peterson, M., Pieper, C., Sloan, R., Hall, K.... Morey, M. (2017). Economic nalysis of primary care based physical activity counseling in older men: The VA-LIFE trial. Journal of the American Geriatrics Society, 65(3), 533-539. doi:10.1111/jgs.14567. 
da Costa, B.R., Jüni, P., (2014). Systematic reviews and meta-analyses of randomized trials: principles and pitfalls, European Heart Journal, 35(47) 33363345, https://doi.org/10.1093/eurheartj/ehu424

Dasso, N. (2018). How is exercise different than PA? A concept analysis. Nursing forum: An independent voice for nursing, 54(1), 45-52. doi: 10.1111/nuf.12296.

Deeks, J. J, Higgins, J.P.T., Altman, D.G. (2019). Chapter 10: Analysing data and undertaking meta-analyses. In J.P.T. Higgins, J. Thomas, J. Chandler, M. Cumpston, T. Li, M.J. Page, V.A. Welch, (Eds). Cochrane Handbook for Systematic Reviews of Interventions version 6.0. www.training.cochrane.org/handbook

de Morton, N.A. (2009). The PEDro scale is a valid measure of the methodological quality of clinical trials: A demographic study. Australian Journal of Physiotherapy, 55(2), 129133. https://doi.org/10.1016/S0004-9514(09)70043-1de sota Barereto, Rolland, Y., Cesari, M., Dupuy, C., Andrieu, S., Vellas, B., \& MAPT study group. (2018). Effects of multidomain lifestyle intervention, omega-3 supplementation or their combination on physical activity levels in older adults: Secondary analysis of the Multidomain Alzheimer Preventive Trial (MAPT) randomised controlled trial. Age and Ageing, 47(2), 281-288. https://doi.org/10.1093/ageing/afx164

de Vries, N. M., Staal, J. B., van der Wees, P. J., Adang, E. M. M., Akkermans, R., Olde Rikkert, M. G. M., \& Nijhuis-van der Sanden, M. W. G. (2016). Patient-centred physical therapy is (cost-) effective in increasing physical activity and reducing frailty in older adults with mobility problems: A randomized controlled trial with 6 months follow-up. Journal of Cachexia, Sarcopenia and Muscle, 7(4), 422-435. https://doi.org/10.1002/jcsm.12091 
Dubbert, P., Morey, M., Kirchner, K., Meydrech, E. \& Grothe, K. (2008). Counseling for homebased waking and strength exercise in older primary care patients. Archives of Internal Medicine, 168(9), 979-986. doi:10.1001/archinte.168.9.979

Fowles, J., O’Brien, M.W., Solmundson, K., Oh, P.I., Shields, C.A. (2018). Exercise is Medicine Canada physical activity counselling and exercise prescription training improves counselling, prescription and referral practices among physicians across Canada. Applied Physiology, Nutrition and Metabolism, 43, 535-539. http://doi.org/10.1139/apnm-20170763

García-Hermoso, A. Ramirez-Vélez, R., Sález de Asteasu, M.L. Martínez-Velilla,N., ZambomFerraresi, Valenzuela, P.L., Lucia, A., \& Izquierdo, M. (2020). Safety and effectiveness of long term exercise interventions in older adults: A systematic review and metaanalysis of randomized controlled trials. Sports Medicine, 50, 1095-1106. https://doi.org/10.1007/s40279-020-01259-y

Gibbs, J.C., McArthur, C., Milligan, J., Clemson, L., Lee, L., Boscart, V.M., Heckman, G., Stolee, P., Giangregorio,, L.M.(2019). Measuring the implementation of lifestyle-integrated functional exercise in primary care for older adults: Results of a feasibility study. Canadian Journal of Aging, 38(3), 350-366. https://www.muse.jhu.edu/article/731700.

Glanville, J. (2019). Searching bibliographical databases In Cooper, H., Hedges,L. \& Valentine, J. C.(eds). The Handbook of research and meta-analysis. Russel Sage Foundation: New York. 
Goldberg, D., Cho, B., Lin, H. (2019). Factors influencing U.S. physicians' decision to provide behavioral counseling. Preventive Medicine, 119, 70-76. https://doi.org/10.1016/j.ypmed.2018.12.015

González, K. , Fuentes, J. , \& Márquez, J. L. (2017). Physical inactivity, sedentary behavior and chronic disease. Korean Journal of Family Medicine, 38, 111-115. https://doi. org/10. 4082/kjfm. 2017. 38. 3. 111

Guure, C.B., Ibrahim, N.A., Adam, M.B. \& Sai, S.M. (2017). Research article impact of physical activity on cognitive decline, dementia, and its subtypes: Meta-analysis of prospective studies. Hindawi: BioMed Research International, 2017. https://doi.org/10.1155/2017/9016924

Harvey, S., Rissel, C., Pijnappels, M. (2018). Associations between bicycling and reduced fallrelted physical performance in older adults, 26, 514-519. https://doi.org/10.1123/japa.2017-0243

Hébert, E., Caughy, M. \& Shuval, K. (2012). Primary care providers' perceptions of physical activity counseling in a clinical setting: A systematic review. British Journal of Sports Medicine,46(9), 625-631. doi:10.1136/bjsports-2011-090734

Herghelegiu, A. M., Moser, A., Prada, G. I., Born, S., Wilhelm, M., \& Stuck, A. E. (2017). Effects of health risk assessment and counselling on physical activity in older people: A pragmatic randomised trial. PloS One, 12(7), e0181371. https://doi.org/10.1371/journal.pone.0181371 
Hoffman, G. , Hays, R. , Shapiro, M. , Wallace, S. , \& Ettner, S. (2017). The cost of fall-related injuries among older adults: Annual per-faller, service component and patient out-ofpocket costs. Health Service Research, 52(5), 1794-1816.

Huffman, M.K., Amireault, S. (2020).What Keeps Them Going, and What Gets Them Back? Older Adults' Beliefs About Physical Activity Maintenance, The Gerontologist, gnaa087, https://doi-org.proxy.mul.missouri.edu/10.1093/geront/gnaa087

Hutton, J. L. , \& Williamson, P. (2000). Bias in meta-analysis due to outcome variable selection within studies. Journal of the Royal Statistical Society, 49(3), 359-370.

Justin, M., Azizan, A., Hassan, V., Salleh, Z., Manaf, H. (2013). Barriers to participation in physical activity and exercise among middle-aged and elderly individuals. Singapore Medicine Journal, 54(10): 581-586 doi:10.11622/smedj.2013203

Kanfer, R., \& Kanfer, F. H. (1991). Goals and self-regulation: Applications of theory to work settings. In M. L. Maehr \& P. R. Pintrich (Eds.), Advances in Motivation and Achievement (Vol. 7, pp. 287-326). JAI Press

Kerr, J., Rosenberg, D., Millstein, R. A., Bolling, K., Crist, K., Takemoto, M., Godbole, S., Moran, K., Natarajan, L., Castro-Sweet, C., \& Buchner, D. (2018). Cluster randomized controlled trial of a multilevel physical activity intervention for older adults. The International Journal of Behavioral Nutrition and Physical Activity, 15(1), 32. https://doi.org/10.1186/s12966-018-0658-4

Kerse, N.M., Flicker, L., Jolley, D., Arroll, B., Young, Y. (1999). Improving the health behaviours of elderly people: Randomized controlled trial of a general practice education programme. $B M J, 319,683-687$. 
Kerse, N., Elley, R., Robinson, E., Arroll, B. (2005). Is physical activity counseling effective for older people? A randomized controlled trial in primary care. Journal of the American Geriatrics Society, 53(11), 1951-1956. https://doi-

org.proxy.mul.missouri.edu/10.1111/j.1532-5415.2005.00466.x

Knowles, M. (2018). Number of nurse practitioners in U.S. hits record high. Becker's Hospital Review. https://www.beckershospitalreview.com/workforce/number-of-nursepractitioners-in-us-hits-record-high.html

Kojima, G. (2018). Frailty of a predictor of nursing home placement among community dwelling older adults: A systematic review and meta-analysis. Journal of Geriatric Physical Therapy, 42(1), 42-48. doi: 10.1519/JPT.0000000000000097Kolt, G.S., Schofield, G.M., Kerse, N., Garrett, N. and Oliver, M. (2007). Effect of telephone counseling on physical activity for low-active older people in primary care: A randomized controlled trial. Journal of the American Geriatrics Society, 55, 986-992. doi:10.1111/j.15325415.2007.01203.x

Kolt, G. S. , Schofield, G. M. , Kerse, N. , Garrett, N. , Ashton, T. , \& Patel, A. (2012). Healthy steps trial: Pedometer-based advice and physical activity for low-active older adults. Annals of Family Medicine, 10(3), 206-212. Scopus. https://doi. org/10. 1370/afm. 1345

Kolt, G.S., Schofield, G.M., Kerse, N., Garrett, N. and Oliver, M. (2007). Effect of telephone counseling on physical activity for low-active older people in primary care: A randomized controlled trial. Journal of the American Geriatrics Society, 55, 986-992. doi:10.1111/j.1532-5415.2007.01203.x 
Kredlow, M.A., Capozzoli, M.C., Hearon, B. A., Calkins, A.W., Otto, M.W.(2015). The effects of physical activity on sleep: A meta-analytic review. Journal of Behavioral Medicine, $38,427-449$. DOI 10.1007/s10865-015-9617-6

Kyu, H., Bachman, V.F., Alexander,L.T., Mumford, J.E., Afshin,A., Estep, K., Veerman, J.L., Delwiche, K., Iannarone, M.L., Moyer, M.L., Cercy, K., Vos, T., Murray, C.J.L., Forouzanfar, M.H. (2016). Physical activity and risk of breast cancer, colon cancer, diabetes, ischemic heart disease, and ischemic stroke events: systematic review and doseresponse meta-analysis for the Global Burden of Disease Study 2013. BMJ 354(i3857). doi: 10.1136/bmj.i3857

Langlois, F. Vu, T. T. M. , Chasse, K. , Dupuis, G. Kergoat, M. J. (2012). Benefits of physical activity training on cognition and quality of life in frail older adults. Journals of Gerontology Series B: Psychological Services and Social Sciences, 68(3), 400-404. doi:10. 1093/geronb/gbs069.

Lee, P.G., Jackson, E.A., Richardson, C.R. (2017). Exercise prescription in older adults. American Academy of Family Physicians, 97(7), 425-432Li, I., Shiroma, E.J., Lobelo, F., Puska, P., Blair, S.N., \& Katzmarzyk, P.T. (2012). Effects of physical inactivity on major non-communicable diseases worldwide: An analysis of burden of disease and life expectancy. The Lancet, 380(9838). DOI: https://doi.org/10.1016/S0140-6736(12)610319

Lilienthal, K. R., Pignol, A. E., Holm, J. E., \& Vogeltanz-Holm, N. (2014). Telephone-based motivational interviewing to promote PA and stage of change progression in older adults. Journal of Physical Activity, 22(4), 527-535. doi. Org/10.1123/JAPA.2013- 
0056Lion, A., Vuillemin, A., Thornton, F., Theisen, D., Stranges, S. \& Ward, M. (2018). Physical activity promotion in primary care: A utopian quest? Health Promotion International, 34, 877-886. doi: 10.1093/heapro/day038.

Lipsey, M.W., \& Wilson, D.B. (2000). Practical Meta-Analysis. Thousand Oaks, CA: Sage Publications.

Livingston, G. (2019). Americans 60 and older are spending more time in front of their screens then a decade ago. Pew Research Center. https://www.pewresearch.org/facttank/2019/06/18/americans-60-and-older-are-spending-more-time-in-front-of-theirscreens-than-a-decadeago/?utm_source=Pew+Research+Center\&utm_campaign=041770d7ae-InternetScience_2019_06_27\&utm_medium=email\&utm_term=0_3e953b9b70-041770d7ae400310621

Mackenzie, L., \& Clemson, L. (2014). Can chronic disease management plans including occupational therapy and physiotherapy services contribute to reducing fall risk in older people? Australian Family Physician, 43(4). 211-216.

Maher, C.G., Sherrington, C., Herbert, R.D., Moseley, A.M., Elkins, A. (2003). Reliability of the PEDro scale for rating quality of randomized controlled trials, Physical Therapy, 83(8), 713-721. https://doi.org/10.1093/ptj/83.8.713

Malan, Z., Mash, B., Everett-Murphy, K. (2015). A situational analysis of training for behavior change counselling for primary care providers. South Africa. African Journal of Primary Health Care and Family Medicine, 7(1). Doi: 10.4102/phcfm.v7i1.731 
Märki, A., Bauer, G., Angst, F., Nigg, C., Gillmann, G., \& Gehring, T. (2006). Systematic counseling by general practitioners for promoting PA in elderly patients: A feasibility study. Swiss Medical Weekly, 136, 482-488. doi.org/10.1007/s00038-006-5065-y

Marques, A., Miguel, P., Martins, J., Gouveia, E., Valeiro, M. (2019). Cross-sectional and prospective relationship between low-to-moderate-intensity physical activity and chronic diseases in older adults from 13 European Countries. Journal of Physical Activity and Aging, 27(1), 93-101. https://journals.humankinetics.com/view/journals/japa/27/1/articlep93.xml

Mathew, A., Jones, N., Thomas, A.., van den Berg, P., Foster, C. (2017). An education programme influencing health professionals to recommend exercise to their type 2 diabetes patients - Understanding the processes. BMC Health Services Research, 17(130). doi: 10.1186/s12913-017-2040-7

McAuley, L., Pham, B., Tugwell, P., \& Moher, D. (2000). Does the inclusion of grey literature influence estimates of intervention effectiveness reported in meta-analyses? Lancet (London, England), 356(9237), 1228-1231. https://doi.org/10.1016/S01406736(00)02786-0

McMurdo, M. E. T., Sugden, J., Argo, I., Boyle, P., Johnston, D. W., Sniehotta, F. F., \& Donnan, P. T. (2010). Do pedometers increase physical activity in sedentary older women? A randomized controlled trial. Journal of the American Geriatrics Society, 58(11), 20992106. https://doi.org/10.1111/j.1532-5415.2010.03127.x 
Michie, S., West, R., Spring, B. (2013). Moving from theory to practice and back in social and health psychology. American Psychology Association, 32(5), 581-585. https://doi.org/10.1037/a0030205

Moher, D., Liberati, A., Tetzlaff, J., \& Altman, D.G. (2009). Preferred reporting items for systematic reviews and meta-analyses: The PRISMA statement. Annals of Internal Medicine, 151(4), 264-269. doi: 10.7326/0003-4819-151-4-200908180-00135

Mosen D, Glauber H, Stoneburner A, Feldstein A, Fortmann S. (2017). Assessing the association between exercise status and poor glycemic control. Journal of Patient Centered Research and Reviews, 4(3).

Morey, M.C., Ekelund, C., Pearson, M., Crowley, G., Peterson, M., Sloane, R., Pieper,C., McConnell, E., \& Bosworth, H. (2006). Project LIFE: A partnership to increase physical activity in elders with multiple chronic illnesses. Journal of Physical Activity and Aging, 14, 324-343.

Morey, M., Peterson, M. Pieper, C., Sloane, R., Crowley, G., Cowper, P., McConnell, E., Bosworth, H., Ekelund, C., \& Pearson, M. (2009). The veterans learning to improve fitness and function elders' study: A randomized trial of primary care-based PA counseling for older men. Journal of the American Geriatric Society, 57(7), 1166-1174

Mutrie, N., Doolin, O., Fitzsimons, C. F., Grant, P. M., Granat, M., Grealy, M., ... Skelton, D. A. (2012). Increasing older adults' walking through primary care: Results of a pilot randomized controlled trial. Family practice, 29(6), 633-642. doi:10.1093/fampra/cms038 
National Institute on Aging. (2018). Exercise and physical activity guide.

https://order.nia.nih.gov/publication/exercise-physical-activity-your-everyday-guidefrom-the-national-institute-on-aging

Navarro, J. E.J.Sanz, J.L.G., Del Castillo, J.M., Izquierdo, A.C., Rodreiquez, M. M. (2007). Motivational factors and physician advice for physical activity in older urban adults. Journal of Aging \& Physical Activity, 15(3), 241-256.

Newson, R. S., \& Kemps, E. B. (2007). Factors that promote and prevent exercise engagement in older adults. Journal of Aging and Health, 19(3), 470-481. https://doi.org/10.1177/0898264307300169

Office of Disease Prevention and Health Promotion. (2018). Physical activity. https://www. healthypeople. gov/2020/data-search/Search-the-Data\#topic-area=3504;

Olanrewaju, O., Kelly, S., Cowan, A., Brayne, C., \& Lafortune, L. (2016). Physical activity in community dwelling older people: A systematic review of reviews of interventions and Context. PLOS ONE, 11(12), 1-19. doi: 10.1371/journal.pone.0168614

Oliveira, J.S., Sherrington, C., Amorim, A., Dario, A., Tiedemann, A. (2017). What is the effect of health coaching on physical activity participation in people aged 60 years and over? A systematic review of randomized controlled trials. British Journal of Sports Medicine, 51, 1425-1432, doi.org/10.1136/bjsports-2016-096943

Orrow, G., Kinmonth, A.L., Sanderson, S., \& Sutton, S. (2012). Effectiveness of physical activity interventions based in primary care: Systematic review and meta-analysis of randomized controlled trials. British Medical Journal, 344. doi: https://doi.org/10.1136/bmj.e1389 
Ou, S., Chen, Y., Shih, C. \& Tarng, D. (2017).Impact of physical activity on the association between lipid profiles and mortality among older people. Scientific Reports 7. https://doi.org/10.1038/s41598-017-07857-7

Overdof, V., Kollia, B., Makarec, K. \& Alleva Szeles, C. (2016). The relationship between physical activity and depressive symptoms in healthy older women. Gerontology and Geriatric Medicine, 2, 1-8. https://doi.org/10.1177/2333721415626859

Parker, C.A. \& Ellis, R. (2016). Effect of electronic messaging on physical activity participation among older adults. Journal of Aging Research, 2016, https://doi.org/10.1155/2016/6171028

Patel, A., Schofield, G., Kolt, G. \& Koegh, J. (2011). General practitioners' views and experiences of counseling for PA through the New Zealand Green Prescription program. BMC Family Practice, 12(119). doi: 10.1186/1471-2296-12-119

Paulo, T.R.S., Tribess, S., Sasaki, J.E., Meneguci, J., Martins, C.A., Freitas, I.F., Roma-Perez, V., Virtuoso, J.S.(2016). A cross-sectional study of the relationship of physical activity with depression and cognitive deficits in older adults. Journal of Aging \& Physical Activity, 24(2), 311-324. https//doi.org/10.1123/japa.2014.0253

Pavey, T.J., Fox, K.R., Anokye, N., Green, C., Mutrie, N., Trueman, P. (2011). Effect of exercise referral schemes in primary care on physical activity and improving health outcomes: Systematic review and meta-analysis. British Medical Journal, 343. doi: https://doi.org/10.1136/bmj.d6462

Pérula, L.A., Varas-Fabra, F., Rodriquez, V., Ruiz-Moral, R., Fernandez, J.A., Gonzalez, J., Perula, C.J., Roldan, A.M., de Dios, C. (2012). Effectiveness of a multifactorial 
intervention among community-living older adults: A randomized controlled trial. Archives of Physical Medicine and Rehabilitation, 93(10). 1677-1684. https://doi.org/10.1016/j.apmr.2012.03.035

Pfeiffer, B., Clay, S., Conaster, R. (2001). A green prescription study: Does written exercise prescribed by a physician result in increased physical activity among older adults .Journal of Aging and Health, 13(4), 527-538. https://doi.org/10.1177\%2F089826430101300405Piggot, T.D. (2019). Missing data in meta-analysis. In Cooper, H., Hedges,L. \&Valentine, J. C.(eds). The Handbook of research and meta-analysis. Russel Sage Foundation: New York.

Prochaska, J.O., Redding, C.A., \& Viswanath, K. (2015). The transtheoretical model and stages of change. In K. Glanz, B.K. Rimer \& F.M. Lewis, (Eds.) Health Behavior: Theory, Research, and Practice (3rd Ed.). San Francisco, CA: Jossey-Bass, Inc.

Ramos, M., Lamotte, M., Gerlier, L., Sangre,, P., Miquel-Cases, A., Haughney, J. (2019). Costeffectiveness of physical activity in the management of COPD patients in the UK. International Journal of Chronic Obstructive Pulmonary Disease, 14, 227-239. Doi: 10.2147/COPD.s181194.

Rasinaho, M., Hirvensalo, M., Törmäkangas, T., Leinonen, R., Lintunen, T., \& Rantanen, T. (2012). Effect of physical activity counseling on physical activity of older people in Finland (ISRCTN 07330512). Health Promotion International, 27(4), 463-474. https://doi.org/10.1093/heapro/dar057

Reis, E., Laughlin, G., Bergstrom, J., Kritz-Silverstein, D., Richard, E., Barrett-Connor, E., McEvoy, L. (2019). Lifetime physical activity and late-life cognitive function: the 
Rancho Bernardo study, Age and Ageing, 48(2), 241-

246, https://doi.org/10.1093/ageing/afy188

Robare, J. F., Bayles, C. M., Newman, A. B., Williams, K., Milas, C., Boudreau, R., McTigue, K., Albert, S. M., Taylor, C., \& Kuller, L. H. (2011). The "10 keys" to healthy aging: 24month follow-up results from an innovative community-based prevention program. Health Education \& Behavior, 38(4), 379-388. https://doi.org/10.1177/1090198110379575

Ryan, R. M. \& Deci, E. L. (2000). Self-determination theory and the facilitation of intrinsic motivation, social development, and well-being. American Psychologist, 55, 6878. https://dx.doi.org/10.1037/0003-066X.55.1.68

Saaksjarvi, K., Knelt, P., Mannisto, S., Lyytinen, J. , Kanerva, N., Heliovaara, M. (2014). (2014). Reduced risk of Parkinson's disease associated with lower body mass index and heavy leisure-time physical activity. European Journal of Epidemiology, 29, 285-292.

Sallis, J. F. \& Saelens, B. E. (2000). Assessment of physical activity by self-report: Status, limitations, and further directions. Research Quarterly for Exercise and Sport, 71(2), S1.doi: $10.1080 / 02701367.2000 .11082780$

Schutzer, K. Graves, S. (2004). Barriers and motivations to exercise in older adults. Preventive Medicine, 39, 1056-1061.

Shirley, D., van der Ploeg, H., Bauman, A. (2010). Physical activity promotion in the physical therapy setting: Perspectives from practitioners and students, Physical Therapy, 90,(9), 1311-1322. https://doi.org/10.2522/ptj.20090383 
Sims, J., Smith, F., Duffy, A. \& Hilton, S. (1999). The vagaries of self-reports of physical activity: A problem revisited and addressed in a study of exercise promotion in the over 65s in general practice. Family Practice, 16(2), 152-157. Doi: 10.1093/fampra/16.2.152

Stathokostas, L., Theou, O., Little, R.M.D., Vandervoort, A.A, Raina, R..(2013). Physical activity-related injuries in older adults: A scoping review. Sports Medicine, 83(10), 955963.

Sterne, J.A.C., Sutton A. J., Loannidis, J.P.A., Terrin, N., Jones, D.R., Lau, J., Carpenter, J., Rucker, G., Harbord, R.M., Schmid, C.H., Tetzlaff, J., Deeks, J., Peters, J., Macaskill, P., Schwarzer, G., Duval, S., Altman, D.G. Moher, D., Higgins, J.P.T. (2011).

Recommendations for examining and interpreting funnel plot asymmetry in metaanalysis of randomised controlled trials. The BMJ, 343(d4002). doi: https://doi.org/10.1136/bmj.d4002

Stevens, Z., Barlow, C., Kendrick, D., Masud, T., Skelton, D., Dinan-Young, S., \& Iliffe, S. (2014). Effectiveness of general practice-based physical activity promotion for older adults: Systematic review. Primary Health Care Research \& Development, 15(2), 190201. doi:10.1017/S1463423613000017

Stuck AE, Moser A, Morf U, Wirz U, Wyser J, et al. (2015) Effect of Health Risk Assessment and Counselling on Health Behaviour and Survival in Older People: A Pragmatic Randomised Trial. PLOS Medicine 12(10). e1001889. https://doi.org/10.1371/journal.pmed.1001889

Swinburn, B., Walter, L., Arroll, B., Tilyare, M., \& Russell, D. (1998). The green prescription study: A randomized controlled trial of written exercise counseling provided by general 
practitioners. American Journal of Public Health, 88(2), 288-291. doi:

10.2105/AJPH.88.2.288.

Tarazona-Santabalina, F. J. Gómez-Cabrera, M.C., Pérez-Ros, P., Martínez-Arnau, F.M., Cabo, H., Tsaparas, K., Salvador-Pascual, A., Rodriguez-Mañas, L., Viña, J. (2016). A multicomponent exercise intervention that reverses frailty and improves cognition, emotion and social networking in the community-dwelling frail elderly: A randomized clinical trial. JAMDA, 17(5). 426-433. http://dx.doi.org/10.1016/j.jamda.2016.01.019

Thompson, W. G., Kuhle, C. L., Koepp, G. A., McCrady-Spitzer, S. K., \& Levine, J. A. (2014). "Go4Life" exercise counseling, accelerometer feedback, and activity levels in older people. Archives of Gerontology and Geriatrics, 58(3), 314-319. https://doi.org/10.1016/j.archger.2014.01.004

Thornton, A. , \& Peter, L. (1999). Publication bias in meta-analysis: its causes and consequences. Journal of Clinical Epidemiology, 53, 207-216.

United Nations: Department of Economic and Social Affairs. (2019). World population ageing. https://www. un. org/en/development/desa/population/publications/pdf/ageing/WorldPopulationAgeing201 9-Highlights. Pdf

United States Census Bureau. (2018). Income and poverty in the United States: 2018. Retrieved from https://www. census. gov/library/publications/2019/demo/p60-266. html

United States Department of Health and Human Services (2020). Office of Disease Promotion and Health. About healthy people. Retrieved from https://www. healthypeople. gov/2020/About-Healthy-PeopleUnited States Department of Health and Human Services 
(2018). Physical activity guidelines for Americans (2nd ed). Retrieved from https://health. gov/paguidelines/secondedition/pdf/Physical_Activity_Guidelines_2nd_edition.Pdf

United States Department of Health and Human Services. National Institute on Aging. (2017). Supporting older adults with chronic conditions. Retrieved from https://www.nia.nih.gov/health/supporting-older-patients-chronic-conditions

United States Department of Health and Human Services (2018). Physical activity guidelines for Americans (2nd ed). Retrieved from https://health.gov/paguidelines/secondedition/pdf/Physical_Activity_Guidelines_2nd_edition.pdf

United States Department of Health and Human Services (2018). Facts and statistics: Physical Activity. Retrieved from https://www.hhs.gov/fitness/resource-center/facts-andstatistics/index.html\#footnote-4United States Department of Health and Human Serviced (2018). 2017 profile of older Americans. Administration of Community Living, Administration on Aging. https://acl.gov/sites/default/files/Aging\%20and\%20Disability\%20in\%20America/2017Ol derAmericansProfile.pdf

Valentine, J.C. (2019). Incorporating judgments about study quality into research synthesis. In Cooper, H., Hedges,L. \& Valentine, J. C.(eds). The Handbook of research and metaanalysis. Russel Sage Foundation: New York.

Verhagen A. P., de Vet, H. C., de Bie, R. A., Kessels, A. G., Boers, M., Bouter, L. M. \& Knipschild, P. G. (1998). The Delphi list: a criteria list for quality assessment of 
randomised clinical trials for conducting systematic reviews developed by Delphi consensus. Journal of Clinical Epidemiology,51(12):1235-41). 10. 1016/s08954356(98)00131-0

Vevea, J., Coburn, K. \& Sutton, A. (2019). Heterogeneity in meta-analysis. In Cooper, H., Hedges,L. \& Valentine, J. C. (eds.). The Handbook of research and meta-analysis. New York: Russel Sage Foundation

Walsh, J., Swangard, D., Davis, T., McPhee, S. (1999). Exercise counseling by primary care physicians in the era of managed care. American Journal of Preventive Medicine, 16(4), doi:10.1016/S0749-3797(99)00021-5

Watson, K.B., Carolson, S.A., Gunn, J.P., Galuska, D.A., O'Connor, A., Greenlund, K.J., \& Fulton, J.E. (1999). Physical inactivity among adults aged 50 years and older - United Stated, 2014. Morbidity and Mortality Weekly Report, 65, 954-958. Doi: http://dx.doi.org/10.15585/mmwr.mm6536a3.Weinstock, R.S., Brooks, G., Palmas, W., Morin, P.C., Teresi, J.A., Eimicke, J.P., Silver, S/. Izquierdo, R., Goland, R., Shea, S. Lessened decline in physical activity and impairment of older adults with diabetes with telemedicine and pedometer use: results from the IDEATel study, Age and Ageing, 40(1)98-105 https://doi.org/10.1093/ageing/afq147

Witham, M.D., Fulton, R.L., Creig, C.A. Johnston, D.W., Lang, C.C., van der Pol, M., Boyers, D., Struthers, A.D., McMurdo, M.E.T. (2012). Efficacy and cost of an exercise program for functionally impaired older patients with heart failure: A randomized controlled trial. 
Circulation: Heart Failure, 5, 209-216.

https://doi.org/10.1161/CIRCHEARTFAILURE.111.963132

World Health Organization. (2019). Primary Health Care. https://www.who.int/news-room/factsheets/detail/primary-health-care

World Health Organizations (2018). Global Action Plan for the Prevention of Noncommunicable Diseases 2013-2020. http://africahealthforum.afro.who.int/firstedition/IMG/pdf/global_action_plan_for_the_prevention_and_control_of_ncds_20132020.pdf

World Health Organization. (2018). Physical Activity. https://www.who.int/en/news-room/factsheets/detail/physical-activityWorld Health Organization (2008). Global strategy on diet, physical activity and health. Retrieved from https://www. who. int/dietphysicalactivity/physical_activity_intensity/en/

World Health Organization. (2013). Physical activity a global world health problem. https://www.who.int/dietphysicalactivity/factsheet_inactivity/en/

World Health Organization. (2010). Global recommendations on physical activity for health. https://www.ncbi.nlm.nih.gov/books/NBK305048/

World Health Organization (2008). Global strategy on diet, physical activity and health. https://www. who. int/dietphysicalactivity/physical_activity_intensity/en/

Xue Q. L. (2011). The frailty syndrome: definition and natural history. Clinics in geriatric medicine, 27(1), 1-15. https://doi.org/10.1016/j.cger.2010.08.009 
Zenko, Z., Willis, E. A., \& White, D. A. (2019). Proportion of adults meeting the 2018 physical activity guidelines for Americans according to accelerometers. Frontiers in Public Health, 7, 135. doi:10.3389/fpubh.2019.00135

Zhong, S., Jiang, T., M, T., Zhang, X., Chen, W., Lv, M., \& Zhao, J. (2014). Association between physical activity and mortality in breast cancer: A Meta-analysis of cohort studies. European Journal of Epidemiology, 29(6). Doi: 10.1007/s10654-014-9916-1. 
Jennifer Otmanowski has been a nurse for 39 years. She earned her Bachelor of Science in Nursing from Lake Superior State College, Sault Ste. Marie, Michigan, and her Master of Science in Nursing Education from Spring Arbor University, Spring Arbor, Michigan. Currently she is a Doctor of Philosophy in Nursing candidate at the University of Missouri, Columbia, Missouri. She is also an associate professor of nursing at Baker College in Jackson, Michigan, where she teaches Health Assessment and Geriatrics. She is a certified nurse educator (CNE). 